\title{
A Review on Graphene-Based Nanomaterials in Biomedical Applications and Risks in Environment and Health
}

\author{
Thabitha P. Dasari Shareena ${ }^{1}$ - Danielle McShan $^{1} \cdot$ Asok K. Dasmahapatra $^{1} \cdot$ Paul B. Tchounwou $^{1}$
}

Received: 7 March 2018/Accepted: 22 April 2018/Published online: 21 May 2018

(C) The Author(s) 2018

\section{Highlights}

- Structures and properties of graphene-based nanomaterials (GBNs) including graphene, graphene oxide (GO), reduced graphene oxide (RGO) and modified graphene are introduced briefly.

- Recent advances in GBNs for the biomedical applications in drug delivery, biosensor, bioimaging and tissue engineering are summarized and analyzed.

- Potential risks resulted from the vast production and applications of GBNs to the environment and health are discussed to ensure sustainable development of GBNs.

\begin{abstract}
Graphene-based nanomaterials (GBNs) have attracted increasing interests of the scientific community due to their unique physicochemical properties and their applications in biotechnology, biomedicine, bioengineering, disease diagnosis and therapy. Although a large amount of researches have been conducted on these novel nanomaterials, limited comprehensive reviews are published on their biomedical applications and potential environmental and human health effects. The present research aimed at addressing this knowledge gap by examining and discussing: (1) the history, synthesis, structural properties and recent developments of GBNs for biomedical applications; (2) GBNs uses as therapeutics, drug/gene delivery and antibacterial materials; (3) GBNs applications in tissue engineering and in research as biosensors and bioimaging materials; and (4) GBNs potential environmental effects and human health risks. It also discussed the perspectives and challenges associated with the biomedical applications of GBNs.
\end{abstract}

Paul B. Tchounwou

paul.b.tchounwou@jsums.edu

1 RCMI Center for Environmental Health, Jackson State University, Jackson, MS 39217, USA

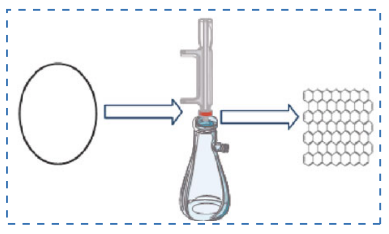

Synthesis \& Structure of GBNs

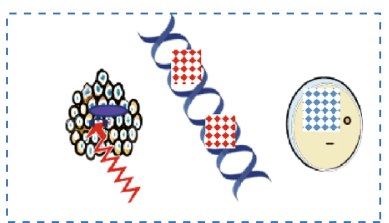

GBNs as therapeutics

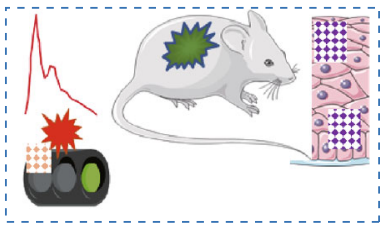

GBNs in biosensor, bioimaging \& tissue engineering

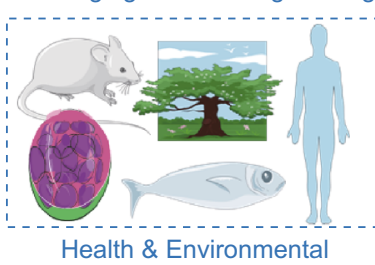
Risks of GBNs
Keywords Graphene-based nanomaterials - Biomedical . Delivery · Biosensors · Tissue engineering - Bioimaging · Health and environment risks 


\section{Introduction}

This review focuses on the recent advances in graphenebased nanomaterials (GBNs) in the field of biomedical applications and their potential environmental and health risks. Graphene, the mother of all carbon atoms, is a single atomic thick, nanosized, two-dimensional structure and provides high surface area with adjustable surface chemistry to form hybrids. It was synthesized from graphite. In this review, we addressed the current state of the science and identified the knowledge gap for the future research development. The broad family of GBNs listed in this review includes graphene, graphene oxide (GO), reduced graphene oxide (RGO) and chemically modified graphene (that bears functional groups covalently bound to the surface of the individual layers of graphitic carbon) [1].

\subsection{History of GBNs}

Although carbon-based materials such as fullerene, graphite, graphene and carbon nanotubes have been widely used due to their unique properties and nanoscale dimensions [2-7], GBNs have attracted considerable interests in recent years (2003-2018) owing to their applications in medicine, biotechnology and various interdisciplinary sciences [8-15]. To date, although significant advances have been made, further studies are needed in many areas related to the multiple biomedical applications of GBNs. A graphical analysis (Fig. 1) of a number of publications was obtained from the years 2003-2017 based on the keywords 'graphene' and 'biomedical applications of graphene' using Scopus as a search engine. A growing number of publications (Fig. 1a, b) indicate new potential applications of GBNs to anticipate more emphasis on the research with these novel materials. Among GBNs, GO is one of the most potential materials for biomedical applications [16-18]. GBNs, compared to the other carbon-based materials, have the large surface area, easily modified by different functional groups and better solubility that makes them an excellent choice for biomedical use. GBNs are not homogeneous, and they vary in number, lateral dimension, surface chemistry, defect density or quality of the individual graphene sheets and composition or purity [19].

Even though graphene came into existence in the year 1859 by a British Chemist Benjamin Collins Brodie [20], it has been studied theoretically for many years by Wallace [21]. However, graphene has attracted attention among the scientific community since it was developed as a single layer of material by Novoselov et al. [22] by using the scotch tape method. The timeline of selected events in the history of graphene is highlighted (Fig. 2) [1, 23].

\subsection{Structure and Properties of GBNs}

GBNs have been classified based on the number of layers in the sheet, oxygen content and their chemical composition. There are many structural differences between GO and RGO which determine their physicochemical

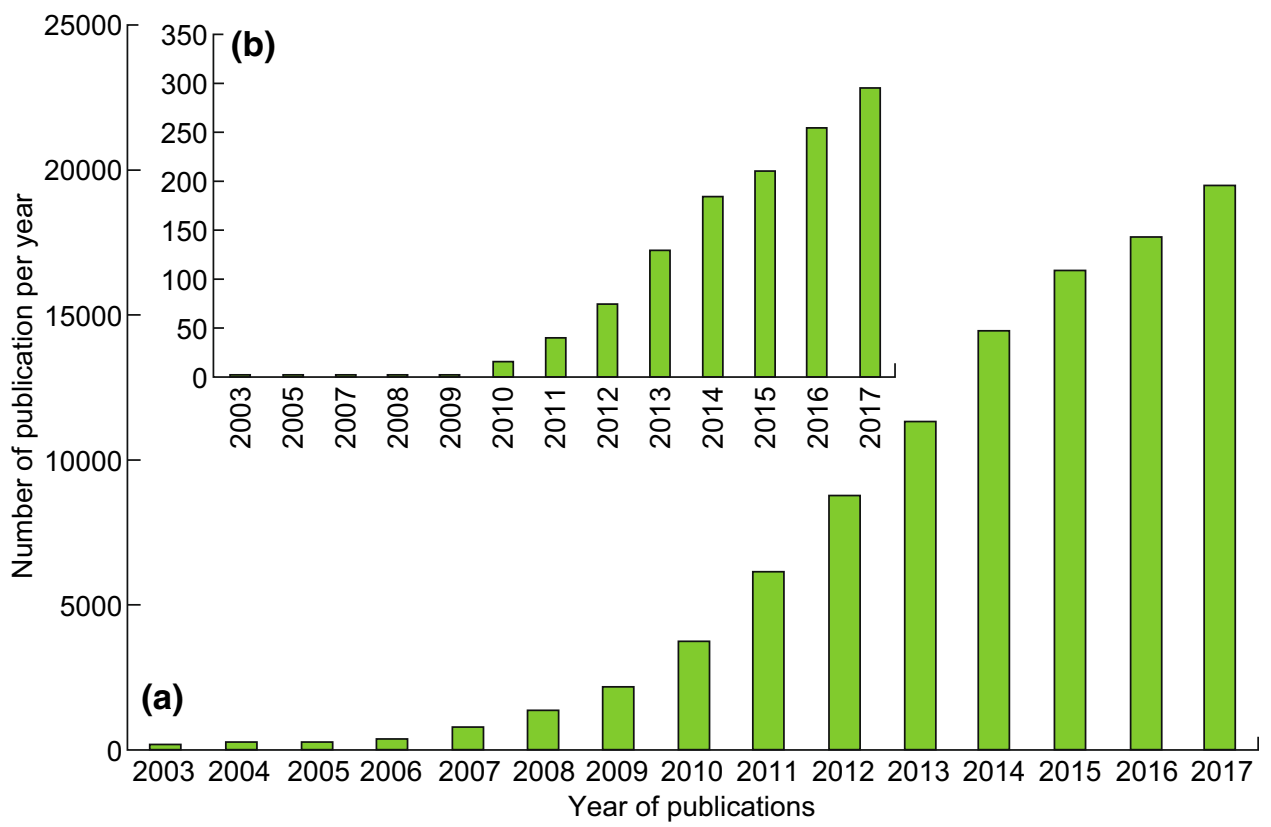

Fig. 1 a Graphical analysis of a number of publications on 'graphene' and b 'biomedical applications of graphene' for the past 14 years. Data retrieved from Scopus 


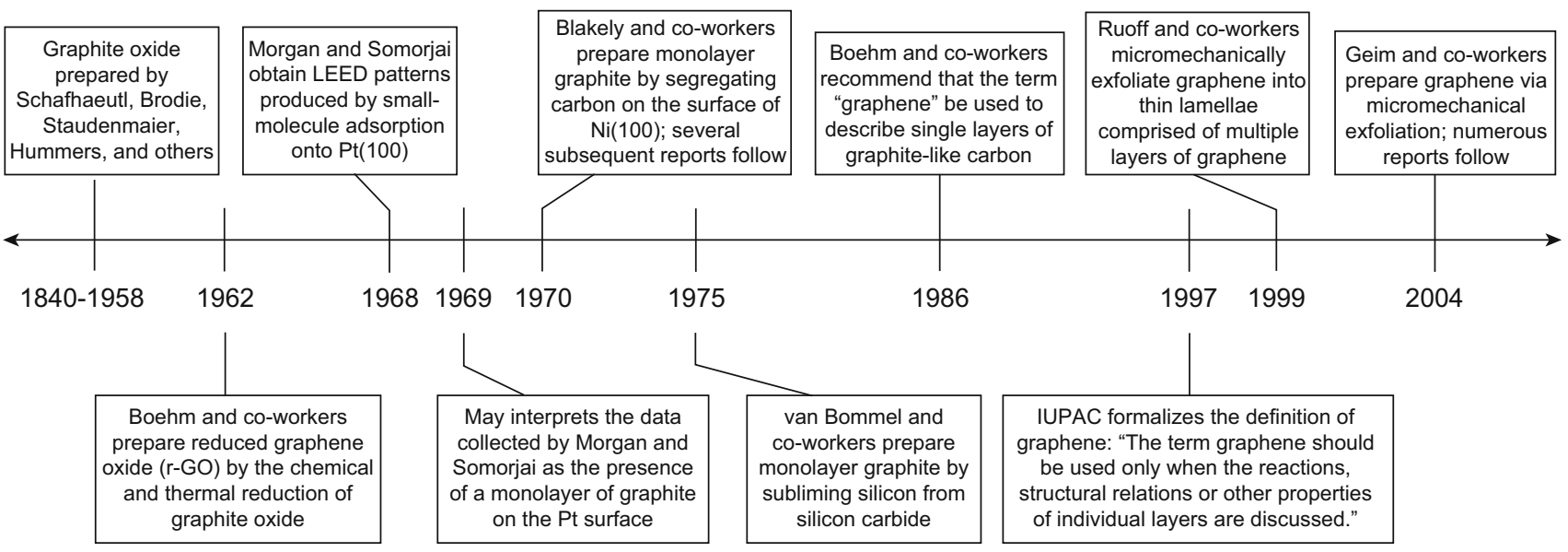

Fig. 2 Timeline of selected events in the history of the preparation, isolation and characterization of graphene (Figures are adapted with permission from Ref. [1]). Copyright (C) 2010 WILEY-VCH Verlag GmbH and Co. KGaA, Weinheim

properties. Figure 3 is a schematic representation of chemical structures of graphene, GO and RGO [24]. The analytical techniques such as Raman spectroscopy, transmission electron microscopy (TEM), solid-state Fourier transform nuclear magnetic resonance (FT-NMR) spectroscopy and atomic force microscopy (AFM) are being used to understand the structural properties of GBNs [25].

\subsubsection{Graphene}

Graphene is a single carbon layer of the graphite structure. It is a two-dimensional planar and hexagonal array of carbon atoms. Each of these carbons is $s p^{2}$-hybridized and has four bonds, one $\sigma$ bond with each of its three neighbors and one $\pi$-bond that is oriented out of the plane. It has a hexagonal pattern, forming a honeycomb crystal lattice. It is produced by mechanical or chemical exfoliation of graphite via chemical vapor deposition. It has a large specific surface area, high intrinsic mobility and high thermal conductivity. Graphene is considered as hydrophobic because of the absence of oxygen groups.

\subsubsection{Graphene Oxide}

GO is a single layer of graphite oxide, often produced by exfoliation of graphite oxide. GO is produced by acid-base treatment of graphite oxide followed by sonication. Several functional groups such as oxygen, epoxide groups, and carbonyl, hydroxyl and phenol groups are present on the surface of GO. The apparent difference between graphene and $\mathrm{GO}$ is the presence of oxygen atoms bound to carbon. GO is the product of hydrophilic derivative of graphene.

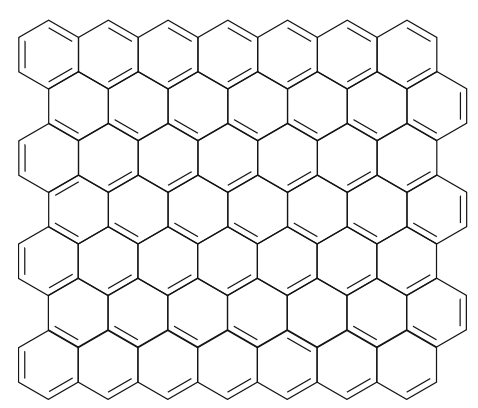

(a)

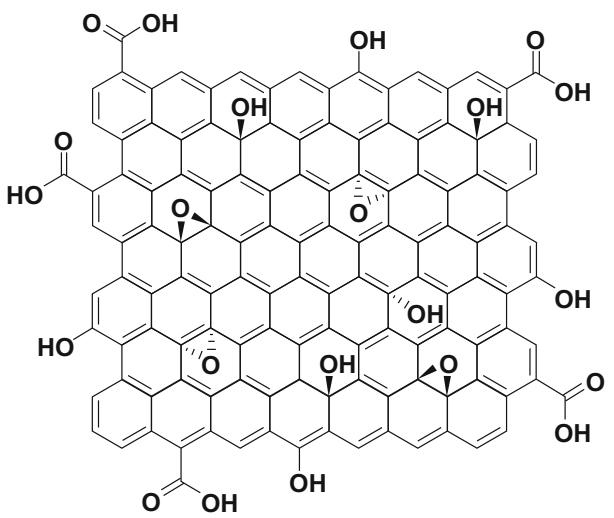

(b)

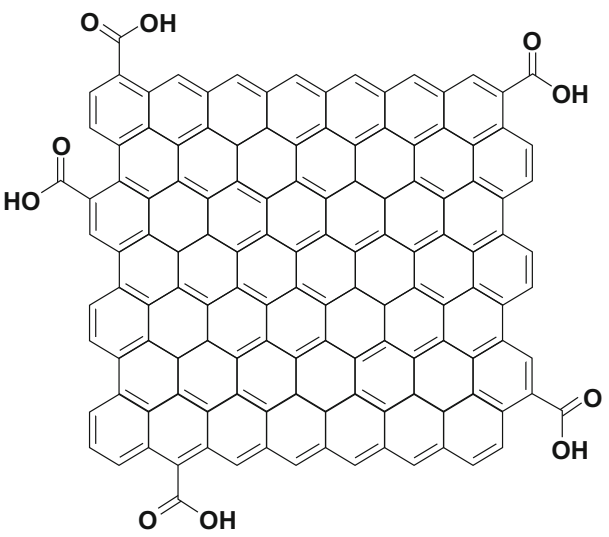

(c)

Fig. 3 Schematic representation of structures of graphene, GO and RGO [24]. Copyright (c) Elsevier 2016 
GO has both aromatic $\left(s p^{2}\right)$ and aliphatic $\left(s p^{3}\right)$ domains which facilitate the interactions at the surface [26-28]. It is synthesized by the Hummer's method and has oxygenated groups on the surface of the molecule. There is no specific structure for GO, but morphological and structural characterization gives an idea of the GO structure [29].

\subsubsection{Reduced Graphene Oxide}

RGO is the product of graphene oxide or graphite oxide by the chemical or thermal reduction. RGO is considered as an intermediate structure between the ideal graphene sheet and highly-oxidized GO [29]. In addition to the above structural properties of GBNs (Fig. 3), the summary of physicochemical properties of GBNs is listed (Table 1).

\subsection{Synthesis of GBNs}

Several approaches have been used for the synthesis of GBNs, either a 'top-down' or a 'bottom-up' approach. Figure 4 illustrates various approaches for the synthesis of GBNs [30]. Each of these methods has its advantages and disadvantages. Reina et al. (2017) emphasized that 'bottom-up' method is appropriate to synthesize GBNs rather than 'top-down' because of the non-uniformity of the synthesized GBNs which interferes with GBN-based electronic devices for biomedical applications [29]. The size, thickness and the number of layers vary based on the starting material used in the synthesis of graphene $[1,23]$.

Graphene was synthesized from graphite via mechanical cleavage (Scotch tape method), liquid phase exfoliation, graphite oxide/fluoride reduction, intercalation and compound exfoliation and from non-graphite sources via epitaxial silicon carbide decomposition, chemical vapor deposition (CVD) growth and bottom-up chemical synthesis [31]. Most commonly, GO can be synthesized via Hummer's method through oxidative exfoliation of graphite using $\mathrm{H}_{2} \mathrm{SO}_{4} / \mathrm{KMnO}_{4}$ [32]. Moreover, RGO was produced from GO with the use of reducing agents hydrazine, hydrazine hydrate, L-ascorbic acid and sodium borohydride [25]. Additionally, graphene nanocomposites were prepared along with metal and metal oxide nanoparticles via in situ synthetic procedures. These in situ synthetic approaches have concerns such as obtaining uniformity of GO via top-down strategy and control of functional groups on GO, which will affect the quality and properties of GBNs [33]. To better control the size and morphology of the modified GOs, 'binding method' is preferred without affecting graphene's structure. The binding method also has its limitations in size control, binding efficiency, the stability of GBNs and the distance maintenance between fluorescent components of GO and RGO's [33]. Moreover, functionalization of GO is a vital step to enhance the GBNs for biomedical applications. Covalent and non-covalent approaches facilitate surface functionalization of GBNs to improve solubility, selectivity and biocompatibility [34]. Muthoosamy and Manickam discussed in detail the exfoliation of GBNs and ultrasoundassisted synthesis. Compared to exfoliation, ultrasonication allows synthesis of GBNs in more homogeneous state [23]. Also, Huang et al. listed multiple graphene-NP composites and their applications in various aspects of our daily life

Table 1 Physicochemical properties of GBNs [118]. Copyright $\odot$ Elsevier 2014

\begin{tabular}{|c|c|c|c|}
\hline Property & Single-layer graphene & Graphene oxide (GO) & Reduced GO \\
\hline $\begin{array}{l}\text { Young's } \\
\text { modulus }\end{array}$ & $1000 \mathrm{GPa}$ & $220 \mathrm{GPa}$ & N/A \\
\hline Fracture strength & $130 \mathrm{GPa}$ & $120 \mathrm{MPa}$ & N/A \\
\hline $\begin{array}{l}\text { Optical } \\
\text { transmittance }\end{array}$ & $97.7 \%$ & $\begin{array}{l}\text { N/A (expected to be lower due to functional groups and } \\
\text { defects) }\end{array}$ & $\begin{array}{l}60-90 \% \text { depending on the } \\
\text { reduction agent and } \\
\text { fabrication method }\end{array}$ \\
\hline $\begin{array}{l}\text { Charge carrier } \\
\text { concentration }\end{array}$ & $1.4 \times 10^{13} \mathrm{~cm}^{-2}$ & $\begin{array}{l}\text { N/A (much lower due to more organic nature, functional } \\
\text { groups and defects) }\end{array}$ & N/A \\
\hline $\begin{array}{l}\text { Room } \\
\text { temperature } \\
\text { mobility }\end{array}$ & $\sim 200,000 \mathrm{~cm}^{2} \mathrm{~V}^{-1} \mathrm{~s}^{-1}$ & $\begin{array}{l}\text { N/A (expected to be much lower than } 15,000 \text { due to } \\
\text { interruption in mobility by defects scattering) }\end{array}$ & $\begin{array}{l}\text { N/A (expected to be } \\
\text { intermediate of two due to les } \\
\text { defects) }\end{array}$ \\
\hline $\begin{array}{l}\text { Thermal } \\
\text { conductivity }\end{array}$ & $\sim 5000 \mathrm{~W} \mathrm{mK}$ & $2000 \mathrm{~W} \mathrm{mK}^{-1}$ for pure $600 \mathrm{~W} \mathrm{mK}{ }^{-1}$ on $\mathrm{Si} / \mathrm{SiO}_{2}$ substrate & $0.14-0.87 \mathrm{~W} \mathrm{mK}^{-1}$ \\
\hline $\begin{array}{l}\text { Electrical } \\
\text { conductivity }\end{array}$ & $10^{4} \mathrm{~S} \mathrm{~cm}^{-1}$ & $10^{-1} \mathrm{~S} \mathrm{~cm}^{-1}$ & $200-35,000 \mathrm{~S} \mathrm{~cm}^{-1}$ \\
\hline
\end{tabular}

N/A not available 


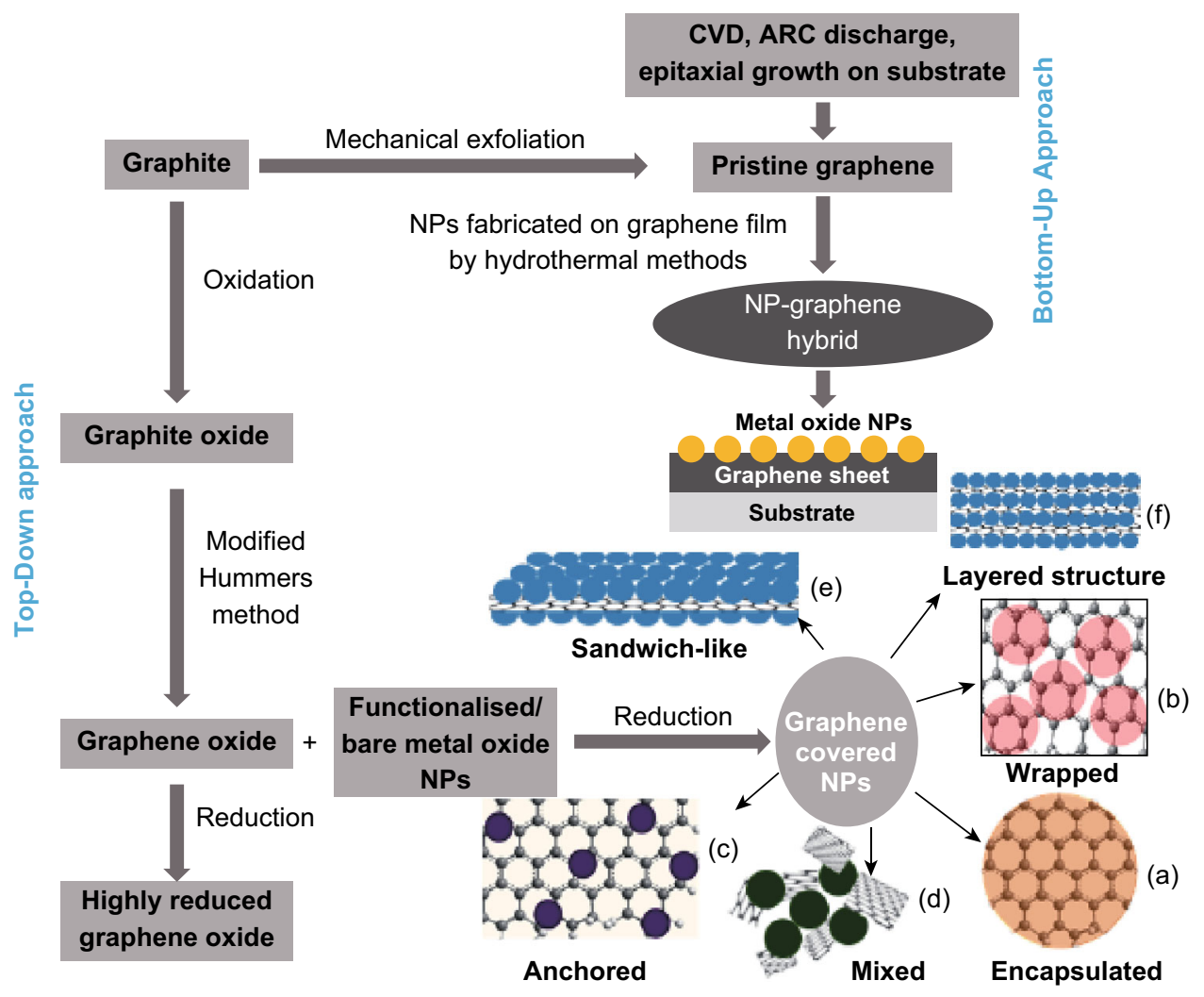

Fig. 4 Schematic presentation of graphene synthesis methods- 'top-down' and 'bottom-up'-used for the formation of GBN hybrids and different structures. a Graphene-encapsulated NPs. b Graphene-wrapped NPs. c NPs anchored to graphene structures. d Mixed graphene-NP structures. e Graphene-NP sandwich structures. f Graphene-NP layered hybrids [30]. Copyright (C) 2017 Jana et al.; licensee Beilstein-Institute

[35]. Typically, most of the synthesis approaches involved chemical reducing agents; therefore, researchers have come up with eco-friendly methods using bacteria, phytoextracts and biomolecules during the synthesis just to avoid the hazardous effects of chemical agents [36, 37].

Surface functionalization of GBNs is an essential step to further biomedical applications. Researchers studied to improve the biocompatibility, solubility and selectivity using various polymers and macromolecules such as polyethylene glycol (PEG), polyvinylpyrrolidone (PVP), chitosan, deoxyribonucleic acid (DNA), enzymes and proteins [38].

\subsection{Recent Advances of GBNs in Emerging Bioapplications}

GBNs with their countless applications are expected to revolutionize various areas such as optical, electrical, thermal and mechanical fields (Fig. 5). Mainly, GBNs have received considerable attention for their potential for applications in various areas such as electronics, desalination, metal detection and removal and nuclear waste treatment [19, 39, 40]. Moreover, GO is suitable for biomedical applications such as drug delivery, gene therapy, biomedical imaging, combined cancer therapy, antibacterial agents, as biosensors. However, the actual application of any nanomaterial in biology and medicine is decided critically by its biocompatibility. To date, none of the GO applications have been approved for clinical trials. Some issues related to toxicity and biosafety became pertinent during preliminary biological application of GO [41]. Graphene materials consist of solely carbon. However, it is a matter of serious concern to understand how carbon derivatives like GO and RGO behave in a biological system and how long it takes to excrete from the human body [9]. However, during fabrication, GBNs usually undergo several chemical treatment processes for functionalization, including doping with metals, oxidation, which introduces functional groups, and also a material reduction. This indicates that some of the graphene derivatives considered for bioapplications contain metals and/or impurities other than carbon. It is known from the information on structural properties of GBNs that graphene is a hydrophobic material, so it requires modification of 


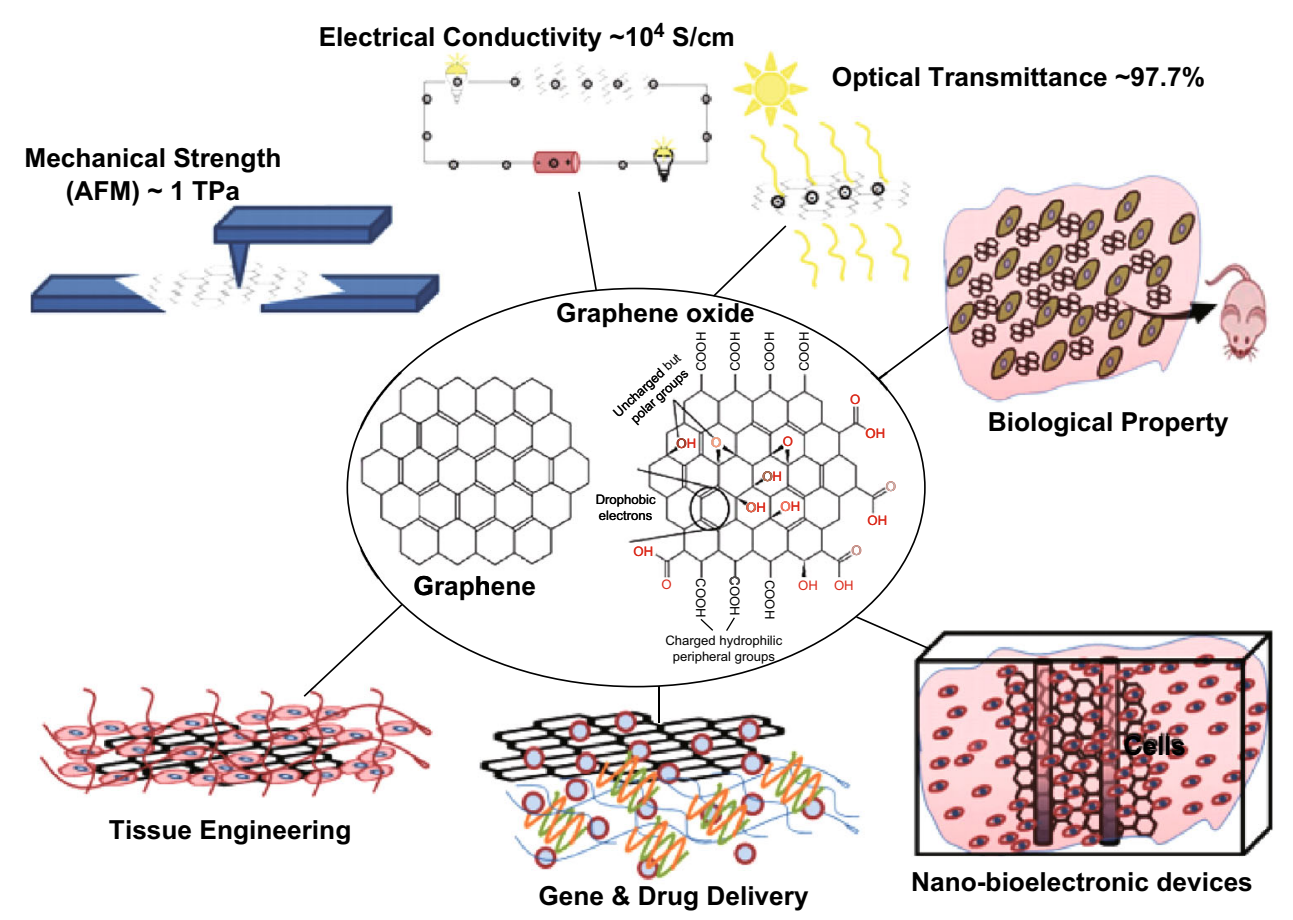

Fig. 5 Schematic overview of medical and non-medical applications of GBNs [118]. Copyright (C) Elsevier 2014

functional groups to make it a biomedical material. This modification may include covalent and non-covalent functionalization. Liu et al. [42] summarized the covalent and non-covalent functionalization. Non-covalent functionalization improves dispersibility, biocompatibility, reactivity, binding capacity or sensing [28]. The formation of hydrogen bonds between polar functional groups on the GO surface and water molecules forms a stable GO colloidal suspension for potential biomedical applications of GO [43, 44]. In bioapplications, both oxidized (GO) and reduced (RGO) graphene oxides are found to be feasible for drug delivery and therapeutic applications. The principal advantage of using GO over other carbon-based materials is due to its aqueous and colloidal stability. The physicochemical characteristics of GO that make it a chemically versatile template with a high surface-to-volume ratio facilitate a variety of biomedical applications such as imaging and cancer therapy, and biosensing. Apart from GO, graphene and RGO have been found to be promising photosensitizing agents for photo-ablation because they generate heat upon irradiation, making it possible for application in combined theranostic therapies.

\section{Biomedical Applications in Therapeutics of GBNs}

Therapeutics is an area of research that deals with the drug delivery and treatment of the infected biological components [45]. During the past 20 years, the rapid development of nanotechnology has brought novel materials which can be used in the diagnosis and therapeutics. Among the carbon nanomaterials, GBNs have gained popularity for their excellent physicochemical properties. Since the discovery of graphene, GBNs are considered as carrier molecules for therapeutics. Properties such as large specific area, $\pi-\pi$ stacking and electrostatic interactions of GBNs facilitate drug loading of partially soluble drugs with high efficiency and potency [46]. GBNs are mostly used in biomedical applications for drug delivery, gene therapy and anticancer therapy.

\subsection{Drug Delivery}

In the past decade, nanomaterial-based drug delivery systems have been extensively investigated for the treatment of cancer, aiming at improved therapeutic efficacy and reduced toxic side effects. Since 2008, many groups have started to explore graphene-based drug delivery systems. The surface area of graphene $\left(2600 \mathrm{~m}^{2} \mathrm{~g}^{-1}\right)$ is higher, which makes them to be explored for drug delivery [27]. 
Basically, a monolayer of graphene represents an extreme case where every atom exposed on the surface, which allows significantly higher drug loading capacity. The two prominent modifications reported in the literature for drug delivery using GBNs are chemical modification via electrostatic interaction and binding to the aromatic molecule via $\pi-\pi$ stacking interaction $[47,48]$. One more advantage of drug delivery through GBNs is the control of release rate for sustainable drug release [49].

Single-layered GO or RGO has an ultra-high surface area available for highly efficient drug loading [42]. Recently, GO has become quite a competitive drug delivery system with the potential to be applied for systemic targeting and local effective drug delivery [50-52]. GO has unique properties such as surface area, layer number, lateral dimension, surface chemistry and purity which are relevant for their drug delivery and biological applications. In recent years, several studies have been conducted on the delivery of anticancer drugs, genes and peptides through graphene derivatives [7, 19, 24]. Approaches such as simple physisorption via $\pi-\pi$ stacking can be used for loading many hydrophobic drugs, such as doxorubicin and docetaxel, with antibodies for the selective killing of cancer cells. Graphene is a new promising material for drug delivery via the nanocarrier approach, due to its small size, intrinsic optical properties, large specific surface area, low cost and useful non-covalent interactions with aromatic drug molecules. The large specific surface area, $\pi-\pi$ stacking and electrostatic or hydrophobic interactions of graphene can assist in high drug loading of less soluble drugs with high efficiency and potency. Joo and his group reported that PEGylated (covalent conjugation with polyethylene glycol) GO loaded with doxorubicin (DOX) via $\pi-\pi$ interactions shows the promising real-time release of DOX from PEGylated GO at specific loci after an external triggering by glutathione (GSH) [27]. Another research group reported that GO loaded with doxorubicin exhibits higher drug release at $\mathrm{pH} 5.3$ due to the reduced interaction between DOX and the drug carrier [53]. GO loaded with DOX shows enhanced cellular toxicity and promising tumor growth inhibition, with almost 66-91\% cell death. Other chemotherapy drugs, such as paclitaxel and methotrexate loaded on GO via $\pi-\pi$ stacking and amide bonds, exhibited an amazing cancerous effect on lung cancer and breast cancer, which resulted in inhibition of about $66-90 \%$ of tumor growth. When ibuprofen, which is used as a nonsteroidal anti-inflammatory drug (NSAID), was conjugated with chitosan-functionalized GO joined by amide linkages, the functionalized GO exhibited higher (20\%) biocompatibility than GO sheets for human acute lymphoblastic leukemia cell lines (CEM) and Michigan Cancer Foundation 7 cell lines (MCF-7) [54]. GO loaded with a second-generation photosensitizer chlorine $6(\mathrm{Ce} 6)$ resulted in its higher accumulation in tumor cells, leading to a higher photodynamic efficacy upon irradiation. Singh et al. listed various studies on GBNs and their composites used for drug delivery systems [19].

It was expected that in 2017 , there will be $1,688,780$ new cancer cases diagnosed and 600,920 cancer deaths in the USA [55, 56]. Compared to the normal tissues, tumor tissues usually possess unique microstructural features, unique microenvironment and physicochemical properties such as abnormal temperature gradients, weak acidity, overexpressed proteins and enzymes [57-60]. The altered tumor intracellular environments, such as $\mathrm{pH}$ inside of endosomes and lysosomes, are considered when developing the anticancer drug that releases upon reaching the targeted site. For the past two decades, the rapid development in nanotechnology for the diagnosis and treatment of cancer has greatly improved. Among the carbon nanomaterials, GBNs gained popularity in anticancer research. Several studies have contributed to the delivery of GBNbased chemotherapeutics for the treatment of cancer. All great potential of graphene oxide cancer therapies encouraged many researchers to combine multifunctionalities for cancer treatment. In this section, we have summarized the recent reports on the various anticancer drugs used as therapeutics along with GBNs. Also, we have discussed the PDT and PTT used along with GBNs in anticancer therapy. Several studies reported on the delivery of anticancer drugs along with the combination of PTT and PDT. Shim et al. [24] provided a list of few anticancer therapeutics delivered using graphene nanosheets via physical absorption or chemical conjugation. They included doxorubicin, camptothecin, paclitaxel, 1,3-bis (2chloroethyl)-1-nitrosourea, fluorouracil, methotrexate, lucanthone, $\beta$-lapachone and ellagic acid. GBNs loaded with chemotherapeutics are listed in Table 2 [24].

Shim et al. [24] listed various anticancer drug categories used in combination with GBN derivatives. These include anthracycline antibiotics, quinolone alkaloids, taxanes, platinum complexes, nitrosourea compounds, pyrimidine analogs, polyphenolic compounds, quinone compounds and other chemotherapeutics [24]. Zhang et al. established a simple strategy to synthesize a 3D nanoscaled, biocompatible, reduction-responsive nanocarrier [(GON-CyALG-PEG), which is used to deliver anticancer drug DOX with high loading and triggered the release of DOX. They could achieve combined chemo- and photo-thermal therapy better than routine therapy [61]. The multifunctional nanocomposite could make the specific treatment and early diagnosis of different tumors a reality.

Chemotherapy and radiation therapy are major therapeutic approaches for the treatment of a wide variety of invasive cancers today. However, one of the major disadvantages of chemotherapy and radiotherapy is their limited 
Table 2 GBNs loaded with chemotherapeutics [24]. Copyright (C) Elsevier 2016

\begin{tabular}{|c|c|c|c|}
\hline Type of GBNs & Chemotherapeutics & Efficacy test & Refs. \\
\hline \multirow[t]{2}{*}{ GO } & Doxorubicin & Doxorubicin-resistant MCF-7 & [162] \\
\hline & & CNE1 cells & [163] \\
\hline \multirow[t]{2}{*}{ GO with PEG } & Doxorubicin & $\begin{array}{l}\text { Doxorubicin-resistant MCF-7 } \\
\text { cells }\end{array}$ & [164] \\
\hline & Doxorubicin & HeLa cells & [165] \\
\hline $\begin{array}{l}\text { Citraconic anhydride-functionalized poly(allylamine)/ } \\
\text { polyethyleneimine-GO }\end{array}$ & Doxorubicin & U87MG, MCF-7 cells & [166] \\
\hline Gold nanocluster-decorated RGO & Doxorubicin & HepG2 cells & [167] \\
\hline Poly( $N$-isopropylacrylamide)-GO & Camptothecin & A-5RT3 cells & [168] \\
\hline Poly( $N$-vinyl caprolactam)-grafted GO & Camptothecin & $\mathrm{KB}$ cells & [169] \\
\hline Poly(vinyl alcohol)-functionalized GO & Camptothecin & MDA-MB-231 cells & [170] \\
\hline Starch-graphene nanosheets & Hydroxycamptothecin & SW-620 cells & [171] \\
\hline Folic acid-modified GO & Doxorubicin, camptothecin & MCF-7 cells & {$[61]$} \\
\hline Poly(lactide) PEG & Paclitaxel & A549 cells & [172] \\
\hline PEGylated GO & Cisplatin analog & 4 T1-bearing mice & [173] \\
\hline $\mathrm{Fe}_{3} \mathrm{O}_{4}$ /graphene nanosheets & Fluorouracil & HepG2 cells & [173] \\
\hline Chitosan-functionalized GO & Fluorouracil & MCF-7 cells & {$[54]$} \\
\hline Gelatin-functionalized graphene nanosheets & Methotrexate & A549 cells & [174] \\
\hline Polyacrylic acid-functionalized GO & $\begin{array}{l}\text { 1,3-Bis (2-chloroethyl)-1- } \\
\text { nitrosourea }\end{array}$ & GL261 cells & [175] \\
\hline Graphene with PEG & Lucanthone & U251 cells & {$[50]$} \\
\hline $\mathrm{Fe}_{3} \mathrm{O}_{4} / \mathrm{RGO}, \mathrm{Fe}_{3} \mathrm{O}_{4} / \mathrm{GO}$ & $\beta$-Lapachone & MCF-7 cells & [176] \\
\hline RGO (modified nanoprobe) & $\beta$-Lapachone & MCF-7 cells & [177] \\
\hline Poloxamer 108-GO, Tween 80-GO, Maltodextrin-GO & Ellagic acid & MCF-7, HT-29 cells & [178] \\
\hline
\end{tabular}

N/A not available; the numbers in the parentheses are respective references

specificity to cancer cells, which lead to the obliteration and other damages to normal tissues and organs. Light irradiation therapeutics, including PTT and PDT, are currently the most promising technology approved by Food and Drug Administration (FDA) to attack cancer with reduced systemic toxicity and improvement of anticancer therapy $[62,63]$. Sreejith et al. described schematic illustrations of PTT and PDT approaches [15]. Chen et al. outlined the recent progress in PTT-related applications of GO [64]. The intrinsic optical absorbance of GBNs in the near-infrared (NIR) region contributes to photo-thermal therapeutic use [65, 66].

The efforts to develop suitable phototherapeutic nanomaterial-targeted cancer cells or tumor are in progress [67-70]. In the past few years, phototherapies based on the unique optical and chemical properties of graphene have raised interest. Compared to noble metal nanoparticles and carbon nanotube, graphene materials, especially GO, possess excellent properties such as greater optical absorption in the NIR region and higher photo-thermal conversion, high specific area and lower cost [71-74]. This makes GBNs an ideal candidate for phototherapy. Within the past few years, the strong intrinsic optical absorbance of GOhybrid materials has been intensively studied for their promising applications in in vivo cancer phototherapy [74-78]. PTT employs an optical-absorbing agent to generate heat under light irradiation, so biological tissues are exposed to a raised temperature to promote the selective destruction of abnormal cells. GO has attention from the PTT field due to its strong optical absorption in the nearinfrared reflectance region.

Zhang et al. developed a dual-drug-loaded, doxorubicin (DOX)-loaded PEGylated nanographene oxide (NGO-PEG (polyethylene glycol)-DOX), which can deliver heat and the drug to the tumorigenic region to facilitate the combining chemotherapy and photo-thermal treatment in one system [63]. In vivo results demonstrated that the approach was superior to chemotherapy or photo-thermal treatment alone. Yang et al. constructed an iron oxide nanoparticle (CRGO-IONP) nanocomposite probe to combine the capability of tumor bioimaging with PTT [47]. Under the guidance of magnetic resonance imaging (MRI), this group found irradiation effectively ablated solid tumors with an 808-nm NIR laser at a low power density of $0.5 \mathrm{~W} \mathrm{~cm}^{2}$ 
with the treatment of RGO-IONP-PEG. Hu et al. synthesized a quantum-dot-tagged CRGO (QD-CRGO) nanocomposite that combines the capability of cell/tumor bright fluorescence bioimaging with photo-thermal therapy [79]. The composite mitigated the toxicity of QDs and prevented fluorescence quenching by maintaining a precisely controlled spacer between the QDs and the RGO. With a folic acid attachment, the composite could target MCF-7 cells selectively. After irradiation at $808 \mathrm{~nm}$, cells were killed by the generated heat from the QD-RGO. The increased temperature also caused a marked decrease in the QD brightness, which provided a means for in situ heat/ temperature sensing and an indicator of the progress of the photo-thermal therapy. Just recently, the Chung group has developed protein-functionalized RGO nanosheets of great stimuli-responsive drug delivery, controlled release and photo-thermal enhancement capability [18].

The doxorubicin (DOX)-loaded bovine serum albumin (BSA)-functionalized RGO (DOX-BSA-RGO) nanosheets demonstrated NIR-induced chemo-photo-thermal therapy of brain tumor cells treated with DOX-BSA-RGO nanosheets without causing a cytotoxic effect before cell intake. Unlike PTT, PDT relies on irradiation of photosensitizers (PSs) with a suitable light to generate free radicals, which results in irreversible damage to cancer cells. However, PDT is still a challenging technique because many of the commonly used PSs are hydrophobic and cause solubility and biocompatibility problems [45]. In efforts to this issue, Zhou et al. immobilized hypocrellin A (HA, a perylene quinonoid hydrophobic non-porphyrin photodynamic antitumor drug) onto GO via the $\pi-\pi$ stacking interaction, hydrophobic effect and hydrogenbonding interactions [63]. GO-HA nanomaterial could be excited by irradiation with light of an appropriate wavelength to generate singlet oxygen. The in vitro tests with HeLa cells revealed highly efficient cellular uptake of GO$\mathrm{HA}$, and the light irradiation of impregnated cells resulted in significant cell death.

To explore dual benefits of PDT and PTT, Tian et al. loaded chlorine 6 (Ce6), a photosensitizer molecule, on PEG-functionalized GO and delivered the multifaceted, complex nanosheet to KB (HeLa derivative) cells. Results show the low power density of 808-nm laser would promote the delivery of $\mathrm{Ce} 6$ molecules by mild local heating because of the photo-thermal effect of GO nanosheets. This is compared with $\mathrm{Ce} 6$ or GO-PEG-Ce6 complex without the near-infrared laser, and PDT efficacy against cancer cells was significantly enhanced [80].

Another study by Yang et al. [47] synthesized multifunctional nanocomposite GO-PEG-FA/Gd/DOX to obtain MRI and therapeutic effect. Another report on the combined chemo-photo-thermal therapy by $\mathrm{Xu}$ et al. [81] showed low toxic nanocomposites NGOHA-AuNRs-DOX which exhibited 1.5- and 4-fold higher cell death than separate chemotherapy and photo-thermal therapy, with biosafety and low side effects compared to non-targeting cells. Au nanoribbon (AuNR)-PEG-GO nanocomposites tested in both in vitro and in vivo showed effective chemophoto-thermal therapy. An ideal nanocomposite combining GO with gold nanoribbon, AuNR-PEG-GO, was synthesized and used for PTT due to AuNR and GO possessing a strong NIR absorption. The composite properties of AuNR-PEG-GO would also be helpful for introducing appropriate functional groups to target specific cancer cells. The AuNR surfaces could also be a good platform through which proteins and other molecules could be linked to target specific cancer cells after inserting the appropriate cross-linkers [82].

Wang et al. developed chitosan (CS)-modified graphene nanogel for noninvasive controlled drug release. In their study, a NIR-triggered drug delivery platform based on the CS-modified chemically reduced graphene oxide (CRGO) incorporated into a thermo-sensitive nanogel (CGN) was developed. The poly(N-isopropyl acrylamide) (PNIPAM) underwent a reversible discontinuous phase transition in water, changing from hydrophilic to hydrophobic, in response to temperature change. This proved that PNIPAM hydrogel was a thermo-sensitive material. CGN exhibited a NIR-induced thermal effect similar to that of CRGO, reversible thermo-responsive characteristics at $37-42{ }^{\circ} \mathrm{C}$ and high DOX loading capacity (48 wt\%). The DOX-loaded CGN (DOX-CGN) released DOX faster at $42{ }^{\circ} \mathrm{C}$ than at $37{ }^{\circ} \mathrm{C}$. When incubated at 37 and $42{ }^{\circ} \mathrm{C}$, DOX-CGN expression was observed in the cytoplasm of cancer cells, and nucleus, respectively, which was revealed thorough fluorescence images. Upon irradiation with NIR light $(808 \mathrm{~nm})$, a rapid, repetitive DOX release from the DOXCGN was observed. Furthermore, the cancer cells incubated with DOX-CGN and irradiated with NIR light displayed significantly greater cytotoxicity than without irradiation owing to a NIR-triggered increase in temperature leading to nuclear DOX release. These results demonstrated that CGN's promising application for ondemand drug release by NIR light is very promising [83].

Jinet al. fabricated GO-modified polylactic acid (PLA) (GO-PLA) microcapsules containing AuNPs and used them for ultrasonic (US)/computed tomography (CT) bimodal imaging-guided PTT. After the use of the microcapsules, the US/CT imaging could offer the accurate size and location of the tumor under the real-time guidance and monitoring, and then the NIR laser-induced PTT could be carried out by the diagnostic imaging results without compromising the normal tissues. This was a promising method suitable for tumor therapy [84].

Recently, a pH-responsive nanocarrier by coating nanographene oxide (NGO) with dual types of polymers, 
PEG and poly(allyl amine hydrochloride) (PAH), was synthesized; the PAH was then modified with 2,3dimethylmaleic anhydride (DA) to obtain $\mathrm{pH}$-dependent charge reversibility. Moreover, a chemotherapy drug (DOX) was loaded on it; this acquired NGO-PEG-DA/ DOX complex exhibited a dual $\mathrm{pH}$-responsiveness, showing distinctly improved cellular uptake under the tumor microenvironmental $\mathrm{pH}$ and augmented DOX release under lowered $\mathrm{pH}$ inside cell lysosomes. Combining such a unique behavior with the followed slow efflux of DOX, NGO-PEG-DA/DOX offered remarkably enhanced killing of drug-resistant cancer cells under the tumor microenvironmental $\mathrm{pH}$ in contrast to free DOX. The combined chemical therapy and PTT were then achieved using NGOPEG-DA/DOX complex, realizing a synergistic therapeutic effect. This work presented a novel design of surface chemistry on NGO for the development of smart DDSs responding to the tumor microenvironment such as $\mathrm{pH}$ with the potential to overcome drug resistance [85].

Multimodality therapy and theranostics are going to attract great attention worldwide owing to its controllable release, minimally invasive properties and high therapeutic efficacy. The multifunctional nanocomposite shows either high photo-thermal energy conversion coefficient or NIRtriggered drug release or $\mathrm{pH}$-sensitive properties or targeting properties with the real-time imaging guidance. So, the construction of other NGO-encapsulated functional nanomaterials for synergistic therapy of malignancy deserves our further efforts. Some most recent examples of multimodality therapy and theranostics are shown by Nellore et al. [86]. Their study investigated the highly selective detection of tumor cells from infected blood samples using AGE-aptamer-conjugated theranostic magnetic nanoparticle-attached hybrid graphene oxide. Their experimental data indicate that hybrid graphene can be used as a multicolor luminescence platform for selective imaging of G361 human malignant melanoma cancer cells. The reported results have also shown that indocyanine green (ICG)-bound AGE-aptamer-attached hybrid graphene oxide is capable of combined synergistic photothermal and photodynamic treatment of cancer. Targeted combined treatment using $785 \mathrm{~nm}$ NIR light indicates that the multimodal therapeutic treatment is highly effective for malignant melanoma cancer therapy. Hu et al. constructed a photo-theranostic nanoagent using indocyanine greenloaded polydopamine-reduced graphene oxide nanocomposites (ICG-PDA-RGO) and determined if the nanostructure could have amplifying PA and PTT effects for cancer theranostics. The results demonstrate that the PDA layer coating on the surface of RGO could effectively absorb a large number of ICG molecules, quench ICG's fluorescence, and enhance the PDA-RGO's optical absorption at $780 \mathrm{~nm}$. The obtained ICG-PDA-RGO exhibits stronger PTT effect and higher PA contrast than that of pure GO and PDA-RGO. After PA imaging-guided PTT treatments, the tumors in 4T1 breast subcutaneous and orthotopic mice models are suppressed completely and no treatment-induced toxicity is observed [87].

\subsection{Gene Delivery}

GBNs can interact not only with the drugs, but also with other biomolecules like nucleic acids, DNA and RNA. Thus, they can be used as carriers and in the identification of nucleic acids due to large $s p^{2}$-hybridized carbon area [88]. Recently, gene therapy has become an important method for treating diseases in regenerative medicine. GO has been demonstrated to adsorb nucleobases by $\pi-\pi$ interaction and also efficiently protect nucleotides from enzymatic cleavage. The basic requirements of a gene delivery vector include protecting DNA from degradation and ensuring high transfection efficiency. Besides, viral and non-viral vectors also have been widely investigated for gene delivery research. Paul et al. [89] found that GO complexed with vascular endothelial growth factor-165 (VEGF) proangiogenic gene is an efficient deliverer for myocardial therapy. Also, graphene oxide nanosheets have been found to be suitable as a vector which is easily up taken by cells [89]. For example, Feng et al. [90] used a polyethylenimine-GO (PEI-GO) carrier to transfect the plasmid DNA into HeLa cells and showed that PEI-GO caused enhancement of the transfection efficiency by proton-sponge effect.

Non-viral gene therapy is a promising approach to treating various diseases caused by genetic disorders [91]. These carriers can transfect cells with new genes from the liquid phase in a conventionally bulky approach or from the surface of the predeposited solid phase in a substratemediated manner. The gene vehicle or vector must protect the loaded DNA from degradation by cellular nucleases facilitating its uptake with high transaction efficiency. The major challenge preventing the achievement of these goals is the lack of efficient and non-mutagenic vectors or gene vehicles [89, 92]. Given the unpredictability of viral vectors, many researchers have switched to synthetic vectors composed of liposomes or more recently graphene derivatives. It has been shown that GO derivatives can improve the penetration of siRNA or plasmid DNA (pDNA) into cells protecting DNA from enzyme cleavage [93]. Moreover, the cytotoxicity of cationic polyethylenimine (PEI) is significantly reduced after complexation or conjugation with GO. Also, Li et al. (2002) managed to pattern preconcentrated PEI/pDNA on absorbent GO mediating highly localized and efficient gene delivery. The patterned substrates exhibited excellent biocompatibility and enabled effective gene transfection for various cell 
lines including stem cells [91]. The distinguishing property of PEI-GO compared to other vehicles is its ability to condense DNA at a low mass ratio $(+49 \mathrm{mV})$ and effectively transport pDNA through the cytoplasm to the nucleus. Also, other carbon vectors such as GO/chitosan, GO-PEG and GO/polyamidoamine (PAMAM) can also be used to deliver pDNA and siRNA. Liu et al. showed that graphene oleate PAMAM exhibited good compatibility and greatly improved green fluorescent protein gene transfection efficiency $(18.3 \%)$ in contrast to ultrasonicated graphene $(1.4 \%)$ and GO PAMAM without oleic modification (7.0\%) [89].

Besides its ability to protect DNA, graphene possesses the unique optical property of absorbing NIR light. Tian et al. showed that localized NIR heating of GO-PEG-Ce6 increased its uptake and efficacy against cancer cells. They attributed the enhanced uptake of GO-PEG-Ce6 to an increase in membrane fluidity upon NIR heating [80]. Moreover, Kim et al. demonstrated that NIR irradiation of functionalized reduced GO can change the membrane integrity of endosomes, thus improving the intracellular lifetime of the drug or gene and their delivery efficacy [94, 95]. Tonelli et al. [7] summarized the graphene-based nanocarriers used for gene delivery.

\subsection{Antibacterial Activity}

Antibiotic resistance has recently become a significant health problem in the world, as there is an increase in the hospital acquired infection from multidrug-resistant pathogens [96]. However, the overuse of traditional antibiotics has led to the problem of antibiotic resistance. From the past two decades efforts have been made to invent novel drugs to treat multidrug-resistant pathogens including nanoparticles. To overcome resistance to antibiotics, many antibacterial medicines have been developed, such as metal and metal oxide nanoparticles [97]. GBNs were proven to be antibacterial because of their unique physiochemical properties. Researchers developed various GBNs-based nanocomposites via surface modification using biomolecules, polymers and inorganic nanostructures to reduce toxicity and increase their antibacterial efficiency. In this part of the section, we have summarized antibacterial activity of GBNs and their mechanism on antibacterial activity.

The versatility of GBNs and various studies confirm that GBNs could be used as antimicrobial agents [98-110]. GBNs and their nanocomposites were used as antibacterial in many fields such as in controlling microbial pathogens [111], wound dressing [112, 113], tissue engineering [114-116], packaging [117], drug delivery [118] and the purification of water [119]. Table 3 shows a recent review that lists various GBNs and their nanocomposites used as antibacterial agents. The promising applications of GBNs as antibacterial in various fields listed are drug delivery, surface infection, dental fillers, membrane antibiotic fouling, water disinfection and food packaging [120]. There are also a vast number of studies on the antibacterial activity of GO and RGO with other metal and metal oxides. GBNs were evaluated for their antibacterial activity (Table 3). In addition, the synergistic antibacterial activity of GBNs was evaluated along with other metal and metal oxides. For example, GO sheets were hybridized with silver nanoparticles (AgNPs) via one-pot hydrothermal, electrostatics interactions, simple missing chemical deposition, sequential repetitive chemical reductions and supercritical $\mathrm{CO}_{2}$. Recently, the contradictory reports on the antibacterial activity of functionalized GBNs have been discussed by Hegab et al. [120].

Increasing number of investigations on the antibacterial activity of GBNs postulated several important mechanisms of antibacterial activity [120, 121]. Recently, GBNs have been widely reported to have antibacterial activity with their sharp edges to bacterial membranes leading to the destruction of lipid biomolecules and oxidative stress [121]. Zhao et al. speculated that [68] the antibacterial activity of GBNs is bacterial species dependent rather than gram dependent [122]. The antibacterial activity of GBNs involves several mechanisms together than an individual mechanism responsible for antibacterial activity (Table 3 and Fig. 6). Therefore, it is necessary to compare different types of GBNs and their effects on the bacterial species to their physiochemical characteristics. GBNs physiochemical parameters, impurities from the synthesis process, a method of antibacterial testing and experimental conditions should be considered for the GBNs which are explored for biomedical applications.

From the above discussion, it is evident that GBNs have the potential to be used as therapeutics. GBNs have been loaded with drugs, bacteria, genes and antibacterial agents using various methods based on physisorption, chemical conjugation, gene technology and others. The loading capacity of the GBNs may differ based on the type of GBNs used, nature of drugs, viral and non-viral vectors, and antibacterial materials. Despite the development of GBN-based materials and their applications in chemotherapy, it is essential to focus more on translational research before their use as therapeutics. 
Table 3 Antibacterial efficiency of graphene-based nanomaterials (data adapted from Ref. [120]). Copyright (C) Elsevier 2016

\begin{tabular}{|c|c|c|c|c|}
\hline GBN nanocomposites & Bacterial strains & $\begin{array}{l}\text { Incubation and } \\
\text { concentration }\left[\mu \mathrm{g} \mathrm{mL}^{-1}\right]\end{array}$ & $\begin{array}{l}\text { Inhibition } \\
(\%)\end{array}$ & Refs. \\
\hline \multicolumn{5}{|l|}{ Graphene $(G)$-based nanocomposite dispersions } \\
\hline Graphene oxide (GO) & Pseudomona aeruginosa & 2 and 175 & 100 & [102] \\
\hline RGO & Escherichia coli & 4 and $10^{2}$ & 88 & [179] \\
\hline GO & E. coli & 2 and 85 & 98.5 & [98] \\
\hline GO & E. coli & 2 and 40 & 69.3 & [180] \\
\hline GO & E. coli & 2 and 40 & 97.7 & [100] \\
\hline G-quantum dots & E. coli, Staphylococcus aureus & 0.25 and 200 & $80 / 92$ & [181] \\
\hline G-gelatine/silver (Ag) nanoprisms & E. coli & 24 and 10 & 99.9 & [182] \\
\hline G-AgNPs & P. aeruginosa & 0.5 and 5 & 100 & [183] \\
\hline G-AgNPs & E. coli & 4 and $10^{2}$ & 100 & [184] \\
\hline G-AgNPs & E. coli & 24 and 10 & 99.9 & [185] \\
\hline G-AgNPs & E. coli/P. aeruginosa & 24 and N/A & $18 / 26 \mathrm{~mm}$ & [186] \\
\hline G-AgNPs & S. aureus/B. subtilis & 24 and N/A & 100 & [187] \\
\hline G-AgNPs & E. coli & 0.3 and N/A & $20 \mathrm{~mm}$ & [188] \\
\hline G-AgNPs & E. coli/S. aureus & 24 and 10 & 100 & [189] \\
\hline G-AgNPs & E. coli/S. aureus & 4 and 45 & 100 & [190] \\
\hline $\begin{array}{l}\text { G-AgNPs/PDDA (polydiallyldimethyl ammonium } \\
\text { chloride) }\end{array}$ & E. coli & 24 and 50 & 100 & [191] \\
\hline G-AgNPs/PEI (polyethyleneimine) & E. coli/S. aureus & 6 and 958 & $14.8 / 20.5$ & [192] \\
\hline G-AgNPs/PDA (polydopamine) & E. coli & 24 and 25 & $23.7 \mathrm{~mm}$ & [193] \\
\hline G-AgNPs/PAA (poly acrylic acid) & E. col./S. aureus & 24 and N/A & $\begin{array}{l}9.9 / \\
11.4 \mathrm{~mm}\end{array}$ & [194] \\
\hline $\begin{array}{l}\text { G-AgNPs/aminophenol AgNPs/aminophenol } \\
\text { AgNPs/aminophenol }\end{array}$ & E. coli/S. aureus & 8 and 500 & 100 & [195] \\
\hline G-Ag/iron oxide $\left(\mathrm{Fe}_{3} \mathrm{O}_{4}\right)$ & E. coli & 24 and N/A & N/A & [196] \\
\hline G-Ag/titanium oxide $\left(\mathrm{TiO}_{2}\right)$ & E. coli & 2 and $10^{2}$ & 67 & [197] \\
\hline $\mathrm{G}-\mathrm{Fe}_{3} \mathrm{O}_{4}$ & E. coli & 2 and $6.6 \times 10^{5}$ & 91.5 & [198] \\
\hline G-ZnO NPs & Salmonella typhi/E. coli. & 24 and $3 \times 10^{3}$ & $13 / 11 \mathrm{~mm}$ & [199] \\
\hline G-ZnO NPs & Salmonella typhi/E. coli. & 12 and $31.25 / 15.62$ & 100 & [200] \\
\hline G-(MnOx), quantum dots $/ \mathrm{TiO}_{2}$ & E. coli/S. aureus & 18 and $31.25 / 15.62$ & $\begin{array}{l}10.9 / \\
10.5 \mathrm{~mm}\end{array}$ & [201] \\
\hline $\mathrm{G}-\mathrm{MnFe}_{2} \mathrm{O}_{4}$ & E. coli & N/A and $10^{2}$ & 82 & [202] \\
\hline $\mathrm{G}^{-\mathrm{TiO}_{2}}$ & E. coli & 0.5 and N/A & 99.6 & [203] \\
\hline G-CuNPs/poly-L-lysine PLL & E. coli & 24 and 50 & 99 & [105] \\
\hline $\mathrm{G}-\mathrm{Bi}_{2} \mathrm{WO}_{6}$ & Mixed culture & 18 and 250 & 100 & [204] \\
\hline G-Ag/cyclodextrin (CD) & B. subtilis & 24 and 0.05 & N/A & [205] \\
\hline G-cadmium sulfide (CdS) & E. coli & 1 and 200 & 99.9 & [206] \\
\hline $\begin{array}{l}\text { G-polyethylene glycol (PEG)/PHGC } \\
\text { (polyhexamethylene guanidine hydrochloride] }\end{array}$ & E. coli/S. aureus & 1 and N/A & 100 & [207] \\
\hline G-chitosan (Cs) & P. aeruginosa & 24 and $3 \times 10^{3}$ & 100 & [208] \\
\hline G-dithiothreitol & E. coli & 4 and $10^{2}$ & 86 & [179] \\
\hline G-Sand & E. coli & 24 and N/A & $20 \mathrm{~mm}$ & [136] \\
\hline G-Ramizol & S. aureus & 20 and N/A & 100 & [209] \\
\hline \multicolumn{5}{|l|}{ G-based nanocomposite Surfaces } \\
\hline G-AgNPs/polyamide (PA) & E. coli & 1 and $10^{3}$ & 98 & [210] \\
\hline $\mathrm{Ag} /$ polyethersulfone (PES) [N/A] & E. coli, $S$. aureus, $P$. aeruginosa & 24 and N/A & N/A & [211] \\
\hline AgNPs/cellulose acetate (CA) & E. coli & 2 and N/A & 86 & [212] \\
\hline
\end{tabular}


Table 3 continued

\begin{tabular}{|c|c|c|c|c|}
\hline GBN nanocomposites & Bacterial strains & $\begin{array}{l}\text { Incubation and } \\
\text { concentration }\left[\mu \mathrm{gLL}^{-1}\right]\end{array}$ & $\begin{array}{l}\text { Inhibition } \\
(\%)\end{array}$ & Refs. \\
\hline AgNPs/polysulfone (PS) & E. coli & 18 and N/A & 100 & [149] \\
\hline Cs & S. aureus & 3 and $6 \times 10^{4}$ & 77 & [213] \\
\hline Polyvinyl alcohol (PVA)/Cs & E. coli & 24 and $4 \times 10^{3}$ & $8.6 \mathrm{~mm}$ & [214] \\
\hline PES & E. coli & 4 and N/A & 71 & [215] \\
\hline PA & E. coli & 1 and N/A & 65 & [216] \\
\hline PA & E. coli & 24 and N/A & 65 & [217] \\
\hline Polypropylene (PP) & E. coli & 12 and & 64 & [218] \\
\hline PLL/hyaluronic acid (HA) [105] & E. coli & 4 and $10^{5}$ & 66 & [219] \\
\hline Polyester (PE)/resin[N/A] & P. aeruginosa & 24 and N/A & $15 \mathrm{~mm}$ & [220] \\
\hline PA/PLL [80] & Mixed culture & 24 and 80 & 99 & [221] \\
\hline PES & E. coli & 24 and N/A & 74.88 & [222] \\
\hline $\mathrm{ZnO} \mathrm{NWs}$ & E. coli & 1 and $10^{3}$ & 95 & [223] \\
\hline $\mathrm{ZnO} \mathrm{NWs}$ & E. coli & 1 and $99.5 \times 10^{3}$ & 99.5 & [223] \\
\hline Stainless steel (SS)/RGO & E. coli/S. aureus & 1 and N/A & $84 / 95$ & [224] \\
\hline $\mathrm{Ti}$ & E. coli/S. aureus & 24 and N/A & $68.4 / 72.9$ & [225] \\
\hline $\mathrm{TiO}_{2}$ & E. coli & 0.5 and N/A & 60 & [107] \\
\hline $\mathrm{Cu}$ & E. coli/S. aureus & 24 and N/A & $56 / 34$ & [226] \\
\hline Benzalkonium bromide (BKB) & E. coli/Listeria & 48 and $4 \times 10^{3}$ & $99.3 / 91$ & [227] \\
\hline \multicolumn{5}{|l|}{ G-based hydrogels } \\
\hline $\mathrm{BKB} / \mathrm{PDA}$ & E. coli/Listeria & 48 and $4 \times 10^{3}$ & $99.3 / 91$ & [227] \\
\hline Agarose & E. coli/S. aureus & N/A and N/A & 100 & [228] \\
\hline $\mathrm{Ag}$ & E. coli/S. aureus & 0.5 and $2.5 \times 10^{3}$ & 100 & [112] \\
\hline $\mathrm{Ag} / \mathrm{PVA}$ & E. coli/S. aureus & 24 and N/A & 100 & [229] \\
\hline
\end{tabular}

N/A not available; the numbers in the parentheses are respective references

\section{Biomedical Applications of GBNs in Engineering}

\subsection{Biosensors}

Biosensing, bioimaging and therapeutics are three important areas of biomedical research. These three areas are classified based on their functionality. For example, biosensing involves qualitative/quantitative recognition of the specific type of analytes by characterizing the spectrochemical, electrochemical or magneto-chemical behavior of the systems. Mostly, biosensors are useful in the detection of biomolecules and chemical analytes [15]. Biomolecules play a crucial role in the disease development, so the detection of biomolecule aids in the diagnosis and therapy is very important. GBNs can detect these biomolecules due to their excellent electrochemical and optical properties. The capacity to adsorb a variety of aromatic molecules via $\pi-\pi$ stacking interaction makes ideal materials for fabricating biosensors [41]. Biosensors are analytical devices consisting of a biological component (receptor) and electronic component (transducer) [123].
GBNs can be used as biosensors due to their electrochemical and optical properties. They also can adsorb aromatic biomolecules through either $\pi-\pi$ interaction or electrostatic interaction [45]. The functional groups, and electrical and optical properties of GBNs allow them to have the specific interactions at the surface of GBNs. Graphene-based biosensors were developed to detect small molecules such as glucose, nicotinamide, dinucleotide adenine, adenine triphosphate, hydrogen peroxide, estrogen $[30,33,124-127]$. Also GBNs are able to detect macromolecules such as biomarkers to diagnose the disease. The commonly employed techniques such as electrochemical and fluorescence resonance energy transfer (FRET) are being used in the construction of biosensors. The other techniques such as fluorescence spectroscopy, surface plasmon resonance (SPR) and surface-enhanced Raman scattering (SERS) have also shown promising results in the detection of biosensors. Compared to conventional methods, the biosensors are enabled to quantitatively detect small molecules to large biomolecules [68]. Among GBNs, GO exhibits characteristic G-band in Raman spectra along with its water solubility and biocompatibility. Most 


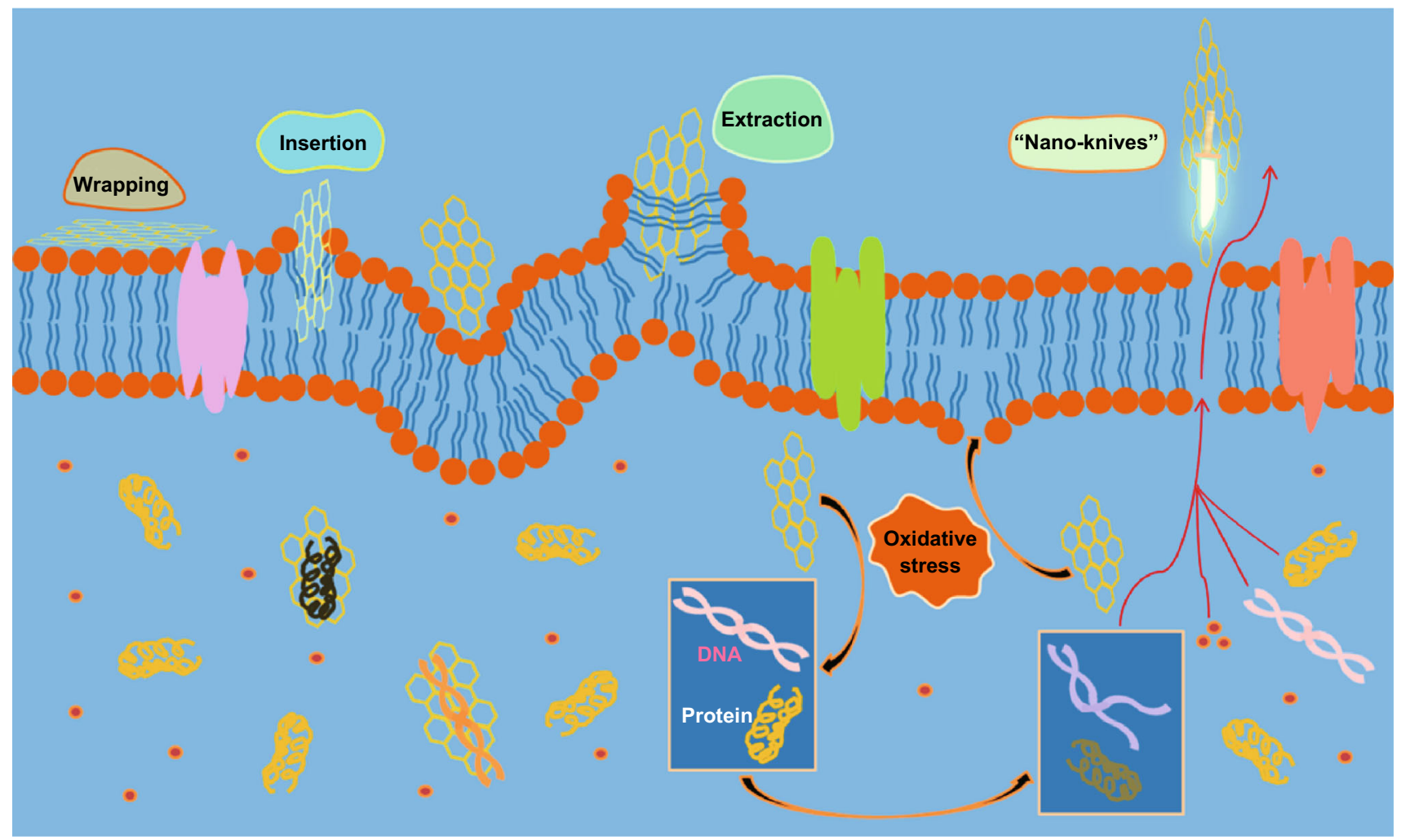

Fig. 6 Schematic mechanism of antibacterial activity of GBNs [161]. Copyright ㄷ 2016 American Chemical Society

commonly, GO-based biosensors are capable of lowering detection limits, fast response time, high sensitivity and increased signal-to-noise ratios [128]. GBN nanocomposites work efficiently in combination with metal nanoparticles, auxiliary biomolecules (chitosan), bioenzyme (horseradish peroxidase) due to their enhanced electronic and synergistic compositions to catalyze glucose enzymatic reaction for electrochemical sensing [129-132]. Recent studies have explored on enzyme-based biosensors. The selective and sensitive detection of glucose was reported in the fabrication of GBN-based electrochemical glucose sensors $[125,129,130,133]$. Other enzyme-based electrochemical biosensors have been developed using enzymes such as horseradish peroxidase (HRP), alcohol dehydrogenase (ADH), organophosphorous hydrolase $(\mathrm{OPH})$ microperoxidase-11, tyrosinase, acetylcholinesterase (AChE), catalase and urease.

\subsection{Bioimaging}

Bioimaging is considered as the ratification of biosensing outcomes in the detection of the specific type of biological components for diagnostic purposes [45]. Bioimaging is an important aspect of diagnostic research, as it can be used to monitor the health conditions of biological components in typically two types of environments, in vivo and in vitro. The primary requirements of materials used for bioimaging are high specificity, non-toxicity and sensitivity. While graphene can alleviate the toxicity of fabricated probes, introducing the selectivity and sensitivity is still a challenge in the material synthesis. The most widely employed GBNs in bioimaging are graphene quantum dots (GQDs). The initial studies on GQDs as imaging probes were reported in the early 2000s, wherein GQDs were prepared by hydrothermal cutting of graphene sheets [21]. As these dots showed remarkable photo-physical properties, fluorescence spectroscopy was the commonly used technique for imaging biological components. Table 4 outlines various GBNs used for bioimaging.

\subsection{Tissue Engineering}

Tissue engineering is an emerging new area in life sciences that targets the development of biological substitutes to modify the function of a tissue to repair and maintain its properties. These biological substitutes also known as scaffolds are made of a biodegradable material [134]. Traditional transplantation has limitations to repair tissue 
Table 4 GBNs in bioimaging (data adapted from Ref. [33]). Copyright (C) Elsevier 2016

\begin{tabular}{|c|c|c|c|c|}
\hline & Purpose & Advantages & Disadvantages & Studies with GBNS \\
\hline $\begin{array}{l}1 \text { Optical } \\
\text { imaging }\end{array}$ & $\begin{array}{l}\text { Utilizes visible light and } \\
\text { spectral properties of photons } \\
\text { to obtain detailed images of } \\
\text { organs and tissues }\end{array}$ & $\begin{array}{l}\text { Low cost, real-time imaging, } \\
\text { short acquisition and } \\
\text { multiplexing capability }\end{array}$ & $\begin{array}{l}\text { Poor tissue penetrability, } \\
\text { strong tissue scattering of } \\
\text { photons in the visible light } \\
\text { region }(395-600 \mathrm{~nm})\end{array}$ & $\begin{array}{l}\text { Nitrogen-doped GQDs } \\
\quad \text { [230] }\end{array}$ \\
\hline \multirow[t]{4}{*}{$\begin{array}{l}1.1 \\
\quad \text { Fluorescence } \\
\text { imaging }\end{array}$} & $\begin{array}{l}\text { Noninvasive technique based on } \\
\text { photons emitted from } \\
\text { fluorescent probes }\end{array}$ & $\begin{array}{l}\text { Minor auto-fluorescence } \\
\text { background, larger imaging } \\
\text { depth, reduced photo- } \\
\text { bleaching and photo-toxicity }\end{array}$ & $\begin{array}{l}\text { Cannot provide quantitative } \\
\text { results. Interference of } \\
\text { fluorescence quenching or } \\
\text { photo-bleaching of } \\
\text { fluorescent dyes, light } \\
\text { absorption and scattering or } \\
\text { tissues and auto- } \\
\text { fluorescence background }\end{array}$ & $\begin{array}{l}\text { nGO-PEG-Rituxan } \\
\text { [231] }\end{array}$ \\
\hline & & & & nGO-PEG-Cy7 [232] \\
\hline & & & & $\begin{array}{l}\text { GO-IRDye800- } \\
\text { VEGF [231] }\end{array}$ \\
\hline & & & & GO-PEG [209] \\
\hline \multirow[t]{2}{*}{$\begin{array}{l}\text { 1.2 Two-photon } \\
\text { fluorescence } \\
\text { imaging } \\
\text { (TPMI) }\end{array}$} & $\begin{array}{l}\text { Detailed analysis of } \\
\text { cellular/subcellular activities } \\
\text { in the deep location of } \\
\text { biological samples }\end{array}$ & $\begin{array}{l}\text { This extends the possibility of } \\
\text { vibrational spectroscopy with } \\
\text { extremely high signal-to- } \\
\text { noise ratio, negligible photo- } \\
\text { bleaching and multiplexing } \\
\text { capabilities to solve chemical } \\
\text { and biochemical problems in } \\
\text { a nondestructive and non- } \\
\text { perturbing manner }\end{array}$ & & N-GQDs [230] \\
\hline & $\begin{array}{l}\text { Excitation wavelength in the } \\
\text { range of } 700-1350 \mathrm{~nm}\end{array}$ & & & \\
\hline \multirow[t]{6}{*}{$\begin{array}{l}\text { 1.3 Raman } \\
\text { imaging }\end{array}$} & $\begin{array}{l}\text { It exploits the inelastic } \\
\text { scattering of phonons derived } \\
\text { from molecular vibrational } \\
\text { excitation modes }\end{array}$ & & & Ag/GO hybrids [210] \\
\hline & & & & $\begin{array}{l}\text { Folic acid-conjugated } \\
\text { Ag/GO hybrids } \\
\text { [233] }\end{array}$ \\
\hline & & & & Au@NGOs [234] \\
\hline & & & & RGO-NS [235] \\
\hline & & & & $\begin{array}{l}\mathrm{Au} / \mathrm{GO} \text { and } \mathrm{Au} / \mathrm{RGO} \\
{[236,237]}\end{array}$ \\
\hline & & & & $\begin{array}{l}\mathrm{AgCu} @ \text { graphene } \\
{[238]}\end{array}$ \\
\hline \multirow[t]{4}{*}{$\begin{array}{l}\text { 2. Radionuclide } \\
\text { imaging }\end{array}$} & $\begin{array}{l}\text { Accurately tracks the } \\
\text { radiolabeled substances } \\
\text { in vivo in a quantitative } \\
\text { manner with excellent } \\
\text { sensitivity }\end{array}$ & PET and SPECT imaging & & $\begin{array}{l}\text { nGO-PEG with } 1251 \\
\text { [232] }\end{array}$ \\
\hline & & $\begin{array}{l}\text { Low background signal and } \\
\text { require little signal } \\
\text { amplification }\end{array}$ & & $\begin{array}{l}\text { 64 Cu-labeled nGO- } \\
\text { PEG [239] }\end{array}$ \\
\hline & & & & $\begin{array}{l}\text { 66 Ga nGO-PEG } \\
{[240]}\end{array}$ \\
\hline & & & & $\begin{array}{l}\text { 198, 199 Au@AF-GO } \\
\text { [241] }\end{array}$ \\
\hline
\end{tabular}


Table 4 continued

\begin{tabular}{|c|c|c|c|c|}
\hline & Purpose & Advantages & Disadvantages & Studies with GBNS \\
\hline \multirow[t]{4}{*}{$\begin{array}{l}\text { 3. Magnetic } \\
\text { resonance } \\
\text { imaging } \\
\text { (MRI) }\end{array}$} & $\begin{array}{l}\text { It has been used to image the } \\
\text { anatomy as well as function } \\
\text { of tissues in a quantitative } \\
\text { manner with excellent spatial } \\
\text { resolution }\end{array}$ & $\begin{array}{l}\text { Noninvasive technique without } \\
\text { ionizing radiation }\end{array}$ & $\begin{array}{l}\text { Low sensitivity, long signal } \\
\text { acquisition time }\end{array}$ & Gd-NGO [242] \\
\hline & & & & GO-IONP [47] \\
\hline & & & & RGO-IONP [243] \\
\hline & & & & Fluorinated GO [244] \\
\hline \multirow[t]{3}{*}{$\begin{array}{l}\text { 4. Photo- } \\
\text { acoustic } \\
\text { imaging } \\
\text { (PAI) }\end{array}$} & $\begin{array}{l}\text { It offers optical absorption } \\
\text { contrast with the resolution of } \\
\text { ultrasound for deep tissue/ } \\
\text { organ imaging }\end{array}$ & $\begin{array}{l}\text { Radiofrequency waves exhibit } \\
\text { lower scattering in the } \\
\text { biological samples }\end{array}$ & & RGO [245] \\
\hline & & & & ICG-GO [246] \\
\hline & & & & BSA-nano-RGO [247] \\
\hline \multirow{2}{*}{$\begin{array}{l}\text { 5. Computed } \\
\text { tomography } \\
\text { (CT) }\end{array}$} & $\begin{array}{l}\text { It provides complementary } \\
\text { anatomical information }\end{array}$ & & & Go@Ag [248] \\
\hline & $\begin{array}{l}\text { It measures the absorption of } \\
\text { X-rays when they pass } \\
\text { through targets }\end{array}$ & & & $\begin{array}{l}\text { GO/BaGdF5/PEG } \\
\quad[249]\end{array}$ \\
\hline \multirow[t]{3}{*}{$\begin{array}{l}\text { 6. Multimodal } \\
\text { imaging }\end{array}$} & $\begin{array}{l}\text { This technique refers to } \\
\text { integrating the merits of } \\
\text { individual imaging modality } \\
\text { and collecting all information } \\
\text { from different imaging } \\
\text { modalities that offers higher } \\
\text { efficiency and accuracy of } \\
\text { diagnosis }\end{array}$ & $\begin{array}{l}\text { Avoids the additional stress on } \\
\text { the body's blood clearance } \\
\text { that accompanies the } \\
\text { administration of multiple } \\
\text { doses of agents }\end{array}$ & & $\begin{array}{l}\text { RGO-IONP-PEG } \\
\text { [243] }\end{array}$ \\
\hline & & & & GO-IONP-Au [250] \\
\hline & & & & $\begin{array}{l}\text { GO-BaGdF5-PEG } \\
\text { [249] }\end{array}$ \\
\hline
\end{tabular}

The numbers in the parentheses are respective references

damage caused by trauma, infection, tumor and deformity. Materials such as hydrogels lack mechanical strength for cells to attach and spread [135]. However, different tissues in the body possess different mechanical, electrical or physical properties. Single materials might not mimic the physical and biological properties of the native tissue; therefore, hybrid bioactive materials with a variety of components that can address different requirements are widely used to fabricate artificial tissues. Hydroxyapatite [HA; $\left.\mathrm{Ca}_{10}(\mathrm{PO} 4)_{6}(\mathrm{OH})_{2}\right]$ is commonly used in various forms and shapes in bone and tissue engineering. However, due to their lack of mechanical strength, its usage is discouraged from replacing various parts of the bone system [136]. Materials such as hydrogels and nano- $\mathrm{TiO}_{2}$ have been used due to the lack of mechanical strength, aggregation and migration of $\mathrm{TiO}_{2}$, limiting their application in tissue engineering [134, 137, 138]. Moreover, the artificial biomarkers such as calcium phosphate $(\mathrm{CaP})$, hydrogels, calcium silicate $(\mathrm{Cs})$ lack the tissue inductive activity and delay the healing of functional modifications. In addition to the above, the compatibility, toxicity and anticoagulant capacity of scaffold material are other factors that limit their use in tissue engineering [137]. We discussed in Section 1.2 of this review, graphene is the basic unit of all forms of GBNs. Graphene has high mechanical strength, high surface area, high conductivity and low density. Graphene is also susceptible to acid and alkali environments and resists corrosion from the surroundings. The unique properties of GBNs, such as high elasticity, flexibility and adaptability to flat and irregular surfaces, make them suitable for the structural reinforcement of materials essential for tissue engineering which can improve adhesion, differentiation and cell function [24, 139, 140]. Among GBNs, GO can be modified easily because of the 
functional groups such as hydroxyl, epoxy, carboxyl on the surface of GO. Moreover GO, RGO and other graphenebased composites can be easily chemically modified because of the functional groups on the surface to interact with various biological molecules such as DNA, proteins, peptides and enzymes. On the other hand, RGO and other GO composites are being used in tissue engineering due to their flexibility to fabricate. Biomaterials like GO can induce specific cellular functions, direct cell differentiation and modulate cell-cell interactions. The fabrication strategies of graphene with biopolymer, protein, peptide, DNA and polysaccharide were discussed [141]. In the literature, it was reported that the GBNs are also applied in cardiac, neural, bone, cartilage, skeletal muscle and skin/ adipose tissue engineering. The reports indicated that GBNs may also have the osteogenic and neural potential [142, 143]. GBNs antimicrobial activity supports its role in tissue engineering by reducing the infections induced by microbes to progress human health [141].

Researchers demonstrated that GO could efficiently support differentiation of stem cells. Park et al. demonstrated that GBNs could be used in stem cell culture substrate to stimulate the cardiomyogenic differentiation process of mesenchymal cells [143]. In another report, Shin et al. developed 3D multilayer tissue constructs and showed strong spontaneous beating and frequency dependency under a low external electric field [114]. The GBN nanocomposite films aid in a suitable environment for the cell growth and the production of extracellular matrix in mesenchymal cells (mMSCs) to differentiated osteoblasts for bone regeneration. Golafshan et al. investigated the cultures of PC12 cells on the scaffolds; the results indicated that these scaffolds could efficiently enhance attachment, spreading and proliferation of PC12 cells [144]. The GBNs ability to maintain high cellular viability for longer periods of time after differentiation is essential for regenerative medicine [141]. In another report, Zhou et al. evaluated GBNs stem cell-based therapies for treating bone diseases [145]. They confirmed that cartilage cells seeded on the GBNs hybrid scaffold retain chondrogenic properties and are suitable substrates. Park et al. solved the problem of the poor survival rate of mesenchymal cells implanted in myocardial tissue by using GO and fibronectin-RGO-MSC hybrids to improve cardiac function restoration [143, 146].

\section{Health and Environmental Risks of GBNs}

GBNs are being used in various biomedical applications in the areas of drug delivery, tissue engineering and antibacterial materials. However, considerable variations need to be addressed before the use of GBNs for treatment in humans as therapeutics. The vast production of GBNs due to their applications might lead to the significant human and environmental exposures. To address the human and environmental risk of GBNs, it is essential to evaluate the level and degree of the toxicity for the effective use of GBNs in biomedical applications [147, 148]. The biological interactions of GBNs can be categorized into biomedical applications and environmental health and safety. Occupational and environmental exposures may also lead to potential toxicity of GBNs through non-biomedical products [149]. It is essential to understand the interactions at the cellular and molecular levels to determine the toxicity of GBNs. By overcoming the challenges to be used in therapeutic delivery, the modification of GBNs in biological systems spurs up further developments in biomedical applications. From a toxicological standpoint, the physicochemical characteristics of GBNs play an essential role in assessing the extent of toxicity. For instance, dose, shape, surface chemistry, exposure route and purity play important roles in differential toxicity of GBNs [19]. Surface area, layer number, lateral dimension, surface chemistry and purity of GBNs also play a vital role in exerting the toxicity [150].

The surface chemistry of GBNs is of utmost importance for any bio-functionalization to be carried out. The surface area of the GBNs decreases as the layer number increases. The number of layers of GBNs is an important characteristic as it determines the specific surface area and bending stiffness. Whereas lateral dimension does not affect specific surface area but defines the dimension of the material, which is significant for the biological phenomena (cell uptake, renal clearance and blood-brain barrier transport) influenced by particle size [150]. Among GBNs, GO is highly reactive because of the solubility and functionalization on the surface compared to graphene and RGO. When it comes to purity, GBNs based on their synthesis process may contain unreacted and residual chemicals resulting in inadequate washing. To report the toxicity in a comprehensive approach, the above-mentioned properties need to be characterized when carrying out biological studies [150]. The route of entry of GBNs into the body via blood circulation or biological barriers may affect different organs. GBNs may enter organs by crossing blood-air barrier, blood testis barrier, blood-brain barrier and blood-placental barrier, because of their nanosize, surface structure, functionalization, charge, impurities, aggregation, corona effects and physical destructions. Several cellular mechanisms such as oxidative stress, DNA damage, inflammatory response, apoptosis, autophagy and necrosis play a significant role in GBNs toxicity [16]. Even though GBNs have suggested various biomedical applications, toxicity and biosafety are the main issues related to their biological applications. 


\subsection{Toxicity In Vitro and In Vivo}

The toxicity of GBNs has been evaluated in different cell lines, including lung epithelial cells, fibroblasts, neuronal cells, cancer cells and animal models (Tables 5, 6). The cell death caused by nanomaterials includes either necrosis triggered by reactive oxygen species or apoptosis via plasma membrane damage. In the past few years, many reviews had published on the toxicity of GBNs in cells and animal models. The review by Ou et al. [16] summarized various toxicity studies conducted in various organs of animals and cells. The data from this review (Tables 5, 6) $[16,38]$ show the development of biocompatible GBNs and their toxicity effects on the cell and animal models. Moreover, Syama et al. [151] summarized approaches to reduced toxicity of graphene by using a biocompatible GBN, using microbes and plant extracts and biocompatible polymers to produce GBNs.

The two aspects that demonstrate the behavior of GBNs in biological fluids are the behavior of graphene as a colloid and the formation of the graphene surface of the protein corona. The GBNs in colloid form interact with the physiological media resulting in aggregation and flocculation of the suspension. Another critical factor affecting the behavior of GBNs is the formation of a protein corona. They explain that two components (soft and hard corona) play a significant role in adsorbing proteins. The particle stability may be enhanced if proteins are adsorbed via hydrophobic region to the basal plane of the flake with the hydrophilic region directed toward the exterior. On the other hand, adverse reactions may occur with the biodistribution and the interaction with the immune system. Hence, it is confirmed that the systemic adverse reactions are caused by GBNs or by modifications performed to GBNs [148]. Cells exposed to nanomaterial may undergo both apoptosis and necrosis. Chemical and physical properties such as reactive oxygen species (ROS) and direct damage to plasma membrane may trigger apoptosis and necrosis respectively. Figure 7 illustrates various toxicity mechanisms of toxicity at the cellular level [151]. Many reports were published on the internalization of GBNs as therapeutic agents as well as they might lead to cell intoxication [152]. The complication of intravenous drug delivery of GBNs bioaccumulation and granuloma formation can be overcome by surface modifications to accomplish selective targeting and support biodegradation [150].

It is evident from the literature [16] that in vitro toxicity results suggest that GBNs can be mostly toxic, but the toxicity is dependent on various factors such layer number, lateral size, stiffness, hydrophobicity, surface functionalization and dose. The four routes for entry of any nanoparticle into the human body include inhalation, ingestion, dermal penetration and injection or implantation for biomedical applications [150]. The route of entry, the dose and the duration of nanoparticles into the human body have a significant effect on the extent and severity of the toxicity [16]. The other significant determinants such as dose and duration of exposure also play a vital role in the level of toxicity.

\subsection{Impact on the Environment}

Graphene is emerging as a dynamic nanocarbon material. Although there are a broad scope and numerous advantages of GBNs in different fields of the scientific world, they also cause toxic effects on different biological models. An increase in the production of GBNs and their expected usage for biomedical purposes raises anxiety about their effects on humans and environment. It is necessary to understand the interaction of GBNs with the living systems to advance the biomedical application of GBNs. Even though the health effects associated with the GBNs have been studied at the cellular and in animal model, the human exposure of GBNs is unknown. Humans can be affected by GBNs via various exposure routes (Fig. 8) [151] from the site of production to the environment. Thereby, both the abiotic and biotic compartments of the ecosystem will get disturbed. It is imperative to investigate the interaction of GBNs across the membranes in the ecosystem to estimate the risk potential of the GBNs released into the environment. Very few reports found the impact of GBNs on the environment. Among GBNs, GO is considered as toxic. Choudhury et al. and $\mathrm{Wu}$ et al. investigated the environmental fate and transport of GO [153-156]. Choudhury et al. investigated the role of sunlight on the physicochemical properties, aggregation and deposition of GO in aquatic environments [155]. They reported that exposure to sunlight has a significant impact on the physiochemical properties of GO and their subsequent transport by reducing the materials stability in the environment. The research needs to be conducted to understand the complex roles of $\mathrm{pH}$, natural organic material and other natural colloids on the fate of photo-transformed GO. Zhao et al. [122] discussed GO transformation to RGO may occur under the direct interaction of aquatic organisms. Hua et al. explored the aggregation and resuspension of GO in simulated natural aquatic environments. The findings indicated that the graphene oxide nanoparticles (GONPs) transport and fate has a significant impact in natural aquatic environments by divalent cations, natural organic matter $(\mathrm{NOM})$ and hydraulics [157].

As it is projected that the GBNs-based products market to reach millions of dollars by 2020 , there will be a generation of GBNs-based wastes into the environment. It is essential to evaluate the potential toxic effects and fate of GBNs in the environment. Only a few researchers 
Table 5 GBNs toxicity effects in various cells (data adapted from Ref. [152]). Copyright (C) Elsevier 2016

\begin{tabular}{|c|c|}
\hline GBNs [Exposure conditions] & Cell types \\
\hline $\begin{array}{l}\text { Pristine graphene }\left[20 \mu \mathrm{g} \mathrm{mL}^{-1} \text { for }\right. \\
\quad 24 \mathrm{~h}]\end{array}$ & Peritoneal macrophages; RAW264.7 \\
\hline $\begin{array}{l}\text { Pristine graphene }\left[0-80 \mu \mathrm{g} \mathrm{mL}^{-1} \text { for }\right. \\
\quad 24 \text { and } 48 \mathrm{~h}]\end{array}$ & RAW264.7 \\
\hline $\begin{array}{l}\text { Pristine graphene; functionalized } \\
\text { graphene }\left[75 \mathrm{~g} \mathrm{~mL}^{-1} \text { for } 24 \text { or }\right. \\
48 \mathrm{~h}]\end{array}$ & RAW264.7 \\
\hline $\begin{array}{l}\text { Graphene; few-layer graphene (FLG) } \\
\text { microsheets [ } 5 \mathrm{~h} \text { for macrophages } \\
\text { and } 24 \mathrm{~h} \text { for other cell types] }\end{array}$ & $\begin{array}{l}\text { Primary human keratinocytes; human } \\
\text { lung epithelial cells; Murine } \\
\text { macrophages }\end{array}$ \\
\hline Graphene $[\mathrm{N} / \mathrm{A}]$ & HeLa; Panc-1 \\
\hline $\begin{array}{l}\text { Graphene quantum dots (GQDs) } \\
{\left[0-200 \mu \mathrm{mL}^{-1} \text {, for } 24,48 \text { or }\right.} \\
72 \mathrm{~h}]\end{array}$ & THP-1 \\
\hline $\begin{array}{l}\text { Pluronic dispersed graphene; GO } \\
\text { (graphene oxide) [administered } \\
\text { directly into the lungs of mice] }\end{array}$ & Lung cells \\
\hline Graphene, GO $\left[20 \mu \mathrm{g} \mathrm{mL}^{-1} ; 24 \mathrm{~h}\right]$ & MDA-MB-231; B16F10 \\
\hline $\begin{array}{l}\text { Carboxyl graphene nanoplatelets } \\
\qquad(\mathrm{CXYG})\left[0-32 \mu \mathrm{g} \mathrm{mL}^{-1} \text { for } 72 \mathrm{~h}\right]\end{array}$ & HepG2 \\
\hline $\mathrm{GO}\left[1-200 \mathrm{mg} \mathrm{L}{ }^{-1}, 24 \mathrm{~h}\right]$ & HepG2 \\
\hline $\mathrm{GO}\left[100 \mathrm{mg} \mathrm{L}^{-1}\right.$ for $\left.48 \mathrm{~h}\right]$ & GLC-82 \\
\hline $\mathrm{GO}\left[0-16 \mu \mathrm{g} \mathrm{mL}^{-1}\right.$ for $\left.72 \mathrm{~h}\right]$ & HepG2 \\
\hline
\end{tabular}

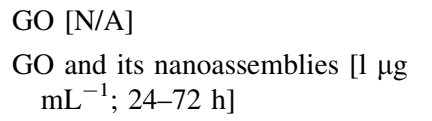

GO, bGO, pGO-5, pGO-30 and GS (graphene sheets) [0-200 $\mathrm{g} \mathrm{mL}^{-1}$, for 3 or $24 \mathrm{~h}$ ]

GO $\left[50 \mu \mathrm{g} \mathrm{mL}^{-1}\right.$ for $\left.24 \mathrm{~h}\right]$
GO [0-100 $\mathrm{g} \mathrm{mL}^{-1} 0-5$ days]
GO [N/A]
GO [20-100 $\mu \mathrm{g} \mathrm{mL}^{-1}$ for $\left.0-12 \mathrm{~h}\right]$
GO [0-20 $\left.\mathrm{g} \mathrm{mL}^{-1}\right]$

GO $\left[5-100 \mu \mathrm{g} \mathrm{mL}^{-1}\right.$ for $\left.24 \mathrm{~h}\right]$

GO $\left[20 \mu \mathrm{g} \mathrm{mL}^{-1}\right.$ for $\left.24 \mathrm{~h}\right]$

GO [1-100 $\mu \mathrm{g} \mathrm{mL}^{-1}$ for $\left.24 \mathrm{~h}\right]$

RAW-264.7; Saos-2; 3T3

Mouse embryonic fibroblast (MEF)

Red blood cells; human skin fibroblasts

MEF

Human fibroblast cell

Red blood cells

A549

Peritoneal macrophage; J774A.1; LLC; MCF-7; HepG2; human umbilical vein endothelial cells (HUVEC)

RAW264.7

J774A.1; RAW 264.7

Human monocyte-derived

\section{Effects}

Refs. macrophages; peritoneal macrophages
Elevated transcription and secretion of cytokines and chemokines, which is triggered by activation of the $\mathrm{NF}-\kappa \mathrm{B}$ signaling pathway

Induction of cytotoxicity through the depletion of the mitochondrial membrane potential and the increase in intracellular reactive oxygen species, then trigger apoptosis by activation of the mitochondrial pathway

High intracellular uptake of functionalized, hydrophilic graphene compared to the hydrophobic pristine graphene

GBNs enter cells through spontaneous membrane penetration at edge asperities and corner sites

The cellular responses are strongly dependent on either cell type or hard corona composition

Induction of inflammatory response, apoptosis and autophagy in macrophages via p38 MAPK and $\mathrm{NF}-\kappa \mathrm{B}$ signaling pathways

Increased rate of mitochondrial respiration and the generation of reactive oxygen species, activating inflammatory and apoptotic pathways

Inhibits the migration and invasion of various cancer cells by inhibiting the activities of ETC complexes

Cytotoxicity in HepG2 cells with plasma membrane damage and induction of oxidative stress

NADPH oxidase-dependent ROS formation; deregulation of antioxidant/DNA repair/apoptosisrelated genes

Alters the miRNA expression profile

Caused cytotoxicity in HepG2 cells with plasma membrane damage and induction of oxidative stress

Impact on cytoskeleton; alterations in cell cycle

Without induction of noticeable harmful effects

All the GO and GS show dose-dependent hemolytic activity on RBCs

[251]

Higher degree of cytotoxicity and apoptosis.

Dose- and time-dependent cytotoxicity, decreasing cell adhesion, inducing cell floating and apoptosis

Strong hemolytic activity

Cytotoxicity of GO is largely attenuated due to the extremely high protein adsorption ability of GO

Microsized GO induced much stronger inflammation responses, while nanosized graphene sheet showed better biocompatibility

Provoked the Toll-like receptor (TLR) signaling cascades and triggered ensuing cytokine responses

Activation of TLR4 signaling leads to GO-mediated macrophagic necrosis

Significant impact on cellular viability, ROS generation and cellular activation 
Table 5 continued

\begin{tabular}{|c|c|c|c|}
\hline GBNs [Exposure conditions] & Cell types & Effects & Refs. \\
\hline $\begin{array}{l}\text { GO, PVP-GO [25-100 } \mu \mathrm{g} \mathrm{mL}^{-1} \text { for } \\
\quad 48 \mathrm{~h}]\end{array}$ & Dendritic cells & $\begin{array}{l}\text { PVP-modified GO has a low immunogenicity than } \\
\text { unadorned GO }\end{array}$ & [272] \\
\hline $\begin{array}{l}\mathrm{GO}, \mathrm{TiO}_{2} \text {-GO [100 and } 300 \mu \mathrm{g} \mathrm{mL}^{-1} \\
\quad \text { for } 4 \mathrm{~h}]\end{array}$ & A549 & $\begin{array}{l}\mathrm{GO} \text { enters A549 cells and locates in the cytoplasm } \\
\text { and nucleus without causing any cell damage. The } \\
\mathrm{TiO}_{2}-\mathrm{GO} \text { composite separated into } \mathrm{GO} \text { and } \mathrm{TiO}_{2} \\
\text { after } \mathrm{TiO}_{2}-\mathrm{GO} \text { composite entered } \mathrm{A} 549 \text { cells }\end{array}$ & [273] \\
\hline $\mathrm{GO}, \mathrm{sGO}\left[12.5 \mu \mathrm{g} \mathrm{mL}^{-1}\right.$ for $\left.48 \mathrm{~h}\right]$ & PC-12 & $\begin{array}{l}\text { Inhibit } A \beta \text { peptide monomer fibrillation and clear } \\
\text { mature amyloid fibrils }\end{array}$ & [274] \\
\hline GO flake $\left[10 \mu \mathrm{g} \mathrm{mL}^{-1}\right]$ & Mesenchymal stem cells (MSC) & $\begin{array}{l}\text { GO flakes effectively prevent a series of adverse cell } \\
\text { signaling cascades that result in the anoikis of } \\
\text { MSCs in response to ROS }\end{array}$ & [275] \\
\hline $\begin{array}{l}\text { GO }\left[37.5 \mu \mathrm{g} \mathrm{mL}^{-1} \text { FITC-PEG-GOs }\right. \\
\quad \text { for } 2 \mathrm{~h}]\end{array}$ & Saos-2; HepG2; RAW-264.7 & $\begin{array}{l}\text { Processes such as micropinocytosis, microtubule- } \\
\text { dependent mechanisms, clathrin-dependent } \\
\text { mechanisms and phagocytosis are involved }\end{array}$ & [276] \\
\hline $\begin{array}{l}\mathrm{GO}\left[20-50 \mu \mathrm{g} \mathrm{mL}^{-1} \text { for } 30 \mathrm{~min}-\right. \\
\quad 14 \mathrm{~h}]\end{array}$ & $\mathrm{C} 2 \mathrm{C} 12$ & $\begin{array}{l}\text { Cells enter through clathrin-mediated endocytosis, } \\
\text { and the increase in graphene size enhances } \\
\text { phagocytotic uptake of the nanosheets }\end{array}$ & [277] \\
\hline $\mathrm{GO}\left[40\right.$ or $80 \mu \mathrm{g} \mathrm{mL}^{-1}$ for $\left.24 \mathrm{~h}\right]$ & $\begin{array}{l}\text { MDA-MB-231; MDA-MB-436; SK- } \\
\text { BR-3 }\end{array}$ & $\begin{array}{l}\text { PEG-GO inhibited the migratory and invasive } \\
\text { properties of human metastatic breast cancer cell } \\
\text { lines by inhibiting ATP synthesis, leading to a } \\
\text { disruption of F-actin cytoskeletal assembly }\end{array}$ & [278] \\
\hline NGO [N/A] & НCТ-116 & No apparent toxicity as drug carrier & [279] \\
\hline NGO [N/A] & $\mathrm{HeLa}$ & No apparent toxicity as drug carrier & [280] \\
\hline $\begin{array}{l}\text { Oxidized graphene nanoribbons (O- } \\
\text { GNR) [10-400 } \mathrm{g} \mathrm{mL}^{-1} \text { for } \\
12-48 \mathrm{~h}]\end{array}$ & HeLa; NIH-3T3; SKBR3; MCF-7 & $\begin{array}{l}\text { Dose-dependent and time-dependent cytotoxic } \\
\text { effects on the four cell lines }\end{array}$ & [281] \\
\hline O-GNR [50 $\mu \mathrm{g} \mathrm{mL}^{-1}$ for $\left.30 \mathrm{~min}\right]$ & MCF-7; A549; MRC5 & $\begin{array}{l}\text { Significant O-GNR-PEG-DSPE uptake into cells } \\
\text { with high EGFR expression }\end{array}$ & [282] \\
\hline $\mathrm{O}-\mathrm{GNR}$ [N/A] & U251; CG-4; MCF-7 & No apparent toxicity as drug carrier & {$[50]$} \\
\hline O-GNR $\left[0-100 \mu \mathrm{g} \mathrm{mL}^{-1}\right.$ for $\left.24 \mathrm{~h}\right]$ & A549 & $\begin{array}{l}\text { GONRs with concentrations } \leq 50 \mu \mathrm{g} / \mathrm{mL} \text { showed no } \\
\text { significant cytotoxicity; GONRs with a } \\
\text { concentration of } 100 \mu \mathrm{g} / \mathrm{mL} \text { exhibited significant } \\
\text { cytotoxicity and resulted in a decrease in cell } \\
\text { growth and induction of cell apoptosis }\end{array}$ & [283] \\
\hline $\begin{array}{l}\text { O-GNR, GNO and GONP } \\
{\left[0-300 \mu \mathrm{g} \mathrm{m}^{-1} 24-72 \mathrm{~h}\right]}\end{array}$ & MSC & $\begin{array}{l}\text { GNOs, GONRs and GONPs at concentrations of less } \\
\text { than } 50 \mu \mathrm{g} / \mathrm{mL} \text { for } 24 \text { or } 72 \mathrm{~h} \text { could be considered } \\
\text { potentially safe incubation conditions for ex vivo } \\
\text { labeling for MSCs }\end{array}$ & [284] \\
\hline GO; RGO [200 $\left.\mu \mathrm{g} \mathrm{mL}^{-1} 24 \mathrm{~h}\right]$ & A549 & $\begin{array}{l}\text { Protein-coated graphene resulted in a markedly less } \\
\text { cytotoxicity than uncoated graphene }\end{array}$ & [285] \\
\hline $\mathrm{GO}, \mathrm{RGO}\left[10 \mu \mathrm{g} \mathrm{mL}^{-1}\right]$ & HUVEC & $\begin{array}{l}\text { Significant increase in both intercellular ROS levels } \\
\text { and mRNA levels of HO1 and TrxR. Moreover, a } \\
\text { significant amount of DNA damage is observed in } \\
\text { GO-treated cells, but not in RGO-treated cells }\end{array}$ & [286] \\
\hline $\begin{array}{l}\mathrm{GO}, \mathrm{RGO}\left[0.0125-12.5 \mu \mathrm{g} \mathrm{cm}^{-2} \text { for }\right. \\
5 \text { days }]\end{array}$ & A549; RAW 264.7 & $\begin{array}{l}\text { Lower concentrations of GO/RGO did not lead to an } \\
\text { increase in ROS production. Cellular } \\
\text { internalization of GO was observed in } \\
\text { phago(endo)somes without signs of any } \\
\text { intracellular damage. }\end{array}$ & [287] \\
\hline $\begin{array}{l}\text { RGO/HARGO (hyaluronic acid GO) } \\
\quad\left[20 \mu \mathrm{g} \mathrm{mL}^{-1} \text { for } 24 \mathrm{~h}\right]\end{array}$ & $\mathrm{KB}$ & $\begin{array}{l}\text { No significant cell death observed in the absence of } \\
\text { NIR irradiation }\end{array}$ & [288] \\
\hline RGO [N/A] & Ramos; CCRF-CEM & No apparent toxicity as drug carrier & [289] \\
\hline RGO [1-200 $\mathrm{mg} \mathrm{L}^{-1}$ for $\left.24 \mathrm{~h}\right]$ & HepG2 & $\begin{array}{l}\text { Hydrophobic RGO was found to mostly adsorbed at } \\
\text { cell surface without internalization, ROS } \\
\text { generation by physical interaction, poor gene } \\
\text { regulation }\end{array}$ & [260] \\
\hline
\end{tabular}


Table 5 continued

\begin{tabular}{|c|c|c|c|}
\hline GBNs [Exposure conditions] & Cell types & Effects & Refs. \\
\hline RGO [1-100 $\left.\mu \mathrm{g} \mathrm{mL}^{-1} 24 \mathrm{~h}\right]$ & Human blood cells; HUVEC & $\begin{array}{l}\text { The biocompatible biopolymer-functionalized RGO } \\
\text { exhibited excellent biocompatibility }\end{array}$ & [290] \\
\hline $\begin{array}{l}\text { RGO, GONP, RGONP } \\
\quad\left[0.01-100 \mu \mathrm{g} \mathrm{mL}^{-1} \text { for } 24 \mathrm{~h}\right]\end{array}$ & MSC & $\begin{array}{l}\text { The RGONPs exhibited a strong potential in } \\
\text { destruction of the cells with the threshold } \\
\text { concentration of } 1.0 \mathrm{mg} / \mathrm{mL} \text {, while the } \\
\text { cytotoxicity of the RGO sheets appeared at high } \\
\text { concentration of } 100 \mathrm{mg} / \mathrm{mL} \text { after } 1 \mathrm{~h}\end{array}$ & [291] \\
\hline $\begin{array}{l}\text { GO, RGO }\left[1-10 \mu \mathrm{g} \mathrm{mL}^{-1} \text { for } 24 \text { or }\right. \\
\quad 48 \mathrm{~h}]\end{array}$ & HUVEC & $\begin{array}{l}\text { GO exhibits higher toxicity than RGO due to ROS } \\
\text { generation. Small flake size graphene exhibits } \\
\text { greater cytotoxicity compared to larger sheets due } \\
\text { to intracellular accumulation of graphene }\end{array}$ & [286] \\
\hline GO, RGO $\left[0-20 \mu \mathrm{g} \mathrm{mL}^{-1}\right]$ & Human platelets & $\begin{array}{l}\text { GO can evoke strong aggregatory response in } \\
\text { platelets comparable to that elicited by thrombin }\end{array}$ & [292] \\
\hline $\begin{array}{l}\mathrm{GO}, \mathrm{RGO}, \mathrm{G}-\mathrm{NH}_{2}\left[2-10 \mu \mathrm{g} \mathrm{mL}^{-1} \text { for }\right. \\
3 \mathrm{~h}]\end{array}$ & Red blood cells & G-NH $\mathrm{N}_{2}$ is not endowed with thrombotoxic property & [293] \\
\hline $\mathrm{GO}, \mathrm{RGO}\left[100 \mu \mathrm{g} \mathrm{mL}^{-1}\right]$ & U87 U118 & $\begin{array}{l}\text { Reduction in cell viability and proliferation and } \\
\text { induced apoptosis }\end{array}$ & [294] \\
\hline $\operatorname{RGO}\left[50 \mu \mathrm{g} \mathrm{mL}^{-1}\right]$ & U87 & $\begin{array}{l}\text { Reduction in GBM tumor volume was observed. } \\
\text { RGO + Arg shows antiangiogenic and } \\
\text { proapoptotic characteristics }\end{array}$ & [295] \\
\hline
\end{tabular}

The numbers in the parentheses are respective references

evaluated the impact of GBNs in environment. Ahmed et al. investigated the acute effects of GO on waste water microbial community [158]. They concluded that GO was toxic to microbial communities in concentrations between 50 and $300 \mathrm{mg} \mathrm{L}^{-1}$. The quality of the effluent was deteriorated by increasing the turbidity of water and the reduction in sludge dewaterability. They also confirmed the reactive oxygen species generation is responsible for the toxicity of GO on microbial communities. Deng et al. studied the characterization factors such as toxic effect factor, fate factor and exposure factor of GO in the environment to study the life cycle impact assessment of GObased nanomaterials [159]. More research has to be conducted as there are very few studies on the environmental risks of GBNs and their strict enforcement on the release of GBNs to mitigate the toxic effects of GBNs. Lee et al. reported their findings on common scenarios (exfoliation, CVD growth and transfer) and the good practices that reduce graphene or GBNs exposure at facilities manufacturing facilities [68]. In addition to toxicity studies, GBNs especially three-dimensional (3D) porous carbon-based materials such as GO and GO-based networks have proven to have potential environmental applications. GBNs were explored for removing organic pollutants to advance in water remediation. Rethinsabapathy et al. summarized 3D GBNs materials used for the adsorption of dyes, heavy metals and radioactive materials from polluted environments [160].

\section{Conclusions and Perspectives}

It is evident that GBNs, because of their unique properties and functionalization, raise a great interest and provide more avenues for the research and development in their applications of translational medicine. The biomedical applications related to the unique physiochemical properties of GBNs focus on their thermal, mechanical and electrochemical features. Many reports have paid attention to GBNs as therapeutics in cancer therapy along with PTT and PDT, gene/drug delivery and as antibacterial agents. The intrinsic optical properties of GBN-based hybrids in the visible and NIR range along with their small size effects, low toxicity and low production costs make the hybrids attractive for bioimaging in clinical diagnostics and photo-thermal cancer therapy. This targeted therapy aids in their high therapeutic effects and fewer side effects. Among GBNs, GO and RGO are considered as the most potent antibacterial agents which can be used in nanohybrids to synthesize novel antibacterial agents. The use of GBNs in bioimaging and biosensing fields is an emerging biomedical application. As the GBNs are used in various fields for biomedical purposes the safety and efficacy of GBNs in clinical trials such as diagnostics and therapeutics require standardized parameters; mainly, biocompatibility, solubility and selectivity are the predominant factors that will further the biomedical applications of GBNs. More studies in computational simulations of GBNs need to be explored for the efficacy of GBNs in clinical trials. 
Table 6 GBNs toxicity effects in various animal models (Data adapted from [16, 296, 297, 298])

\begin{tabular}{lll}
\hline GBNs and exposure conditions Animal model Effects & Refs. \\
\hline
\end{tabular}

Nanoscale graphene oxide (NGO) $[0,1,5$, $10 \mathrm{mg} \mathrm{kg}^{-1}$, intratracheal instillation $0 \mathrm{~h}, 24 \mathrm{~h}$, $48 \mathrm{~h}, 72 \mathrm{~h}$ and 1 week]

Few-layer graphene (FLG) [0.1, or $1 \mathrm{mg} \mathrm{mL}^{-1}$, oral gavage or intratracheal instillation 3 or 28 days]

Graphene platelets (GPs) [inhalation exposure, 1 day-6 weeks]

Graphene nanoplatelets (GPs) [50 $\mu \mathrm{g}$ per mouse, pharyngeal aspiration or intrapleural installation, 24 h-7 days]

GO [0.5 or $4 \mathrm{mg} \mathrm{m}^{-3}$, inhalation exposure, single $6 \mathrm{~h}]$

GO $\left[1.0 \mathrm{mg} \mathrm{kg}^{-1}\right.$, intravenously injected, $\left.24 \mathrm{~h}\right]$

GO [24 $\mathrm{mg} \mathrm{kg}^{-1}$, tail vein injected, 5 days]

GO $\left[1,10 \mathrm{mg} \mathrm{kg}^{-1}\right.$, intravenous injection 14 days]

NGO-PEG [5 $\mathrm{mg} \mathrm{kg}^{-1}$, tail intravenous injection $10 \mathrm{~min}-24 \mathrm{~h}]$

GO, GO-PEG, RGO-PEG, nRGO-PEG

[4 $\mathrm{mg} \mathrm{kg}^{-1}$, intraperitoneal injection 1, 7 and 30 days]

GO, graphene quantum dots (GQD) [20 mg kg-1 intravenous injection or intraperitoneal injection 14 days]

Purified graphene oxide (pGO) [50 $\mu \mathrm{g} / \mathrm{animal}$, intraperitoneal injection $24 \mathrm{~h}, 7$ days]

GO [series concentrations, subcutaneous injection 21 days]

GO [2 or $20 \mathrm{mg} \mathrm{kg}^{-1}$, subcutaneous and intraperitoneal injection]

RGO-iron oxide nanoparticles (RGO-IONP)

[400 $\mu \mathrm{g}$, subcutaneous injection]

GO, GO-PEG [100 $\mathrm{mg} \mathrm{kg}^{-1}$, oral administration; $50 \mathrm{mg} \mathrm{kg}^{-1}$, intraperitoneal injection, 1,7 and 30 days]

RGO [60 $\mathrm{mg} \mathrm{kg}^{-1}$, oral gavage, 5 days]

GO $\left[0.76 \pm 0.16-9.78 \pm 0.29 \mathrm{mg} \mathrm{m}^{-3,6} \mathrm{~h} /\right.$ day for 5 days]

Graphene $\left[0.12-1.88 \mathrm{mg} \mathrm{m}^{-3}, 6 \mathrm{~h} /\right.$ day and 5 days a Male Spragueweek].

Dawley rats

Graphene $\left[0.68 \pm 0.14-3.86 \pm \mathrm{mg} \mathrm{m}^{-3}, 6 \mathrm{~h} /\right.$ day and 5 days a week]

ICR mice

Mice

Female C57BL/6 strain mice

SpragueDawley rats

Male ICR mice

Male and female ICRstrain mice

Male Kunming mice

Balb/c mice

Balb/c mice 6 mice

C57BL/6 male mice

C57BL/6 J mice

Female Balb/c mice

Female Balb/c mice

Male C57black/6 mice Dawley rats
C57BL/6 mice Acute lung injury (ALI) and chronic pulmonary fibrosis

Intratracheally instilled FLG acute lung injury and pulmonary edema, FLG did not show detectable absorption through the gastrointestinal tract by oral gavage

GP caused acute inflammation in lung at 1 day and alleviated inflammation in lung after 6 weeks

Large GPs were inflammogenic in both the lung and the pleural space

The single inhalation exposure to GO induces minimal toxic responses in rat lungs

Accumulated mainly in the liver and lungs

Did not affect pup numbers, sex ratio, weights, pup survival rates or pup growth, low toxicity for male reproduction

Kunming mice Led to high accumulation, long-time retention, pulmonary edema and granuloma formation

NGO-PEG alleviated acute tissue injuries and decreased the early weight loss

Accumulated in the reticuloendothelial system (RES) including liver and spleen over a long time

GO appeared toxic and caused death GQD revealed no accumulation in organs and caused low cytotoxicity

Female C57B1/ Induced moderate inflammation and granuloma formation following

The microsize of GO induced much stronger inflammation responses than the nanosized GO

Both GO and a reduction in GO result in immune cell infiltration, uptake and clearance

RGO-IONP can effectively inactivate multiple-drug-resistant bacteria in subcutaneous abscesses

No obvious tissue uptake via oral administration, indicating the rather limited intestinal adsorption of those nanomaterials

RGO affected general locomotor activity, balance and neuromuscular coordination, but showed little change in exploratory, anxiety-like or learning and memory behaviors

Male Sprague- No significant systemic effects of toxicological importance were observed. Only minimal or unnoticeable GO toxicity in the lungs and other organs

No dose-dependent effects and no distinct lung pathology were observed. This study suggested low toxicity, and a NOAEL of no less than $1.88 \mathrm{mg} / \mathrm{m}^{3}$ was recorded for the body weights, bronchoalveolar lavage fluid inflammatory markers and blood biochemical parameters

Male Sprague- Minimal toxic effect at the concentrations and time points in this Dawley rats study 


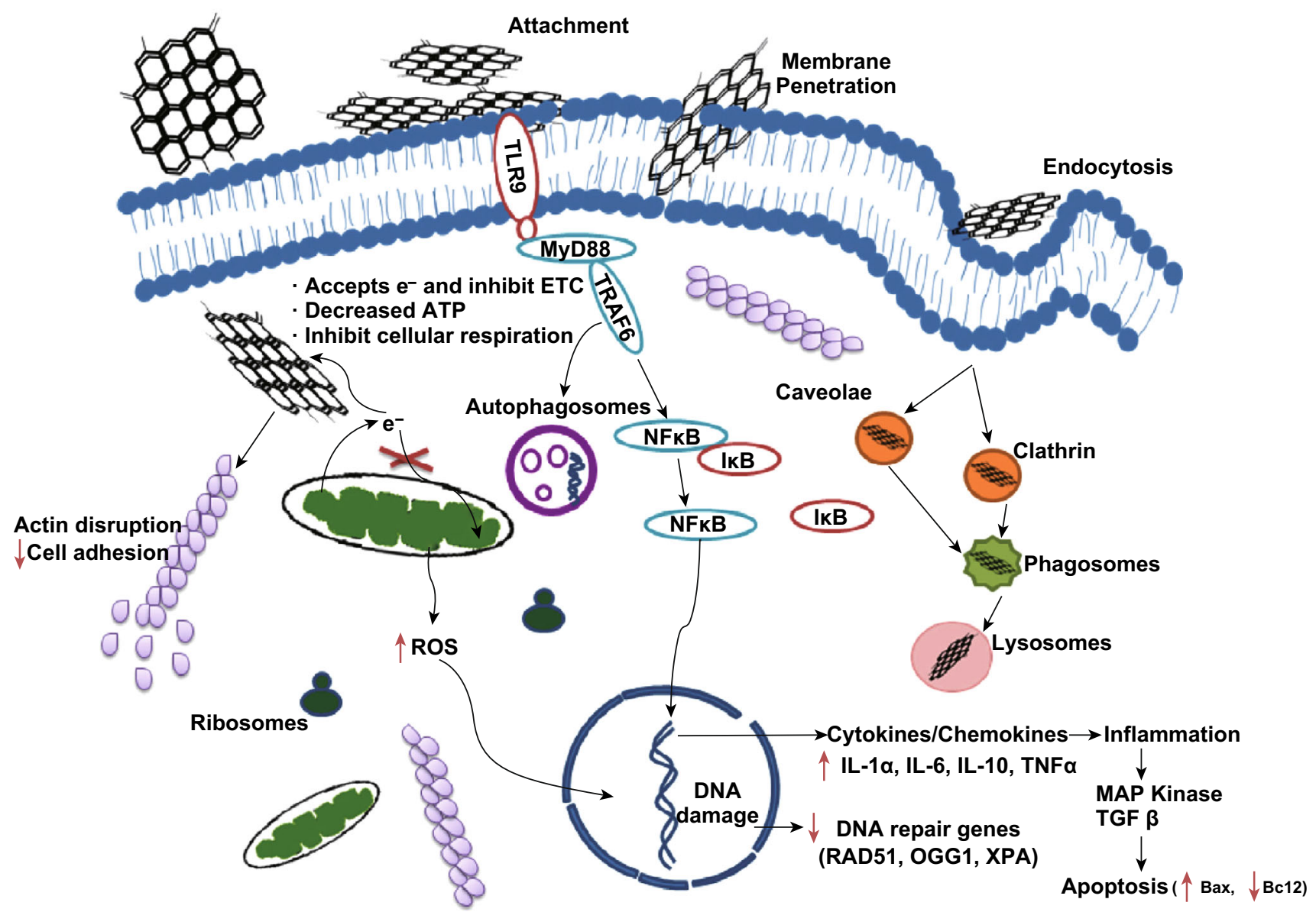

Fig. 7 Mechanisms of toxicity of GBNs [151]. Copyright (c) 2016 Elsevier B.V

The applications of GBNs have expanded quickly into various fields, but still, there is a lack of systematic understanding of biological interactions of GBNs. The experimental data on the toxicity are limited more to in vitro rather than to in vivo. In addition, there should be more knowledge of the long-term toxicity effects of GBNs to further enhance their applications in the biomedical field to assure the human safety. The existing literature does not provide detailed information on the various synthesis procedures and characterization techniques before proceeding to the toxicological assays. More emphasis should be given on the comprehensive understanding of GBNs-based products on adsorption, dispersion and toxicity, and transformation is recommended. Currently, most of the GBNs are focused on lungs and liver. Studies on other organs including brain/central nervous system are very limited or remain unexplored. Moreover, the GBNs due to excellent physicochemical properties can specifically disrupt the neuroendocrine/reproductive organs. To our knowledge, the reports on GBNs as endocrine disruptor are very limited. Additional studies in these areas are also necessary. Furthermore, GBNs can interact with DNA and thus affect the genetics of human populations. Therefore, studies are needed to elucidate transgenerational effects or effects of GBNs on the epigenome. Reina et al. emphasized the guidelines and the development and evaluation of biocompatibility of GBNs [29]. These guidelines include thorough characterization and regulatory standardization of GBNs, standardized data formats to identify the relationships between structure and properties and finally standard references of known activities of biological tests. Also, more research is required to optimize the synthesis with proper characterization methods to the GBNs with unique properties. The majority of research is on the toxicity at the cellular level rather than the interaction of GBNs at the genetic level. Since other GBNs such as 3D porous graphene materials have attracted great attention for environmental applications in the removal of pollutants of organic, inorganic and radionuclides [160], further studies are needed to evaluate their fate and transport as well as their ecological risks in various environmental compartments. Such research would provide a scientific basis to manage their uses and control/prevent their toxic effects. 


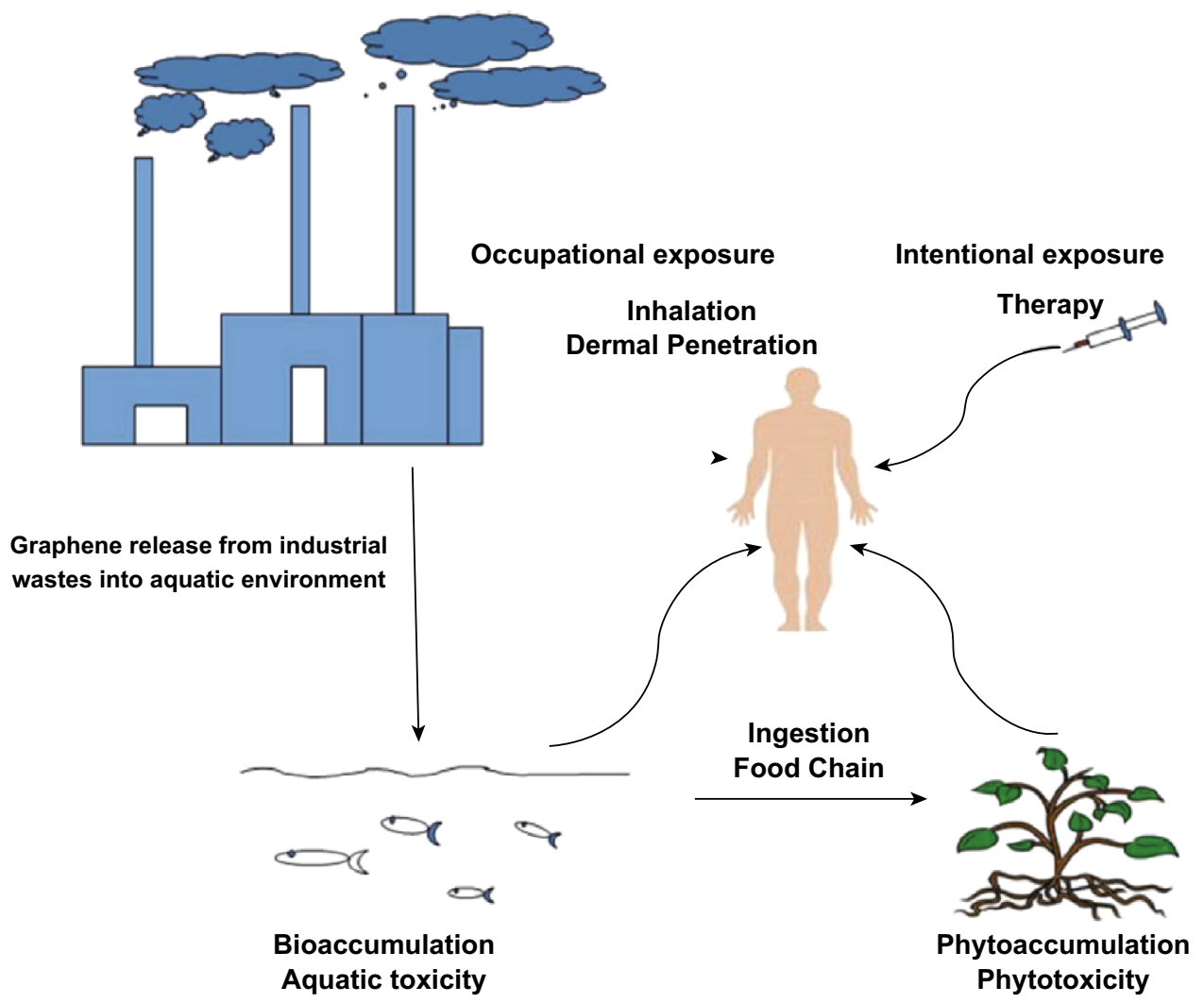

Fig. 8 Human exposure to graphene from the environment: Humans are exposed to nanomaterials either intentionally in the form of therapy or unintentionally via various factors especially during the manufacturing process in industries. Graphene can enter ecosystem mainly through waste disposal from industries or pharmaceuticals, posing a threat to aquatic organisms. Stable graphene that exists in soil or water can enter the human body through food chain [151]. Copyright (C) 2016 Elsevier B.V

Acknowledgements This research was financially supported by National Institutes of Heath NIMHD Grant \# G12MD007581 through the RCMI Center for Environmental Health and by National Science Foundation Grant \# HRD-1547754 through the CREST Center for Nanotoxicity Studies at Jackson State University.

Open Access This article is distributed under the terms of the Creative Commons Attribution 4.0 International License (http://crea tivecommons.org/licenses/by/4.0/), which permits unrestricted use, distribution, and reproduction in any medium, provided you give appropriate credit to the original author(s) and the source, provide a link to the Creative Commons license, and indicate if changes were made.

\section{References}

1. D.R. Dreyer, R.S. Ruoff, C.W. Bielawski, From conception to realization: an historical account of graphene and some perspectives for its future. Angew. Chem. Int. Edit. 49(49), 9336-9344 (2010). https://doi.org/10.1002/anie.201003024

2. G. Eda, M. Chhowalla, Graphene-based composite thin films for electronics. Nano Lett. 9(2), 814-818 (2009). https://doi.org/10. $1021 / \mathrm{n} 18035367$

3. C. Cha, S.R. Shin, N. Annabi, M.R. Dokmeci, A. Khademhosseini, Carbon-based nanomaterials: multifunctional materials for biomedical engineering. ACS Nano 7(4), 2891-2897 (2013). https://doi.org/10.1021/nn401196a
4. O.C. Compton, S.T. Nguyen, Graphene oxide, highly reduced graphene oxide, and graphene: versatile building blocks for carbon-based materials. Small 6(6), 711-723 (2010). https://doi. org/10.1002/smll.200901934

5. J. Wang, Carbon-nanotube based electrochemical biosensors: a review. Electroanalysis 17(1), 7-14 (2005). https://doi.org/10. 1002/elan.200403113

6. M.S. Dresselhaus, P. Avouris, Introduction to carbon materials research. Top. Appl. Phys. 80, 1-9 (2001). https://doi.org/10. 1007/3-540-39947-X_1

7. F.M.P. Tonelli, V.A.M. Goulart, K.N. Gomes, M.S. Ladeira, A.K. Santos, E. Lorençon, L.O. Ladeira, R.R. Resende, Graphene-based nanomaterials: biological and medical applications and toxicity. Nanomedicine 10(15), 2423-2450 (2015). https:// doi.org/10.2217/nnm.15.65

8. J.M. Yoo, J.H. Kang, B.H. Hong, Graphene-based nanomaterials for versatile imaging studies. Chem. Soc. Rev. 44(14), 4835-4852 (2015). https://doi.org/10.1039/c5cs00072f

9. Y. Zhu, S. Murali, W. Cai, X. Li, J.W. Suk, J.R. Potts, R.S. Ruoff, Graphene and graphene oxide: synthesis, properties, and applications. Adv. Mater. 22(35), 3906-3924 (2010). https://doi. org/10.1002/adma.201001068

10. G. Bottari, M.Á. Herranz, L. Wibmer, M. Volland, L. Rodríguez-Pérez et al., Chemical functionalization and characterization of graphene-based materials. Chem. Soc. Rev. 46(15), 4464-4500 (2017). https://doi.org/10.1039/c7cs00229g

11. T.-H. Kim, T. Lee, W. El-Said, J.-W. Choi, Graphene-based materials for stem cell applications. Materials 8(12), 8674-8690 (2015). https://doi.org/10.3390/ma8125481 
12. H. Ren, M. Tang, B. Guan, K. Wang, J. Yang et al., Hierarchical graphene foam for efficient omnidirectional solar-thermal energy conversion. Adv. Mater. 29(38), 1702590 (2017). https:// doi.org/10.1002/adma.201702590

13. F. Liu, C.W. Lee, J.S. Im, Graphene-based carbon materials for electrochemical energy storage. J. Nanomater. 2013, 642915 (2013). https://doi.org/10.1155/2013/642915

14. G. Gonçalves, P. Marques, M. Vila, Graphene-Based Materials in Health and Environment. Carbon Nanostructures (Springer, Switzerland, 2016). https://doi.org/10.1007/978-3-319-45639-3

15. S.S. Nanda, G.C. Papaefthymiou, D.K. Yi, Functionalization of graphene oxide and its biomedical applications. Crit. Rev. Solid State Mater. Sci. 40(5), 291-315 (2015). https://doi.org/10.1080/ 10408436.2014.1002604

16. L. Ou, B. Song, H. Liang, J. Liu, X. Feng, B. Deng, T. Sun, L. Shao, Toxicity of graphene-family nanoparticles: a general review of the origins and mechanisms. Part. Fibre Toxicol. 13(1), 57 (2016). https://doi.org/10.1186/s12989-016-0168-y

17. K.V. Krishna, C. Ménard-Moyon, S. Verma, A. Bianco, Graphene-based nanomaterials for nanobiotechnology and biomedical applications. Nanomedicine 8(10), 1669-1688 (2013). https://doi.org/10.2217/nnm.13.140

18. C. Chung, Y.-K. Kim, D. Shin, S.-R. Ryoo, B.H. Hong, D.-H. Min, Biomedical applications of graphene and graphene oxide. Acc. Chem. Res. 46(10), 2211-2224 (2013). https://doi.org/10. 1021/ar300159f

19. Z.S. Singh, Applications and toxicity of graphene family nanomaterials and their composites. Nanotechnol. Sci. Appl. 2016(9), 15-28 (2016). https://doi.org/10.2147/nsa.s101818

20. D.R. Dreyer, S. Park, C.W. Bielawski, R.S. Ruoff, The chemistry of graphene oxide. Chem. Soc. Rev. 39(1), 228-240 (2010). https://doi.org/10.1039/b917103g

21. P.R. Wallace, The band theory of graphite. Phys. Rev. 72(3), 258 (1947). https://doi.org/10.1103/PhysRev.72.258

22. K.S. Novoselov, Electric field effect in atomically thin carbon films. Science 306(5696), 666-669 (2004). https://doi.org/10. 1126/science. 1102896

23. K. Muthoosamy, S. Manickam, State of the art and recent advances in the ultrasound-assisted synthesis, exfoliation and functionalization of graphene derivatives. Ultrason. Sonochem. 39(2017), 478-493 (2017). https://doi.org/10.1016/j.ultsonch. 2017.05.019

24. G. Shim, M.-G. Kim, J.Y. Park, Y.-K. Oh, Graphene-based nanosheets for delivery of chemotherapeutics and biological drugs. Adv. Drug Deliver. Rev. 105, 205-227 (2016). https:// doi.org/10.1016/j.addr.2016.04.004

25. S. Pei, H.-M. Cheng, The reduction of graphene oxide. Carbon 50(9), 3210-3228 (2012). https://doi.org/10.1016/j.carbon.2011. 11.010

26. H.C. Schniepp, J.L. Li, M.J. McAllister, H. Sai, M. HerreraAlonso et al., Functionalized single graphene sheets derived from splitting graphite oxide. J. Phys. Chem. B 110(17), 8535-8539 (2006). https://doi.org/10.1021/jp060936f

27. T. Kuila, S. Bose, A.K. Mishra, P. Khanra, N.H. Kim, J.H. Lee, Chemical functionalization of graphene and its applications. Prog. Mater Sci. 57(7), 1061-1105 (2012). https://doi.org/10. 1016/j.pmatsci.2012.03.002

28. V. Georgakilas, J.N. Tiwari, K.C. Kemp, J.A. Perman, A.B. Bourlinos, K.S. Kim, R. Zboril, Noncovalent functionalization of graphene and graphene oxide for energy materials, biosensing, catalytic, and biomedical applications. Chem. Rev. 116(9), 5464-5519 (2016). https://doi.org/10.1021/acs.chemrev.5b00620

29. G. Reina, J.M. González-Domínguez, A. Criado, E. Vázquez, A. Bianco, M. Prato, Promises, facts and challenges for graphene in biomedical applications. Chem. Soc. Rev. 46(15), 4400-4416 (2017). https://doi.org/10.1039/c7cs00363c
30. A. Jana, E. Scheer, S. Polarz, Synthesis of graphene-transition metal oxide hybrid nanoparticles and their application in various fields. Beilstein J. Nanotechnol. 8, 688-714 (2017). https://doi. org/10.3762/bjnano.8.74

31. K.E. Whitener, P.E. Sheehan, Graphene synthesis. Diam. Relat. Mater. 46, 25-34 (2014). https://doi.org/10.1016/j.diamond. 2014.04.006

32. J. Xu, Y. Wang, S. Hu, Nanocomposites of graphene and graphene oxides: synthesis, molecular functionalization and application in electrochemical sensors and biosensors. A review. Microchim. Acta 184(1), 1-44 (2016). https://doi.org/10.1007/ s00604-016-2007-0

33. J. Lin, X. Chen, P. Huang, Graphene-based nanomaterials for bioimaging. Adv. Drug Deliver. Rev. 105, 242-254 (2016). https://doi.org/10.1016/j.addr.2016.05.013

34. P. Huang, S. Wang, X. Wang, G. Shen, J. Lin et al., Surface functionalization of chemically reduced graphene oxide for targeted photodynamic therapy. J. Biomed. Nanotechnol. 11(1), 117-125 (2015). https://doi.org/10.1166/jbn.2015.2055

35. X. Huang, F. Boey, H.U.A. Zhang, A brief review on graphenenanoparticle composites. Cosmos 06(02), 159-166 (2010). https://doi.org/10.1142/s0219607710000607

36. M. Agharkar, S. Kochrekar, S. Hidouri, M.A. Azeez, Trends in green reduction of graphene oxides, issues and challenges: a review. Mater. Res. Bull. 59, 323-328 (2014). https://doi.org/10. 1016/j.materresbull.2014.07.051

37. S. Thakur, N. Karak, Alternative methods and nature-based reagents for the reduction of graphene oxide: a review. Carbon 94, 224-242 (2015). https://doi.org/10.1016/j.carbon.2015.06.030

38. H. Zhang, G. Grüner, Y. Zhao, Recent advancements of graphene in biomedicine. J. Mater. Chem. B 2013(1), 2542-2567 (2013). https://doi.org/10.1039/c3tb20405g

39. T.-H. Han, H. Kim, S.-J. Kwon, T.-W. Lee, Graphene-based flexible electronic devices. Mater. Sci. Eng., R 118, 1-43 (2017). https://doi.org/10.1016/j.mser.2017.05.001

40. H. Jang, Y.J. Park, X. Chen, T. Das, M.-S. Kim, J.-H. Ahn, Graphene-based flexible and stretchable electronics. Adv. Mater. 28(22), 4184-4202 (2016). https://doi.org/10.1002/adma. 201504245

41. K. Yang, L. Feng, H. Hong, W. Cai, Z. Liu, Preparation and functionalization of graphene nanocomposites for biomedical applications. Nat. Protoc. 8(12), 2392-2403 (2013). https://doi. org/10.1038/nprot.2013.146

42. J. Liu, L. Cui, D. Losic, Graphene and graphene oxide as new nanocarriers for drug delivery applications. Acta Biomater. 9(12), 9243-9257 (2013). https://doi.org/10.1016/j.actbio.2013. 08.016

43. D.W. Boukhvalov, M.I. Katsnelson, Modeling of graphite oxide. J. Am. Chem. Soc. 130(32), 10697-10701 (2008). https://doi. org/10.1021/ja8021686

44. S.-E. Zhu, M. Krishna Ghatkesar, C. Zhang, G.C.A.M. Janssen, Graphene based piezoresistive pressure sensor. Appl. Phys. Lett. 102(16), 161904 (2013). https://doi.org/10.1063/1.4802799

45. Y. Yang, A.M. Asiri, Z. Tang, D. Du, Y. Lin, Graphene based materials for biomedical applications. Mater. Today 16(10), 365-373 (2013). https://doi.org/10.1016/j.mattod.2013.09.004

46. M. Nurunnabi, K. Parvez, M. Nafiujjaman, V. Revuri, H.A. Khan, X. Feng, Y.-K. Lee, Bioapplication of graphene oxide derivatives: drug/gene delivery, imaging, polymeric modification, toxicology, therapeutics and challenges. RSC Adv. 5(52), 42141-42161 (2015). https://doi.org/10.1039/c5ra04756k

47. K. Yang, L. Feng, X. Shi, Z. Liu, Nano-graphene in biomedicine: theranostic applications. Chem. Soc. Rev. 42(2), 530-547 (2013). https://doi.org/10.1039/c2cs35342c

48. K. Yang, H. Gong, X. Shi, J. Wan, Y. Zhang, Z. Liu, In vivo biodistribution and toxicology of functionalized nano-graphene 
oxide in mice after oral and intraperitoneal administration. Biomaterials 34(11), 2787-2795 (2013). https://doi.org/10.1016/ j.biomaterials.2013.01.001

49. T.L. Moore, R. Podilakrishna, A. Rao, F. Alexis, Systemic administration of polymer-coated nano-graphene to deliver drugs to glioblastoma. Part. Part. Syst. Charact. 31(8), 886-894 (2014). https://doi.org/10.1002/ppsc.201300379

50. S.M. Chowdhury, C. Surhland, Z. Sanchez, P. Chaudhary, M.A. Suresh Kumar et al., Graphene nanoribbons as a drug delivery agent for lucanthone mediated therapy of glioblastoma multiforme. Nanomed. Nanotechnol. Biol. Med. 11(1), 109-118 (2015). https://doi.org/10.1016/j.nano.2014.08.001

51. X. Sun, Z. Liu, K. Welsher, J.T. Robinson, A. Goodwin, S. Zaric, H. Dai, Nano-graphene oxide for cellular imaging and drug delivery. Nano Res. 1(3), 203-212 (2008). https://doi.org/ 10.1007/s12274-008-8021-8

52. Nayak EbPK, Recent advances in graphene research (InTech; 2016). https://doi.org/10.5772/61909

53. H. Wu, W. Lu, J.-J. Shao, C. Zhang, M.-B. Wu, B.-H. Li, Q.-H. Yang, Ph-dependent size, surface chemistry and electrochemical properties of graphene oxide. Carbon 67, 795 (2014). https://doi. org/10.1016/j.carbon.2013.10.044

54. V.K. Rana, M.-C. Choi, J.-Y. Kong, G.Y. Kim, M.J. Kim, S.-H. Kim, S. Mishra, R.P. Singh, C.-S. Ha, Synthesis and drug-delivery behavior of chitosan-functionalized graphene oxide hybrid nanosheets. Macromol. Mater. Eng. 296(2), 131-140 (2010). https://doi.org/10.1002/mame.201000307

55. R.L. Siegel, K.D. Miller, A. Jemal, Cancer statistics, 2016. CACancer J. Clin. 66(1), 7-30 (2016). https://doi.org/10.3322/caac. 21332

56. R.L. Siegel, K.D. Miller, A. Jemal, Cancer statistics, 2017. CACancer J. Clin. 67(1), 7-30 (2017). https://doi.org/10.3322/caac. 21387

57. L. Strauss, C. Bergmann, M. Szczepanski, W. Gooding, J.T. Johnson, T.L. Whiteside, A unique subset of $\mathrm{CD} 4{ }^{+} \mathrm{CD} 25^{\text {high- }}$ Foxp $^{+} \mathrm{T}$ cells secreting interleukin-10 and transforming growth factor- 1 mediates suppression in the tumor microenvironment. Clin. Cancer Res. 13(15), 4345-4354 (2007). https:// doi.org/10.1158/1078-0432.ccr-07-0472

58. J.A. Burger, Cxcr4: a key receptor in the crosstalk between tumor cells and their microenvironment. Blood 107(5), 1761-1767 (2006). https://doi.org/10.1182/blood-2005-08-3182

59. M. Bissell, M. Labarge, Context, tissue plasticity, and cancerare tumor stem cells also regulated by the microenvironment? Cancer Cell 7(1), 17-23 (2005). https://doi.org/10.1016/s15356108(04)00375-7

60. K. Kessenbrock, V. Plaks, Z. Werb, Matrix metalloproteinases: regulators of the tumor microenvironment. Cell 141(1), 52-67 (2010). https://doi.org/10.1016/j.cell.2010.03.015

61. L. Zhang, J. Xia, Q. Zhao, L. Liu, Z. Zhang, Functional graphene oxide as a nanocarrier for controlled loading and targeted delivery of mixed anticancer drugs. Small 6(4), 537-544 (2010). https://doi.org/10.1002/smll.200901680

62. B. Adhikari, A. Biswas, A. Banerjee, Graphene oxide-based hydrogels to make metal nanoparticle-containing reduced graphene oxide-based functional hybrid hydrogels. ACS Appl. Mater. Interfaces. 4(10), 5472-5482 (2012). https://doi.org/10. 1021/am301373n

63. W. Zhang, Z. Guo, D. Huang, Z. Liu, X. Guo, H. Zhong, Synergistic effect of chemo-photothermal therapy using pegylated graphene oxide. Biomaterials 32(33), 8555-8561 (2011). https:// doi.org/10.1016/j.biomaterials.2011.07.071

64. Y.-W. Chen, Y.-L. Su, S.-H. Hu, S.-Y. Chen, Functionalized graphene nanocomposites for enhancing photothermal therapy in tumor treatment. Adv. Drug Deliver. Rev. 105, 190-204 (2016). https://doi.org/10.1016/j.addr.2016.05.022
65. L. Liu, J. Zhang, J. Zhao, F. Liu, Mechanical properties of graphene oxides. Nanoscale 4(19), 5910-5916 (2012). https:// doi.org/10.1039/c2nr31164j

66. X. Bian, Z.-L. Song, Y. Qian, W. Gao, Z.-Q. Cheng et al., Fabrication of graphene-isolated-au-nanocrystal nanostructures for multimodal cell imaging and photothermal-enhanced chemotherapy. Sci. Rep. 4(1), 6093 (2014). https://doi.org/10. 1038/srep06093

67. C. Yao, L. Zhang, J. Wang, Y. He, J. Xin, S. Wang, H. Xu, Z. Zhang, Gold nanoparticle mediated phototherapy for cancer. J. Nanomater. 2016, 5497136 (2016). https://doi.org/10.1155/ 2016/5497136

68. Y.-H. Lee, Y.-H. Lai, Synthesis, characterization, and biological evaluation of anti-her2 indocyanine green-encapsulated pegcoated plga nanoparticles for targeted phototherapy of breast cancer cells. PLoS ONE 11(12), e0168192 (2016). https://doi. org/10.1371/journal.pone.0168192

69. L. Cheng, C. Wang, L. Feng, K. Yang, Z. Liu, Functional nanomaterials for phototherapies of cancer. Chem. Rev. 114(21), 10869-10939 (2014). https://doi.org/10.1021/ cr400532z

70. U. Chitgupi, Y. Qin, J.F. Lovell, Targeted nanomaterials for phototherapy. Nanotheranostics 1(1), 38-58 (2017). https://doi. org/10.7150/ntno. 17694

71. E. Paszko, C. Ehrhardt, M.O. Senge, D.P. Kelleher, J.V. Reynolds, Nanodrug applications in photodynamic therapy. Photodiagn. Photodyn. 8(1), 14-29 (2011). https://doi.org/10.1016/j. pdpdt.2010.12.001

72. D.K. Chatterjee, L.S. Fong, Y. Zhang, Nanoparticles in photodynamic therapy: an emerging paradigm. Adv. Drug Deliver. Rev. 60(15), 1627-1637 (2008). https://doi.org/10.1016/j.addr. 2008.08.003

73. S. Shi, F. Chen, E.B. Ehlerding, W. Cai, Surface engineering of graphene-based nanomaterials for biomedical applications. Bioconjug. Chem. 25(9), 1609-1619 (2014). https://doi.org/10. 1021/bc500332c

74. B. Zhang, Y. Wang, G. Zhai, Biomedical applications of the graphene-based materials. Mater. Sci. Eng., C 61, 953-964 (2016). https://doi.org/10.1016/j.msec.2015.12.073

75. R. Kurapati, K. Kostarelos, M. Prato, A. Bianco, Biomedical uses for $2 \mathrm{D}$ materials beyond graphene: current advances and challenges ahead. Adv. Mater. 28, 6052-6074 (2016). https:// doi.org/10.1002/adma.201506306

76. N. Rahmanian, H. Hamishehkar, J.E.N. Dolatabadi, N. Arsalani, Nano graphene oxide: a novel carrier for oral delivery of flavonoids. Colloid Surfaces B 123, 331-338 (2014). https://doi. org/10.1016/j.colsurfb.2014.09.036

77. Z. Liu, J.T. Robinson, S.M. Tabakman, K. Yang, H. Dai, Carbon materials for drug delivery \& cancer therapy. Mater. Today 14(7-8), 316-323 (2011). https://doi.org/10.1016/s13697021(11)70161-4

78. S. Some, A.R. Gwon, E. Hwang, G.-H. Bahn, Y. Yoon et al., Cancer therapy using ultrahigh hydrophobic drug-loaded graphene derivatives. Sci. Rep. 4(1), 6314 (2014). https://doi.org/ 10.1038/srep06314

79. X. Wang, X. Sun, J. Lao, H. He, T. Cheng, M. Wang, S. Wang, F. Huang, Multifunctional graphene quantum dots for simultaneous targeted cellular imaging and drug delivery. Colloid Surfaces B 122, 638-644 (2014). https://doi.org/10.1016/j.col surfb.2014.07.043

80. B. Tian, C. Wang, S. Zhang, L. Feng, Z. Liu, Photothermally enhanced photodynamic therapy delivered by nano-graphene oxide. ACS Nano 5(9), 7000-7009 (2011). https://doi.org/10. 1021/nn201560b

81. C. Xu, D. Yang, L. Mei, Q. Li, H. Zhu, T. Wang, Targeting chemophotothermal therapy of hepatoma by gold 
nanorods/graphene oxide core/shell nanocomposites. ACS Appl. Mater. Interfaces. 5(24), 12911-12920 (2013). https://doi.org/ $10.1021 / \mathrm{am} 404714 \mathrm{w}$

82. U. Dembereldorj, S.Y. Choi, E.-O. Ganbold, N.W. Song, D. Kim, J. Choo, S.Y. Lee, S. Kim, S.-W. Joo, Gold nanorodassembled pegylated graphene-oxide nanocomposites for photothermal cancer therapy. Photochem. Photobiol. 90(3), 659-666 (2013). https://doi.org/10.1111/php.12212

83. C. Wang, J. Mallela, U.S. Garapati, S. Ravi, V. Chinnasamy, Y. Girard, M. Howell, S. Mohapatra, A chitosan-modified graphene nanogel for noninvasive controlled drug release. Nanomed. Nanotechnol. Biol. Med. 9(7), 903-911 (2013). https://doi.org/ 10.1016/j.nano.2013.01.003

84. Y. Jin, J. Wang, H. Ke, S. Wang, Z. Dai, Graphene oxide modified pla microcapsules containing gold nanoparticles for ultrasonic/ct bimodal imaging guided photothermal tumor therapy. Biomaterials 34(20), 4794-4802 (2013). https://doi.org/10. 1016/j.biomaterials.2013.03.027

85. L. Feng, K. Li, X. Shi, M. Gao, J. Liu, Z. Liu, Smart ph-responsive nanocarriers based on nano-graphene oxide for combined chemo- and photothermal therapy overcoming drug resistance. Adv. Healthc. Mater. 3(8), 1261-1271 (2014). https://doi.org/10.1002/adhm.201300549

86. B.P. Viraka Nellore, A. Pramanik, S.R. Chavva, S.S. Sinha, C. Robinson et al., Aptamer-conjugated theranostic hybrid graphene oxide with highly selective biosensing and combined therapy capability. Faraday Discuss. 175, 257-271 (2014). https://doi.org/10.1039/c4fd00074a

87. D. Hu, J. Zhang, G. Gao, Z. Sheng, H. Cui, L. Cai, Indocyanine green-loaded polydopamine-reduced graphene oxide nanocomposites with amplifying photoacoustic and photothermal effects for cancer theranostics. Theranostics 6(7), 1043-1052 (2016). https://doi.org/10.7150/thno. 14566

88. J. Li, S. Tan, R. Kooger, C. Zhang, Y. Zhang, Micrornas as novel biological targets for detection and regulation. Chem. Soc. Rev. 43(2), 506-517 (2014). https://doi.org/10.1039/c3cs60312a

89. A. Paul, A. Hasan, H.A. Kindi, A.K. Gaharwar, V.T.S. Rao et al., Injectable graphene oxide/hydrogel-based angiogenic gene delivery system for vasculogenesis and cardiac repair. ACS Nano 8(8), 8050-8062 (2014). https://doi.org/10.1021/ nn5020787

90. L. Feng, X. Yang, X. Shi, X. Tan, R. Peng, J. Wang, Z. Liu, Polyethylene glycol and polyethylenimine dual-functionalized nano-graphene oxide for photothermally enhanced gene delivery. Small 9(11), 1989-1997 (2013). https://doi.org/10.1002/ smll.201202538

91. T. Niidome, L. Huang, Gene therapy progress and prospects: nonviral vectors. Gene Ther. 9(24), 1647-1652 (2002). https:// doi.org/10.1038/sj.gt.3301923

92. R. Waehler, S.J. Russell, D.T. Curiel, Engineering targeted viral vectors for gene therapy. Nat. Rev. Genet. 8(8), 573-587 (2007). https://doi.org/10.1038/nrg2141

93. H. Bao, Y. Pan, Y. Ping, N.G. Sahoo, T. Wu, L. Li, J. Li, L.H. Gan, Chitosan-functionalized graphene oxide as a nanocarrier for drug and gene delivery. Small 7(11), 1569-1578 (2011). https://doi.org/10.1002/smll.201100191

94. H. Kim, D. Lee, J. Kim, T.-I. Kim, W.J. Kim, Photothermally triggered cytosolic drug delivery via endosome disruption using a functionalized reduced graphene oxide. ACS Nano 7(8), 6735-6746 (2013). https://doi.org/10.1021/nn403096s

95. H. Kim, W.J. Kim, Photothermally controlled gene delivery by reduced graphene oxide-polyethylenimine nanocomposite. Small 10(1), 117-126 (2013). https://doi.org/10.1002/smll. 201202636
96. T. Sandle, Antibiotic/antimicrobial resistance, in The Sage Encyclopedia of Pharmacology and Society, ed. by S. Boslaugh (Sage, Thousand Oaks, 2016)

97. A.M. Allahverdiyev, K.V. Kon, E.S. Abamor, M. Bagirova, M. Rafailovich, Coping with antibiotic resistance: combining nanoparticles with antibiotics and other antimicrobial agents. Expert Rev. Anti-infe. 9(11), 1035-1052 (2011). https://doi.org/ 10.1586/eri.11.121

98. W. Hu, C. Peng, W. Luo, M. Lv, X. Li, D. Li, Q. Huang, C. Fan, Graphene-based antibacterial paper. ACS Nano 4(7), 4317-4323 (2010). https://doi.org/10.1021/nn101097v

99. Y. Tu, M. Lv, P. Xiu, T. Huynh, M. Zhang et al., Destructive extraction of phospholipids from escherichia coli membranes by graphene nanosheets. Nat. Nanotechnol. 8(8), 594-601 (2013). https://doi.org/10.1038/nnano.2013.125

100. S. Liu, M. Hu, T.H. Zeng, R. Wu, R. Jiang, J. Wei, L. Wang, J. Kong, Y. Chen, Lateral dimension-dependent antibacterial activity of graphene oxide sheets. Langmuir 28(33), 12364-12372 (2012). https://doi.org/10.1021/la3023908

101. M.-C. Wu, A.R. Deokar, J.-H. Liao, P.-Y. Shih, Y.-C. Ling, Graphene-based photothermal agent for rapid and effective killing of bacteria. ACS Nano 7(2), 1281-1290 (2013). https:// doi.org/10.1021/nn304782d

102. S. Gurunathan, J. Woong Han, A. Abdal Daye, V. Eppakayala, J.-H. Kim, Oxidative stress-mediated antibacterial activity of graphene oxide and reduced graphene oxide in pseudomonas aeruginosa. Int. J. Nanomed. 7, 5901-5914 (2012). https://doi. org/10.2147/ijn.s37397

103. I. Ocsoy, M.L. Paret, M.A. Ocsoy, S. Kunwar, T. Chen, M. You, W. Tan, Nanotechnology in plant disease management: DNAdirected silver nanoparticles on graphene oxide as an antibacterial against xanthomonas perforans. ACS Nano 7(10), 8972-8980 (2013). https://doi.org/10.1021/nn4034794

104. C. Li, X. Wang, F. Chen, C. Zhang, X. Zhi, K. Wang, D. Cui, The antifungal activity of graphene oxide-silver nanocomposites. Biomaterials 34(15), 3882-3890 (2013). https://doi.org/10. 1016/j.biomaterials.2013.02.001

105. Y. Ouyang, X. Cai, Q. Shi, L. Liu, D. Wan, S. Tan, Y. Ouyang, Poly-L-lysine-modified reduced graphene oxide stabilizes the copper nanoparticles with higher water-solubility and long-term additively antibacterial activity. Colloid Surfaces B 107, 107-114 (2013). https://doi.org/10.1016/j.colsurfb.2013.01.073

106. N. Hussain, A. Gogoi, R.K. Sarma, P. Sharma, A. Barras, R. Boukherroub, R. Saikia, P. Sengupta, M.R. Das, Reduced graphene oxide nanosheets decorated with au nanoparticles as an effective bactericide: investigation of biocompatibility and leakage of sugars and proteins. ChemPlusChem 79(12), 1774-1784 (2014). https://doi.org/10.1002/cplu.201402240

107. O. Akhavan, E. Ghaderi, Photocatalytic reduction of graphene oxide nanosheets on $\mathrm{TiO}_{2}$ thin film for photoinactivation of bacteria in solar light irradiation. J. Phys. Chem. C 113(47), 20214-20220 (2009). https://doi.org/10.1021/jp906325q

108. Y.-W. Wang, A. Cao, Y. Jiang, X. Zhang, J.-H. Liu, Y. Liu, H. Wang, Superior antibacterial activity of zinc oxide/graphene oxide composites originating from high zinc concentration localized around bacteria. ACS Appl. Mater. Interfaces. 6(4), 2791-2798 (2014). https://doi.org/10.1021/am4053317

109. I.E. Mejías Carpio, C.M. Santos, X. Wei, D.F. Rodrigues, Toxicity of a polymer-graphene oxide composite against bacterial planktonic cells, biofilms, and mammalian cells. Nanoscale 4(15), 4746-4756 (2012). https://doi.org/10.1039/ c2nr30774j

110. S. Some, S.-M. Ho, P. Dua, E. Hwang, Y.H. Shin, H. Yoo, J.-S. Kang, D.-K. Lee, H. Lee, Dual functions of highly potent graphene derivative-poly-L-lysine composites to inhibit bacteria 
and support human cells. ACS Nano 6(8), 7151-7161 (2012). https://doi.org/10.1021/nn302215y

111. J. Tang, Q. Chen, L. Xu, S. Zhang, L. Feng, L. Cheng, H. Xu, Z. Liu, R. Peng, Graphene oxide-silver nanocomposite as a highly effective antibacterial agent with species-specific mechanisms. ACS Appl. Mater. Interfaces. 5(9), 3867-3874 (2013). https:// doi.org/10.1021/am4005495

112. Z. Fan, B. Liu, J. Wang, S. Zhang, Q. Lin, P. Gong, L. Ma, S. Yang, A novel wound dressing based on ag/graphene polymer hydrogel: effectively kill bacteria and accelerate wound healing. Adv. Funct. Mater. 24(25), 3933-3943 (2014). https://doi.org/ 10.1002/adfm.201304202

113. B. Lu, T. Li, H. Zhao, X. Li, C. Gao, S. Zhang, E. Xie, Graphene-based composite materials beneficial to wound healing. Nanoscale 4(9), 2978-2982 (2012). https://doi.org/10.1039/ c2nr11958g

114. S.R. Shin, Y.-C. Li, H.L. Jang, P. Khoshakhlagh, M. Akbari, A. Nasajpour, Y.S. Zhang, A. Tamayol, A. Khademhosseini, Graphene-based materials for tissue engineering. Adv. Drug Deliver. Rev. 105, 255-274 (2016). https://doi.org/10.1016/j.addr. 2016.03.007

115. O. Akhavan, Graphene scaffolds in progressive nanotechnology/ stem cell-based tissue engineering of the nervous system. J. Mater. Chem. B 4(19), 3169-3190 (2016). https://doi.org/10. 1039/c6tb00152a

116. A.L. Rutz, K.E. Hyland, A.E. Jakus, W.R. Burghardt, R.N. Shah, A multimaterial bioink method for $3 \mathrm{~d}$ printing tunable, cell-compatible hydrogels. Adv. Mater. 27(9), 1607-1614 (2015). https://doi.org/10.1002/adma.201405076

117. S. Seethamraju, S. Kumar, K.B. Bharadwaj, G. Madras, S. Raghavan, P.C. Ramamurthy, Million-fold decrease in polymer moisture permeability by a graphene monolayer. ACS Nano 10(7), 6501-6509 (2016). https://doi.org/10.1021/acsnano. $6 \mathrm{~b} 02588$

118. S. Goenka, V. Sant, S. Sant, Graphene-based nanomaterials for drug delivery and tissue engineering. J. Control. Release 173, 75-88 (2014). https://doi.org/10.1016/j.jconrel.2013.10.017

119. J. Abraham, K.S. Vasu, C.D. Williams, K. Gopinadhan, Y. Su et al., Tunable sieving of ions using graphene oxide membranes. Nat. Nanotechnol. 12(6), 546-550 (2017). https://doi.org/10. 1038/nnano.2017.21

120. H.M. Hegab, A. ElMekawy, L. Zou, D. Mulcahy, C.P. Saint, M. Ginic-Markovic, The controversial antibacterial activity of graphene-based materials. Carbon 105, 362-376 (2016). https:// doi.org/10.1016/j.carbon.2016.04.046

121. H. Ji, H. Sun, X. Qu, Antibacterial applications of graphenebased nanomaterials: recent achievements and challenges. Adv. Drug Deliver. Rev. 105, 176-189 (2016). https://doi.org/10. 1016/j.addr.2016.04.009

122. J. Zhao, Z. Wang, J.C. White, B. Xing, Graphene in the aquatic environment: adsorption, dispersion, toxicity and transformation. Environ. Sci. Technol. 48(17), 9995-10009 (2014). https:// doi.org/10.1021/es5022679

123. M.E. Foo, S.C.B. Gopinath, Feasibility of graphene in biomedical applications. Biomed. Pharmacother. 94, 354-361 (2017). https://doi.org/10.1016/j.biopha.2017.07.122

124. P. Wu, Y. Qian, P. Du, H. Zhang, C. Cai, Facile synthesis of nitrogen-doped graphene for measuring the releasing process of hydrogen peroxide from living cells. J. Mater. Chem. 22(13), 6402-6412 (2012). https://doi.org/10.1039/c2jm16929k

125. X. Kang, J. Wang, H. Wu, I.A. Aksay, J. Liu, Y. Lin, Glucose oxidase-graphene-chitosan modified electrode for direct electrochemistry and glucose sensing. Biosens. Bioelectron. 25(4), 901-905 (2009). https://doi.org/10.1016/j.bios.2009.09.004

126. L. Jiang, Y. Liu, S. Liu, G. Zeng, X. Hu et al., Adsorption of estrogen contaminants by graphene nanomaterials under natural organic matter preloading: comparison to carbon nanotube, biochar, and activated carbon. Environ. Sci. Technol. 51(11), 6352-6359 (2017). https://doi.org/10.1021/acs.est.7b00073

127. L. Tang, Y. Wang, Y. Li, H. Feng, J. Lu, J. Li, Preparation, structure, and electrochemical properties of reduced graphene sheet films. Adv. Funct. Mater. 19(17), 2782-2789 (2009). https://doi.org/10.1002/adfm.200900377

128. D. Chen, H. Feng, J. Li, Graphene oxide: preparation, functionalization, and electrochemical applications. Chem. Rev. 112(11), 6027-6053 (2012). https://doi.org/10.1021/cr300115g

129. D. Lin, J. Wu, H. Ju, F. Yan, Nanogold/mesoporous carbon foam-mediated silver enhancement for graphene-enhanced electrochemical immunosensing of carcinoembryonic antigen. Biosens. Bioelectron. 52, 153-158 (2014). https://doi.org/10. 1016/j.bios.2013.08.051

130. B. Liu, D. Tang, J. Tang, B. Su, Q. Li, G. Chen, A graphenebased au(111) platform for electrochemical biosensing based catalytic recycling of products on gold nanoflowers. Analyst 136(11), 2218-2220 (2011). https://doi.org/10.1039/c0an00921k

131. K.T. Nguyen, Y. Zhao, Integrated graphene/nanoparticle hybrids for biological and electronic applications. Nanoscale 6(12), 6245-6266 (2014). https://doi.org/10.1039/c4nr00612g

132. J. Tian, T. Huang, P. Wang, J. Lu, God/hrp bienzyme synergistic catalysis in a 2-D graphene framework for glucose biosensing. J. Electrochem. Soc. 162(12), B319-B325 (2015). https://doi. org/10.1149/2.0411512jes

133. C. Shan, H. Yang, D. Han, Q. Zhang, A. Ivaska, L. Niu, Graphene/AuNPs/chitosan nanocomposites film for glucose biosensing. Biosens. Bioelectron. 25(5), 1070-1074 (2010). https://doi.org/10.1016/j.bios.2009.09.024

134. P. Song, X. Zhang, M. Sun, X. Cui, Y. Lin, Graphene oxide modified $\mathrm{TiO}_{2}$ nanotube arrays: enhanced visible light photoelectrochemical properties. Nanoscale 4(5), 1800 (2012). https:// doi.org/10.1039/c2nr11938b

135. X. Wu, S.-J. Ding, K. Lin, J. Su, A review on the biocompatibility and potential applications of graphene in inducing cell differentiation and tissue regeneration. J. Mater. Chem. B 5(17), 3084-3102 (2017). https://doi.org/10.1039/c6tb03067j

136. V. Poornima Parvathi, M. Umadevi, R. Bhaviya Raj, Improved waste water treatment by bio-synthesized graphene sand composite. J. Environ. Manag. 162, 299-305 (2015). https://doi.org/ 10.1016/j.jenvman.2015.07.055

137. A. El-Fiqi, J.H. Lee, E.-J. Lee, H.-W. Kim, Collagen hydrogels incorporated with surface-aminated mesoporous nanobioactive glass: improvement of physicochemical stability and mechanical properties is effective for hard tissue engineering. Acta Biomater. 9(12), 9508-9521 (2013). https://doi.org/10.1016/j.act bio.2013.07.036

138. V. Rosa, Z. Zhang, R.H.M. Grande, J.E. Nör, Dental pulp tissue engineering in full-length human root canals. J. Dent. Res. 92(11), 970-975 (2013). https://doi.org/10.1177/0022034513505772

139. L. Qiu, J.Z. Liu, S.L.Y. Chang, Y. Wu, D. Li, Biomimetic superelastic graphene-based cellular monoliths. Nat. Commun. 3, 1241 (2012). https://doi.org/10.1038/ncomms2251

140. L. Wang, C. Lu, B. Zhang, B. Zhao, F. Wu, S. Guan, Fabrication and characterization of flexible silk fibroin films reinforced with graphene oxide for biomedical applications. RSC Adv. 4(76), 40312-40320 (2014). https://doi.org/10.1039/c4ra04529g

141. D. Li, T. Liu, X. Yu, D. Wu, Z. Su, Fabrication of graphenebiomacromolecule hybrid materials for tissue engineering application. Polym. Chem. 8(30), 4309-4321 (2017). https://doi. org/10.1039/C7PY00935F

142. T.R. Nayak, H. Andersen, V.S. Makam, C. Khaw, S. Bae et al., Graphene for controlled and accelerated osteogenic differentiation of human mesenchymal stem cells. ACS Nano 5(6), 4670-4678 (2011). https://doi.org/10.1021/nn200500h 
143. S.Y. Park, J. Park, S.H. Sim, M.G. Sung, K.S. Kim, B.H. Hong, S. Hong, Enhanced differentiation of human neural stem cells into neurons on graphene. Adv. Mater. 23(36), H263-H267 (2011). https://doi.org/10.1002/adma.201101503

144. G. Nasim, G. Hamidreza, K. Mahshid, F. Mohammadhossein, A facile one-step strategy for development of a double network fibrous scaffold for nerve tissue engineering. Biofabrication 9(2), 025008 (2017). https://doi.org/10.1088/1758-5090/aa68ed

145. M. Zhou, Y. Zhai, S. Dong, Electrochemical sensing and biosensing platform based on chemically reduced graphene oxide. Anal. Chem. 81(14), 5603-5613 (2009). https://doi.org/ 10.1021/ac900136z

146. S. Park, J. An, I. Jung, R.D. Piner, S.J. An, X. Li, A. Velamakanni, R.S. Ruoff, Colloidal suspensions of highly reduced graphene oxide in a wide variety of organic solvents. Nano Lett. 9(4), 1593-1597 (2009). https://doi.org/10.1021/nl803798y

147. A. Bianco, Graphene: safe or toxic? The two faces of the medal. Angew. Chem. Int. Edit. 52(19), 4986-4997 (2013). https://doi. org/10.1002/anie.201209099

148. C. McCallion, J. Burthem, K. Rees-Unwin, A. Golovanov, A. Pluen, Graphene in therapeutics delivery: problems, solutions and future opportunities. Eur. J. Pharm. Biopharm. 104, 235-250 (2016). https://doi.org/10.1016/j.ejpb.2016.04.015

149. E. Mahmoudi, L.Y. Ng, M.M. Ba-Abbad, A.W. Mohammad, Novel nanohybrid polysulfone membrane embedded with silver nanoparticles on graphene oxide nanoplates. Chem. Eng. J. 277, 1-10 (2015). https://doi.org/10.1016/j.cej.2015.04.107

150. V.C. Sanchez, A. Jachak, R.H. Hurt, A.B. Kane, Biological interactions of graphene-family nanomaterials: an interdisciplinary review. Chem. Res. Toxicol. 25(1), 15-34 (2012). https://doi.org/10.1021/tx200339h

151. S. Syama, P.V. Mohanan, Safety and biocompatibility of graphene: a new generation nanomaterial for biomedical application. Int. J. Biol. Macromol. 86, 546-555 (2016). https://doi.org/ 10.1016/j.ijbiomac.2016.01.116

152. B. Zhang, P. Wei, Z. Zhou, T. Wei, Interactions of graphene with mammalian cells: molecular mechanisms and biomedical insights. Adv. Drug Deliver. Rev. 105, 145-162 (2016). https:// doi.org/10.1016/j.addr.2016.08.009

153. I. Chowdhury, M.C. Duch, N.D. Mansukhani, M.C. Hersam, D. Bouchard, Colloidal properties and stability of graphene oxide nanomaterials in the aquatic environment. Environ. Sci. Technol. 47(12), 6288-6296 (2013). https://doi.org/10.1021/ es $400483 \mathrm{k}$

154. I. Chowdhury, M.C. Duch, N.D. Mansukhani, M.C. Hersam, D. Bouchard, Interactions of graphene oxide nanomaterials with natural organic matter and metal oxide surfaces. Environ. Sci. Technol. 48(16), 9382-9390 (2014). https://doi.org/10.1021/ es5020828

155. I. Chowdhury, W.-C. Hou, D. Goodwin, M. Henderson, R.G. Zepp, D. Bouchard, Sunlight affects aggregation and deposition of graphene oxide in the aquatic environment. Water Res. 78, 37-46 (2015). https://doi.org/10.1016/j.watres.2015.04.001

156. L. Wu, L. Liu, B. Gao, R. Muñoz-Carpena, M. Zhang, H. Chen, Z. Zhou, H. Wang, Aggregation kinetics of graphene oxides in aqueous solutions: experiments, mechanisms, and modeling. Langmuir 29(49), 15174-15181 (2013). https://doi.org/10.1021/ la404134x

157. Z. Hua, Z. Tang, X. Bai, J. Zhang, L. Yu, H. Cheng, Aggregation and resuspension of graphene oxide in simulated natural surface aquatic environments. Environ. Pollut. 205, 161-169 (2015). https://doi.org/10.1016/j.envpol.2015.05.039

158. F. Ahmed, D.F. Rodrigues, Investigation of acute effects of graphene oxide on wastewater microbial community: a case study. J. Hazard. Mater. 256-257, 33-39 (2013). https://doi.org/ 10.1016/j.jhazmat.2013.03.064
159. Y. Deng, J. Li, M. Qiu, F. Yang, J. Zhang, C. Yuan, Deriving characterization factors on freshwater ecotoxicity of graphene oxide nanomaterial for life cycle impact assessment. Int. J. Life Cycle Ass. 22(2), 222-236 (2016). https://doi.org/10.1007/ s11367-016-1151-4

160. M. Rethinasabapathy, S.-M. Kang, S.-C. Jang, Y.S. Huh, Threedimensional porous graphene materials for environmental applications. Carbon lett 22, 1-13 (2017). https://doi.org/10. 5714/cl.2017.22.001

161. X. Zou, L. Zhang, Z. Wang, Y. Luo, Mechanisms of the antimicrobial activities of graphene materials. J. Am. Chem. Soc. 138(7), 2064-2077 (2016). https://doi.org/10.1002/chin. 201622265

162. J. Wu, Y.-S. Wang, X.-Y. Yang, Y.-Y. Liu, J.-R. Yang, R. Yang, N. Zhang, Graphene oxide used as a carrier for adriamycin can reverse drug resistance in breast cancer cells. Nanotechnology 23(35), 355101 (2012). https://doi.org/10.1088/0957-4484/23/ $35 / 355101$

163. D. Ma, J. Lin, Y. Chen, W. Xue, L.-M. Zhang, In situ gelation and sustained release of an antitumor drug by graphene oxide nanosheets. Carbon 50(8), 3001-3007 (2012). https://doi.org/10. 1016/j.carbon.2012.02.083

164. U. Dembereldorj, M. Kim, S. Kim, E.-O. Ganbold, S.Y. Lee, S.W. Joo, A spatiotemporal anticancer drug release platform of pegylated graphene oxide triggered by glutathione in vitro and in vivo. J. Mater. Chem. 22(45), 23845-23851 (2012). https:// doi.org/10.1039/c2jm34853e

165. H. Wen, C. Dong, H. Dong, A. Shen, W. Xia et al., Engineered redox-responsive peg detachment mechanism in pegylated nanographene oxide for intracellular drug delivery. Small 8(5), 760-769 (2012). https://doi.org/10.1002/smll.201101613

166. T. Zhou, X. Zhou, D. Xing, Controlled release of doxorubicin from graphene oxide based charge-reversal nanocarrier. Biomaterials 35(13), 4185-4194 (2014). https://doi.org/10.1016/j. biomaterials.2014.01.044

167. C. Wang, J. Li, C. Amatore, Y. Chen, H. Jiang, X.-M. Wang, Gold nanoclusters and graphene nanocomposites for drug delivery and imaging of cancer cells. Angew. Chem. Int. Edit. 50(49), 11644-11648 (2011). https://doi.org/10.1002/anie. 201105573

168. Y. Pan, H. Bao, N.G. Sahoo, T. Wu, L. Li, Water-soluble poly(n-isopropylacrylamide)-graphene sheets synthesized via click chemistry for drug delivery. Adv. Funct. Mater. 21(14), 2754-2763 (2011). https://doi.org/10.1002/adfm.201100078

169. T. Kavitha, I.-K. Kang, S.-Y. Park, Poly ( $n$-vinyl caprolactam) grown on nanographene oxide as an effective nanocargo for drug delivery. Colloid Surfaces B 115, 37-45 (2014). https://doi. org/10.1016/j.colsurfb.2013.11.022

170. N.G. Sahoo, H. Bao, Y. Pan, M. Pal, M. Kakran, H.K.F. Cheng, L. Li, L.P. Tan, Functionalized carbon nanomaterials as nanocarriers for loading and delivery of a poorly water-soluble anticancer drug: a comparative study. Chem. Commun. 47(18), 5235-5237 (2011). https://doi.org/10.1039/c1cc00075f

171. K. Liu, Y. Wang, H. Li, Y. Duan, A facile one-pot synthesis of starch functionalized graphene as nano-carrier for ph sensitive and starch-mediated drug delivery. Colloid Surfaces B 128, 86-93 (2015). https://doi.org/10.1016/j.colsurfb.2015.02.010

172. A. Angelopoulou, E. Voulgari, E.K. Diamanti, D. Gournis, K. Avgoustakis, Graphene oxide stabilized by pla-peg copolymers for the controlled delivery of paclitaxel. Eur. J. Pharm. Biopharm. 93, 18-26 (2015). https://doi.org/10.1016/j.ejpb.2015.03. 022

173. J. Li, Z. Lyv, Y. Li, H. Liu, J. Wang, W. Zhan, H. Chen, H. Chen, X. Li, A theranostic prodrug delivery system based on $\mathrm{Pt}(\mathrm{IV})$ conjugated nano-graphene oxide with synergistic effect to enhance the therapeutic efficacy of Pt drug. Biomaterials 51, 
12-21 (2015). https://doi.org/10.1016/j.biomaterials.2015.01. 074

174. J. An, Y. Gou, C. Yang, F. Hu, C. Wang, Synthesis of a biocompatible gelatin functionalized graphene nanosheets and its application for drug delivery. Mater. Sci. Eng., C 33(5), 2827-2837 (2013). https://doi.org/10.1016/j.msec.2013.03.008

175. J.-P. Chen, Y.-J. Lu, S.-C. Hung, J.-P. Chen, K.-C. Wei, Improving thermal stability and efficacy of benu in treating glioma cells using paa-functionalized graphene oxide. Int. J. Nanomed. 2012(7), 1737-1747 (2012). https://doi.org/10. 2147/ijn.s29376

176. X. Fan, G. Jiao, W. Zhao, P. Jin, X. Li, Magnetic $\mathrm{Fe}_{3} \mathrm{O}_{4}$-graphene composites as targeted drug nanocarriers for ph-activated release. Nanoscale 5(3), 1143-1152 (2013). https://doi.org/10. 1039/c2nr33158f

177. X.T. Zheng, P. Chen, C.M. Li, Anticancer efficacy and subcellular site of action investigated by real-time monitoring of cellular responses to localized drug delivery in single cells. Small 8(17), 2670-2674 (2012). https://doi.org/10.1002/smll. 201102636

178. M. Kakran, N.G. Sahoo, H. Bao, Y. Pan, L. Li, Functionalized graphene oxide as nanocarrier for loading and delivery of ellagic acid. Curr. Med. Chem. 18(29), 4503-4512 (2011). https://doi. org/10.2174/092986711797287548

179. S. Gurunathan, J.W. Han, A.A. Dayem, V. Eppakayala, M.-R. Park, D.-N. Kwon, J.-H. Kim, Antibacterial activity of dithiothreitol reduced graphene oxide. J. Ind. Eng. Chem. 19(4), 1280-1288 (2013). https://doi.org/10.1016/j.jiec.2012.12.029

180. S. Liu, T.H. Zeng, M. Hofmann, E. Burcombe, J. Wei, R. Jiang, J. Kong, Y. Chen, Antibacterial activity of graphite, graphite oxide, graphene oxide, and reduced graphene oxide: membrane and oxidative stress. ACS Nano 5(9), 6971-6980 (2011). https:// doi.org/10.1021/nn202451x

181. B.Z. Ristic, M.M. Milenkovic, I.R. Dakic, B.M. TodorovicMarkovic, M.S. Milosavljevic et al., Photodynamic antibacterial effect of graphene quantum dots. Biomaterials 35(15), 4428-4435 (2014). https://doi.org/10.1016/j.biomaterials.2014. 02.014

182. D. Zhang, X. Liu, X. Wang, Green synthesis of graphene oxide sheets decorated by silver nanoprisms and their anti-bacterial properties. J. Inorg. Biochem. 105(9), 1181-1186 (2011). https://doi.org/10.1016/j.jinorgbio.2011.05.014

183. A.F. de Faria, D.S.T. Martinez, S.M.M. Meira, A.C.M. de Moraes, A. Brandelli, A.G.S. Filho, O.L. Alves, Anti-adhesion and antibacterial activity of silver nanoparticles supported on graphene oxide sheets. Colloid Surfaces B 113, 115-124 (2014). https://doi.org/10.1016/j.colsurfb.2013.08.006

184. S. Vijay Kumar, N.M. Huang, H.N. Lim, A.R. Marlinda, I. Harrison, C.H. Chia, One-step size-controlled synthesis of functional graphene oxide/silver nanocomposites at room temperature. Chem. Eng. J. 219, 217-224 (2013). https://doi.org/10. 1016/j.cej.2012.09.063

185. Z. Zhu, M. Su, L. Ma, L. Ma, D. Liu, Z. Wang, Preparation of graphene oxide-silver nanoparticle nanohybrids with highly antibacterial capability. Talanta 117, 449-455 (2013). https:// doi.org/10.1016/j.talanta.2013.09.017

186. M.R. Das, R.K. Sarma, R. Saikia, V.S. Kale, M.V. Shelke, P. Sengupta, Synthesis of silver nanoparticles in an aqueous suspension of graphene oxide sheets and its antimicrobial activity. Colloid Surfaces B 83(1), 16-22 (2011). https://doi.org/10.1016/ j.colsurfb.2010.10.033

187. M.R. Das, R.K. Sarma, S.C. Borah, R. Kumari, R. Saikia et al., The synthesis of citrate-modified silver nanoparticles in an aqueous suspension of graphene oxide nanosheets and their antibacterial activity. Colloid Surfaces B 105, 128-136 (2013). https://doi.org/10.1016/j.colsurfb.2012.12.033
188. M.S. Haider, A.C. Badejo, G.N. Shao, S.M. Imran, N. Abbas, Y.G. Chai, M. Hussain, H.T. Kim, Sequential repetitive chemical reduction technique to study size-property relationships of graphene attached ag nanoparticle. Solid State Sci. 44, 1-9 (2015). https://doi.org/10.1016/j.solidstatesciences.2015.03.024

189. V.H. Nguyen, B.-K. Kim, Y.-L. Jo, J.-J. Shim, Preparation and antibacterial activity of silver nanoparticles-decorated graphene composites. J. Supercrit. Fluid. 72, 28-35 (2012). https://doi.org/ 10.1016/j.supflu.2012.08.005

190. Q. Bao, D. Zhang, P. Qi, Synthesis and characterization of silver nanoparticle and graphene oxide nanosheet composites as a bactericidal agent for water disinfection. J. Colloid Interface Sci. 360(2), 463-470 (2011). https://doi.org/10.1016/j.jcis.2011.05. 009

191. J. Shen, T. Li, M. Shi, N. Li, M. Ye, Polyelectrolyte-assisted one-step hydrothermal synthesis of ag-reduced graphene oxide composite and its antibacterial properties. Mater. Sci. Eng., C 32(7), 2042-2047 (2012). https://doi.org/10.1016/j.msec.2012. 05.017

192. X. Cai, M. Lin, S. Tan, W. Mai, Y. Zhang, Z. Liang, Z. Lin, X. Zhang, The use of polyethyleneimine-modified reduced graphene oxide as a substrate for silver nanoparticles to produce a material with lower cytotoxicity and long-term antibacterial activity. Carbon 50(10), 3407-3415 (2012). https://doi.org/10. 1016/j.carbon.2012.02.002

193. H. Zhou, Y. Liu, W. Chi, C. Yu, Y. Yu, Preparation and antibacterial properties of ag@polydopamine/graphene oxide sheet nanocomposite. Appl. Surf. Sci. 282, 181-185 (2013). https://doi.org/10.1016/j.apsusc.2013.05.099

194. Z. Tai, H. Ma, B. Liu, X. Yan, Q. Xue, Facile synthesis of Ag/ GNS-g-PAA nanohybrids for antimicrobial applications. Colloid Surfaces B 89, 147-151 (2012). https://doi.org/10.1016/j.col surfb.2011.09.006

195. B. Pant, P. Pokharel, A.P. Tiwari, P.S. Saud, M. Park, Z.K. Ghouri, S. Choi, S.-J. Park, H.-Y. Kim, Characterization and antibacterial properties of aminophenol grafted and ag nps decorated graphene nanocomposites. Ceram. Int. 41(4), 5656-5662 (2015). https://doi.org/10.1016/j.ceramint.2014.12. 150

196. M.K. Joshi, H.R. Pant, H.J. Kim, J.H. Kim, C.S. Kim, One-pot synthesis of ag-iron oxide/reduced graphene oxide nanocomposite via hydrothermal treatment. Colloid Surf. A-Physicochem. Eng. Asp. 446, 102-108 (2014). https://doi.org/10.1016/ j.colsurfa.2014.01.058

197. L. Liu, H. Bai, J. Liu, D.D. Sun, Multifunctional graphene oxide-tio2-ag nanocomposites for high performance water disinfection and decontamination under solar irradiation. J. Hazard. Mater. 261, 214-223 (2013). https://doi.org/10.1016/j.jhazmat. 2013.07.034

198. C.-H. Deng, J.-L. Gong, G.-M. Zeng, C.-G. Niu, Q.-Y. Niu, W. Zhang, H.-Y. Liu, Inactivation performance and mechanism of escherichia coli in aqueous system exposed to iron oxide loaded graphene nanocomposites. J. Hazard. Mater. 276, 66-76 (2014). https://doi.org/10.1016/j.jhazmat.2014.05.011

199. S. Bykkam, S. Narsingam, M. Ahmadipour, T. Dayakar, K. Venkateswara Rao, C. Shilpa Chakra, S. Kalakotla, Few layered graphene sheet decorated by zno nanoparticles for anti-bacterial application. Superlattices Microstruct. 83, 776-784 (2015). https://doi.org/10.1016/j.spmi.2015.03.063

200. T. Kavitha, A.I. Gopalan, K.-P. Lee, S.-Y. Park, Glucose sensing, photocatalytic and antibacterial properties of graphene- $\mathrm{ZnO}$ nanoparticle hybrids. Carbon 50(8), 2994-3000 (2012). https:// doi.org/10.1016/j.carbon.2012.02.082

201. S. Cao, C. Chen, J. Zhang, C. Zhang, W. Yu, B. Liang, Y. Tsang, Mnox quantum dots decorated reduced graphene oxide/ $\mathrm{TiO}_{2}$ nanohybrids for enhanced activity by a UV pre-catalytic 
microwave method. Appl. Catal. B-Environ. 176-177, 500-512 (2015). https://doi.org/10.1016/j.apcatb.2015.04.041

202. S. Chella, P. Kollu, E.V.P.R. Komarala, S. Doshi, M. Saranya et al., Solvothermal synthesis of $\mathrm{MnFe}_{2} \mathrm{O}_{4}$-graphene composite-investigation of its adsorption and antimicrobial properties. Appl. Surf. Sci. 327, 27-36 (2015). https://doi.org/10.1016/j. apsusc.2014.11.096

203. Y.-N. Chang, X.-M. Ou, G.-M. Zeng, J.-L. Gong, C.-H. Deng et al., Synthesis of magnetic graphene oxide- $\mathrm{TiO}_{2}$ and their antibacterial properties under solar irradiation. Appl. Surf. Sci. 343, 1-10 (2015). https://doi.org/10.1016/j.apsusc.2015.03.082

204. C. Chen, S. Cao, W. Yu, X. Xie, Q. Liu, Y. Tsang, Y. Xiao, Adsorption, photocatalytic and sunlight-driven antibacterial activity of bi2wo6/graphene oxide nanoflakes. Vacuum 116, 48-53 (2015). https://doi.org/10.1016/j.vacuum.2015.02.031

205. T. Li, J. Shen, N. Li, M. Ye, Facile in situ synthesis of hydrophilic rgo-cd-ag supramolecular hybrid and its enhanced antibacterial properties. Mater. Sci. Eng., C 39, 352-358 (2014). https://doi.org/10.1016/j.msec.2014.03.027

206. C.-H. Deng, J.-L. Gong, G.-M. Zeng, Y. Jiang, C. Zhang, H.-Y. Liu, S.-Y. Huan, Graphene-cds nanocomposite inactivation performance toward escherichia coli in the presence of humic acid under visible light irradiation. Chem. Eng. J. 284, 41-53 (2016). https://doi.org/10.1016/j.cej.2015.08.106

207. P. Li, S. Sun, A. Dong, Y. Hao, S. Shi, Z. Sun, G. Gao, Y. Chen, Developing of a novel antibacterial agent by functionalization of graphene oxide with guanidine polymer with enhanced antibacterial activity. Appl. Surf. Sci. 355, 446-452 (2015). https://doi.org/10.1016/j.apsusc.2015.07.148

208. H.N. Lim, N.M. Huang, C.H. Loo, Facile preparation of graphene-based chitosan films: enhanced thermal, mechanical and antibacterial properties. J. Non Cryst. Solids 358(3), 525-530 (2012). https://doi.org/10.1016/j.jnoncrysol.2011.11.007

209. M. Haniff Wahid, U.H. Stroeher, E. Eroglu, X. Chen, K. Vimalanathan, C.L. Raston, R.A. Boulos, Aqueous based synthesis of antimicrobial-decorated graphene. J. Colloid Interface Sci. 443, 88-96 (2015). https://doi.org/10.1016/j.jcis.2014.11. 043

210. A. Soroush, W. Ma, M. Cyr, M.S. Rahaman, B. Asadishad, N. Tufenkji, In situ silver decoration on graphene oxide-treated thin film composite forward osmosis membranes: biocidal properties and regeneration potential. Environ. Sci. Technol. Lett. 3(1), 13-18 (2015). https://doi.org/10.1021/acs.estlett.5b00304

211. V. Vatanpour, A. Shockravi, H. Zarrabi, Z. Nikjavan, A. Javadi, Fabrication and characterization of anti-fouling and anti-bacterial ag-loaded graphene oxide/polyethersulfone mixed matrix membrane. J. Ind. Eng. Chem. 30, 342-352 (2015). https://doi. org/10.1016/j.jiec.2015.06.004

212. X.-F. Sun, J. Qin, P.-F. Xia, B.-B. Guo, C.-M. Yang, C. Song, S.-G. Wang, Graphene oxide-silver nanoparticle membrane for biofouling control and water purification. Chem. Eng. J. 281, 53-59 (2015). https://doi.org/10.1016/j.cej.2015.06.059

213. M. Mazaheri, O. Akhavan, A. Simchi, Flexible bactericidal graphene oxide-chitosan layers for stem cell proliferation. Appl. Surf. Sci. 301, 456-462 (2014). https://doi.org/10.1016/j.apsusc. 2014.02.099

214. Y. Liu, M. Park, H.K. Shin, B. Pant, J. Choi, Y.W. Park, J.Y. Lee, S.-J. Park, H.-Y. Kim, Facile preparation and characterization of poly(vinyl alcohol)/chitosan/graphene oxide biocomposite nanofibers. J. Ind. Eng. Chem. 20(6), 4415-4420 (2014). https://doi.org/10.1016/j.jiec.2014.02.009

215. L. Duan, Y. Wang, Y. Zhang, J. Liu, Graphene immobilized enzyme/polyethersulfone mixed matrix membrane: enhanced antibacterial, permeable and mechanical properties. Appl. Surf. Sci. 355, 436-445 (2015). https://doi.org/10.1016/j.apsusc.2015. 07.127
216. F. Perreault, M.E. Tousley, M. Elimelech, Thin-film composite polyamide membranes functionalized with biocidal graphene oxide nanosheets. Environ. Sci. Technol. Lett. 1(1), 71-76 (2013). https://doi.org/10.1021/ez4001356

217. L. He, L.F. Dumée, C. Feng, L. Velleman, R. Reis, F. She, W. Gao, L. Kong, Promoted water transport across graphene oxidepoly(amide) thin film composite membranes and their antibacterial activity. Desalination 365, 126-135 (2015). https://doi.org/ 10.1016/j.desal.2015.02.032

218. Z.-B. Zhang, J.-J. Wu, Y. Su, J. Zhou, Y. Gao, H.-Y. Yu, J.-S. $\mathrm{Gu}$, Layer-by-layer assembly of graphene oxide on polypropylene macroporous membranes via click chemistry to improve antibacterial and antifouling performance. Appl. Surf. Sci. 332, 300-307 (2015). https://doi.org/10.1016/j.apsusc.2015.01.193

219. R. Major, M. Sanak, A. Mzyk, L. Lipinska, M. Kot, P. Lacki, F. Bruckert, B. Major, Graphene based porous coatings with antibacterial and antithrombogenous function-materials and design. Arch. Civ. Mech. Eng. 14(4), 540-549 (2014). https:// doi.org/10.1016/j.acme.2014.04.012

220. C. Bora, P. Bharali, S. Baglari, S.K. Dolui, B.K. Konwar, Strong and conductive reduced graphene oxide/polyester resin composite films with improved mechanical strength, thermal stability and its antibacterial activity. Compos. Sci. Technol 87, 1-7 (2013). https://doi.org/10.1016/j.compscitech.2013.07.025

221. H.M. Hegab, A. ElMekawy, T.G. Barclay, A. Michelmore, L. Zou, C.P. Saint, M. Ginic-Markovic, Fine-tuning the surface of forward osmosis membranes via grafting graphene oxide: performance patterns and biofouling propensity. ACS Appl. Mater. Interfaces. 7(32), 18004-18016 (2015). https://doi.org/10.1021/ acsami.5b04818

222. L. Yu, Y. Zhang, B. Zhang, J. Liu, H. Zhang, C. Song, Preparation and characterization of hpei-go/pes ultrafiltration membrane with antifouling and antibacterial properties. J. Membr. Sci. 447, 452-462 (2013). https://doi.org/10.1016/j.memsci. 2013.07.042

223. A. Nourmohammadi, R. Rahighi, O. Akhavan, A. Moshfegh, Graphene oxide sheets involved in vertically aligned zinc oxide nanowires for visible light photoinactivation of bacteria. J. Alloys Compd. 612, 380-385 (2014). https://doi.org/10.1016/j. jallcom.2014.05.195

224. O. Akhavan, E. Ghaderi, Toxicity of graphene and graphene oxide nanowalls against bacteria. ACS Nano 4(10), 5731-5736 (2010). https://doi.org/10.1021/nn101390x

225. A. Janković, S. Eraković, M. Vukašinović-Sekulić, V. Mišković-Stanković, S.J. Park, K.Y. Rhee, Graphene-based antibacterial composite coatings electrodeposited on titanium for biomedical applications. Prog. Org. Coat. 83, 1-10 (2015). https://doi.org/10.1016/j.porgcoat.2015.01.019

226. L. Dellieu, E. Lawarée, N. Reckinger, C. Didembourg, J.J. Letesson, M. Sarrazin, O. Deparis, J.Y. Matroule, J.F. Colomer, Do CVD grown graphene films have antibacterial activity on metallic substrates? Carbon 84, 310-316 (2015). https://doi.org/ 10.1016/j.carbon.2014.12.025

227. X. Wang, Z. Liu, X. Ye, K. Hu, H. Zhong, X. Yuan, H. Xiong, Z. Guo, A facile one-pot method to two kinds of graphene oxide-based hydrogels with broad-spectrum antimicrobial properties. Chem. Eng. J. 260, 331-337 (2015). https://doi.org/ 10.1016/j.cej.2014.08.102

228. Y. Wang, P. Zhang, C.F. Liu, C.Z. Huang, A facile and green method to fabricate graphene-based multifunctional hydrogels for miniature-scale water purification. RSC Adv. 3(24), 9240-9246 (2013). https://doi.org/10.1039/c3ra22687e

229. R. Surudžić, A. Janković, N. Bibić, M. Vukašinović-Sekulić, A. Perić-Grujić, V. Mišković-Stanković, S.J. Park, K.Y. Rhee, Physico-chemical and mechanical properties and antibacterial activity of silver/poly(vinyl alcohol)/graphene nanocomposites 
obtained by electrochemical method. Compos. Part B-Eng. 85, 102-112 (2016). https://doi.org/10.1016/j.compositesb.2015.09. 029

230. Q. Liu, B. Guo, Z. Rao, B. Zhang, J.R. Gong, Strong twophoton-induced fluorescence from photostable, biocompatible nitrogen-doped graphene quantum dots for cellular and deeptissue imaging. Nano Lett. 13(6), 2436-2441 (2013). https://doi. org/10.1021/nl400368v

231. Z. Sun, P. Huang, G. Tong, J. Lin, A. Jin et al., Vegf-loaded graphene oxide as theranostics for multi-modality imagingmonitored targeting therapeutic angiogenesis of ischemic muscle. Nanoscale 5(15), 6857-6866 (2013). https://doi.org/10. 1039/c3nr01573d

232. K. Yang, S. Zhang, G. Zhang, X. Sun, S.-T. Lee, Z. Liu, Graphene in mice: ultrahigh in vivo tumor uptake and efficient photothermal therapy. Nano Lett. 10(9), 3318-3323 (2010). https://doi.org/10.1021/nl100996u

233. Z. Liu, Z. Guo, H. Zhong, X. Qin, M. Wan, B. Yang, Graphene oxide based surface-enhanced raman scattering probes for cancer cell imaging. Phys. Chem. Chem. Phys. 15(8), 2961-2966 (2013). https://doi.org/10.1039/c2cp43715e

234. X. Ma, Q. Qu, Y. Zhao, Z. Luo, Y. Zhao, K.W. Ng, Y. Zhao, Graphene oxide wrapped gold nanoparticles for intracellular raman imaging and drug delivery. J. Mater. Chem. B 1(47), 6495-6500 (2013). https://doi.org/10.1039/c3tb21385d

235. Y. Wang, L. Polavarapu, L.M. Liz-Marzán, Reduced graphene oxide-supported gold nanostars for improved sers sensing and drug delivery. ACS Appl. Mater. Interfaces. 6(24), 21798-21805 (2014). https://doi.org/10.1021/am501382y

236. J. Huang, L. Zhang, B. Chen, N. Ji, F. Chen, Y. Zhang, Z. Zhang, Nanocomposites of size-controlled gold nanoparticles and graphene oxide: formation and applications in sers and catalysis. Nanoscale 2(12), 2733-2738 (2010). https://doi.org/ $10.1039 / \mathrm{c} 0 \mathrm{nr} 00473 \mathrm{a}$

237. J. Huang, C. Zong, H. Shen, M. Liu, B. Chen, B. Ren, Z. Zhang, Mechanism of cellular uptake of graphene oxide studied by surface-enhanced Raman spectroscopy. Small 8(16), 2577-2584 (2012). https://doi.org/10.1002/smll.201102743

238. Z.-L. Song, Z. Chen, X. Bian, L.-Y. Zhou, D. Ding et al., Alkyne-functionalized superstable graphitic silver nanoparticles for raman imaging. J. Am. Chem. Soc. 136(39), 13558-13561 (2014). https://doi.org/10.1021/ja507368z

239. H. Hong, K. Yang, Y. Zhang, J.W. Engle, L. Feng et al., In vivo targeting and imaging of tumor vasculature with radiolabeled, antibody-conjugated nanographene. ACS Nano 6(3), 2361-2370 (2012). https://doi.org/10.1021/nn204625e

240. H. Hong, Y. Zhang, J.W. Engle, T.R. Nayak, C.P. Theuer, R.J. Nickles, T.E. Barnhart, W. Cai, In vivo targeting and positron emission tomography imaging of tumor vasculature with 66galabeled nano-graphene. Biomaterials 33(16), 4147-4156 (2012). https://doi.org/10.1016/j.biomaterials.2012.02.031

241. Y. Fazaeli, O. Akhavan, R. Rahighi, M.R. Aboudzadeh, E. Karimi, H. Afarideh, In vivo spect imaging of tumors by 198,199au-labeled graphene oxide nanostructures. Mater. Sci. Eng., C 45, 196-204 (2014). https://doi.org/10.1016/j.msec. 2014.09.019

242. H.-W. Yang, C.-Y. Huang, C.-W. Lin, H.-L. Liu, C.-W. Huang et al., Gadolinium-functionalized nanographene oxide for combined drug and microrna delivery and magnetic resonance imaging. Biomaterials 35(24), 6534-6542 (2014). https://doi. org/10.1016/j.biomaterials.2014.04.057

243. K. Yang, L. Hu, X. Ma, S. Ye, L. Cheng, X. Shi, C. Li, Y. Li, Z. Liu, Multimodal imaging guided photothermal therapy using functionalized graphene nanosheets anchored with magnetic nanoparticles. Adv. Mater. 24(14), 1867 (2012). https://doi.org/ 10.1002/adma.201290077
244. Y.H. Hu, The first magnetic-nanoparticle-free carbon-based contrast agent of magnetic-resonance imaging-fluorinated graphene oxide. Small 10(8), 1451-1452 (2013). https://doi.org/10. 1002/smll.201303644

245. G. Lalwani, X. Cai, L. Nie, L.V. Wang, B. Sitharaman, Graphene-based contrast agents for photoacoustic and thermoacoustic tomography. Photoacoustics 1(3-4), 62-67 (2013). https://doi.org/10.1016/j.pacs.2013.10.001

246. Y.-W. Wang, Y.-Y. Fu, Q. Peng, S.-S. Guo, G. Liu, J. Li, H.-H. Yang, G.-N. Chen, Dye-enhanced graphene oxide for photothermal therapy and photoacoustic imaging. J. Mater. Chem. B 1(42), 5762-5767 (2013). https://doi.org/10.1039/c3tb20986e

247. Z. Sheng, L. Song, J. Zheng, D. Hu, M. He et al., Proteinassisted fabrication of nano-reduced graphene oxide for combined in vivo photoacoustic imaging and photothermal therapy. Biomaterials 34(21), 5236-5243 (2013). https://doi.org/10.1016/ j.biomaterials.2013.03.090

248. J. Shi, L. Wang, J. Zhang, R. Ma, J. Gao, Y. Liu, C. Zhang, Z. Zhang, A tumor-targeting near-infrared laser-triggered drug delivery system based on go@ag nanoparticles for chemo-photothermal therapy and x-ray imaging. Biomaterials 35(22), 5847-5861 (2014). https://doi.org/10.1016/j.biomaterials.2014. 03.042

249. H. Zhang, H. Wu, J. Wang, Y. Yang, D. Wu, Y. Zhang, Y. Zhang, Z. Zhou, S. Yang, Graphene oxide- $\mathrm{BaGdF}_{5}$ nanocomposites for multi-modal imaging and photothermal therapy. Biomaterials 42, 66-77 (2015). https://doi.org/10.1016/j.bioma terials.2014.11.055

250. X. Shi, H. Gong, Y. Li, C. Wang, L. Cheng, Z. Liu, Graphenebased magnetic plasmonic nanocomposite for dual bioimaging and photothermal therapy. Biomaterials 34(20), 4786-4793 (2013). https://doi.org/10.1016/j.biomaterials.2013.03.023

251. H. Zhou, K. Zhao, W. Li, N. Yang, Y. Liu, C. Chen, T. Wei, The interactions between pristine graphene and macrophages and the production of cytokines/chemokines via tlr- and nf- $\mathrm{kb}$-related signaling pathways. Biomaterials 33(29), 6933-6942 (2012). https://doi.org/10.1016/j.biomaterials.2012.06.064

252. Y. Li, Y. Liu, Y. Fu, T. Wei, L. Le Guyader, G. Gao, R.-S. Liu, Y.-Z. Chang, C. Chen, The triggering of apoptosis in macrophages by pristine graphene through the MAPK and TGF-beta signaling pathways. Biomaterials 33(2), 402-411 (2012). https:// doi.org/10.1016/j.biomaterials.2011.09.091

253. A. Sasidharan, L.S. Panchakarla, A.R. Sadanandan, A. Ashokan, P. Chandran et al., Hemocompatibility and macrophage response of pristine and functionalized graphene. Small $\mathbf{8}(8)$, 1251-1263 (2012). https://doi.org/10.1002/smll.201102393

254. Y. Li, H. Yuan, A. von dem Bussche, M. Creighton, R.H. Hurt, A.B. Kane, H. Gao, Graphene microsheets enter cells through spontaneous membrane penetration at edge asperities and corner sites. Proc. Natl. Acad. Sci. U.S.A. 110(30), 12295-12300 (2013). https://doi.org/10.1073/pnas.1222276110

255. H. Mao, W. Chen, S. Laurent, C. Thirifays, C. Burtea, F. Rezaee, M. Mahmoudi, Hard corona composition and cellular toxicities of the graphene sheets. Colloid Surfaces B 109, 212-218 (2013). https://doi.org/10.1016/j.colsurfb.2013.03.049

256. Y. Qin, Z.-W. Zhou, S.-T. Pan, Z.-X. He, X. Zhang, J.-X. Qiu, W. Duan, T. Yang, S.-F. Zhou, Graphene quantum dots induce apoptosis, autophagy, and inflammatory response via p38 mitogen-activated protein kinase and nuclear factor- $\mathrm{kb}$ mediated signaling pathways in activated thp-1 macrophages. Toxicology 327, 62-76 (2015). https://doi.org/10.1016/j.tox.2014.10.011

257. M.C. Duch, G.R.S. Budinger, Y.T. Liang, S. Soberanes, D. Urich et al., Minimizing oxidation and stable nanoscale dispersion improves the biocompatibility of graphene in the lung. Nano Lett. 11(12), 5201-5207 (2011). https://doi.org/10.1021/ nl202515a 
258. H. Zhou, B. Zhang, J. Zheng, M. Yu, T. Zhou et al., The inhibition of migration and invasion of cancer cells by graphene via the impairment of mitochondrial respiration. Biomaterials 35(5), 1597-1607 (2014). https://doi.org/10.1016/j.biomaterials.2013. 11.020

259. T. Lammel, P. Boisseaux, M.-L. Fernández-Cruz, J.M. Navas, Internalization and cytotoxicity of graphene oxide and carboxyl graphene nanoplatelets in the human hepatocellular carcinoma cell line hep g2. Part. Fibre Toxicol. 10(1), 27 (2013). https:// doi.org/10.1186/1743-8977-10-27

260. N. Chatterjee, H.-J. Eom, J. Choi, A systems toxicology approach to the surface functionality control of graphene-cell interactions. Biomaterials 35(4), 1109-1127 (2014). https://doi. org/10.1016/j.biomaterials.2013.09.108

261. Y. Li, Q. Wu, Y. Zhao, Y. Bai, P. Chen, T. Xia, D. Wang, Response of micrornas to in vitro treatment with graphene oxide. ACS Nano 8(3), 2100-2110 (2014). https://doi.org/10. $1021 / \mathrm{nn} 4065378$

262. M.-C. Matesanz, M. Vila, M.-J. Feito, J. Linares, G. Gonçalves, M. Vallet-Regi, P.-A.A.P. Marques, M.-T. Portolés, The effects of graphene oxide nanosheets localized on f-actin filaments on cell-cycle alterations. Biomaterials 34(5), 1562-1569 (2013). https://doi.org/10.1016/j.biomaterials.2012.11.001

263. Y. Li, Z. Lu, Z. Li, G. Nie, Y. Fang, Cellular uptake and distribution of graphene oxide coated with layer-by-layer assembled polyelectrolytes. J. Nanopart. Res. 16(5), 2384 (2014). https://doi.org/10.1007/s11051-014-2384-4

264. K.-H. Liao, Y.-S. Lin, C.W. Macosko, C.L. Haynes, Cytotoxicity of graphene oxide and graphene in human erythrocytes and skin fibroblasts. ACS Appl. Mater. Interfaces. 3(7), 2607-2615 (2011). https://doi.org/10.1021/am200428v

265. W. Zhang, L. Yan, M. Li, R. Zhao, X. Yang et al., Deciphering the underlying mechanisms of oxidation-state dependent cytotoxicity of graphene oxide on mammalian cells. Toxicol. Lett. 237(2), 61-71 (2015). https://doi.org/10.1016/j.toxlet.2015.05. 021

266. K. Wang, J. Ruan, H. Song, J. Zhang, Y. Wo, S. Guo, D. Cui, Biocompatibility of graphene oxide. Nanoscale Res. Lett. 6, 8 (2010). https://doi.org/10.1007/s11671-010-9751-6

267. M. Papi, M.C. Lauriola, V. Palmieri, G. Ciasca, G. Maulucci, M. De Spirito, Plasma protein corona reduces the haemolytic activity of graphene oxide nano and micro flakes. RSC Adv. 5(99), 81638-81641 (2015). https://doi.org/10.1039/c5ra15083c

268. W. Hu, C. Peng, M. Lv, X. Li, Y. Zhang, N. Chen, C. Fan, Q. Huang, Protein corona-mediated mitigation of cytotoxicity of graphene oxide. ACS Nano 5(5), 3693-3700 (2011). https://doi. org/10.1021/nn200021j

269. H. Yue, W. Wei, Z. Yue, B. Wang, N. Luo, Y. Gao, D. Ma, G. $\mathrm{Ma}, \mathrm{Z}$. Su, The role of the lateral dimension of graphene oxide in the regulation of cellular responses. Biomaterials 33(16), 4013-4021 (2012). https://doi.org/10.1016/j.biomaterials.2012. 02.021

270. G. Qu, S. Liu, S. Zhang, L. Wang, X. Wang et al., Graphene oxide induces toll-like receptor 4 (tlr4)-dependent necrosis in macrophages. ACS Nano 7(7), 5732-5745 (2013). https://doi. org/10.1021/nn402330b

271. J. Russier, E. Treossi, A. Scarsi, F. Perrozzi, H. Dumortier, L. Ottaviano, M. Meneghetti, V. Palermo, A. Bianco, Evidencing the mask effect of graphene oxide: a comparative study on primary human and murine phagocytic cells. Nanoscale $\mathbf{5}(22)$, 11234-11247 (2013). https://doi.org/10.1039/c3nr03543c

272. X. Zhi, H. Fang, C. Bao, G. Shen, J. Zhang, K. Wang, S. Guo, T. Wan, D. Cui, The immunotoxicity of graphene oxides and the effect of pvp-coating. Biomaterials 34(21), 5254-5261 (2013). https://doi.org/10.1016/j.biomaterials.2013.03.024
273. C. Jin, F. Wang, Y. Tang, X. Zhang, J. Wang, Y. Yang, Distribution of graphene oxide and $\mathrm{TiO}_{2}$-graphene oxide composite in a549 cells. Biol. Trace Elem. Res. 159(1-3), 393-398 (2014). https://doi.org/10.1007/s12011-014-0027-3

274. Z. Yang, C. Ge, J. Liu, Y. Chong, Z. Gu, C.A. Jimenez-Cruz, Z. Chai, R. Zhou, Destruction of amyloid fibrils by graphene through penetration and extraction of peptides. Nanoscale 7(44), 18725-18737 (2015). https://doi.org/10.1039/c5nr01172h

275. J. Park, B. Kim, J. Han, J. Oh, S. Park et al., Graphene oxide flakes as a cellular adhesive: prevention of reactive oxygen species mediated death of implanted cells for cardiac repair. ACS Nano 9(5), 4987-4999 (2015). https://doi.org/10.1021/ $\mathrm{nn} 507149 \mathrm{w}$

276. J. Linares, M.C. Matesanz, M. Vila, M.J. Feito, G. Gonçalves, M. Vallet-Regí, P.A.A.P. Marques, M.T. Portolés, Endocytic mechanisms of graphene oxide nanosheets in osteoblasts, hepatocytes and macrophages. ACS Appl. Mater. Interfaces. 6(16), 13697-13706 (2014). https://doi.org/10.1021/am5031598

277. Q. Mu, G. Su, L. Li, B.O. Gilbertson, L.H. Yu, Q. Zhang, Y.-P. Sun, B. Yan, Size-dependent cell uptake of protein-coated graphene oxide nanosheets. ACS Appl. Mater. Interfaces. 4(4), 2259-2266 (2012). https://doi.org/10.1021/am300253c

278. T. Zhou, B. Zhang, P. Wei, Y. Du, H. Zhou et al., Energy metabolism analysis reveals the mechanism of inhibition of breast cancer cell metastasis by PEG-modified graphene oxide nanosheets. Biomaterials 35(37), 9833-9843 (2014). https://doi. org/10.1016/j.biomaterials.2014.08.033

279. Z. Liu, J.T. Robinson, X. Sun, H. Dai, Pegylated nanographene oxide for delivery of water-insoluble cancer drugs. J. Am. Chem. Soc. 130(33), 10876-10877 (2008). https://doi.org/10. $1021 / j a 803688 x$

280. Y. Zeng, Z. Yang, S. Luo, H. Li, C. Liu, Y. Hao, J. Liu, W. Wang, R. Li, Fast and facile preparation of pegylated graphene from graphene oxide by lysosome targeting delivery of photosensitizer to efficiently enhance photodynamic therapy. RSC Adv. 5(71), 57725-57734 (2015). https://doi.org/10.1039/ c5ra07535a

281. S. Mullick Chowdhury, G. Lalwani, K. Zhang, J.Y. Yang, K. Neville, B. Sitharaman, Cell specific cytotoxicity and uptake of graphene nanoribbons. Biomaterials 34(1), 283-293 (2013). https://doi.org/10.1016/j.biomaterials.2012.09.057

282. S. Mullick Chowdhury, P. Manepalli, B. Sitharaman, Graphene nanoribbons elicit cell specific uptake and delivery via activation of epidermal growth factor receptor enhanced by human papillomavirus E5 protein. Acta Biomater. 10(10), 4494-4504 (2014). https://doi.org/10.1016/j.actbio.2014.06.030

283. D.A. Mbeh, O. Akhavan, T. Javanbakht, M. Mahmoudi, L.H. Yahia, Cytotoxicity of protein corona-graphene oxide nanoribbons on human epithelial cells. Appl. Surf. Sci. 320, 596-601 (2014). https://doi.org/10.1016/j.apsusc.2014.09.155

284. Y. Talukdar, J.T. Rashkow, G. Lalwani, S. Kanakia, B. Sitharaman, The effects of graphene nanostructures on mesenchymal stem cells. Biomaterials 35(18), 4863-4877 (2014). https://doi.org/10.1016/j.biomaterials.2014.02.054

285. Y. Chong, C. Ge, Z. Yang, J.A. Garate, Z. Gu, J.K. Weber, J. Liu, R. Zhou, Reduced cytotoxicity of graphene nanosheets mediated by blood-protein coating. ACS Nano 9(6), 5713-5724 (2015). https://doi.org/10.1021/nn5066606

286. S. Das, S. Singh, V. Singh, D. Joung, J.M. Dowding et al., Oxygenated functional group density on graphene oxide: its effect on cell toxicity. Part. Part. Syst. Charact. 30(2), 148-157 (2013). https://doi.org/10.1002/ppsc.201200066

287. L. Horváth, A. Magrez, M. Burghard, K. Kern, L. Forró, B. Schwaller, Evaluation of the toxicity of graphene derivatives on cells of the lung luminal surface. Carbon 64, 45-60 (2013). https://doi.org/10.1016/j.carbon.2013.07.005 
288. W. Miao, G. Shim, G. Kim, S. Lee, H.-J. Lee, Y.B. Kim, Y. Byun, Y.-K. Oh, Image-guided synergistic photothermal therapy using photoresponsive imaging agent-loaded graphene-based nanosheets. J. Control. Release 211, 28-36 (2015). https://doi. org/10.1016/j.jconrel.2015.05.280

289. M.-G. Kim, J.Y. Park, W. Miao, J. Lee, Y.-K. Oh, Polyaptamer DNA nanothread-anchored, reduced graphene oxide nanosheets for targeted delivery. Biomaterials 48, 129-136 (2015). https:// doi.org/10.1016/j.biomaterials.2015.01.009

290. C. Cheng, S. Nie, S. Li, H. Peng, H. Yang, L. Ma, S. Sun, C. Zhao, Biopolymer functionalized reduced graphene oxide with enhanced biocompatibility via mussel inspired coatings/anchors. J. Mater. Chem. B 1(3), 265-275 (2013). https://doi.org/10. 1039/c2tb00025c

291. O. Akhavan, E. Ghaderi, A. Akhavan, Size-dependent genotoxicity of graphene nanoplatelets in human stem cells. Biomaterials 33(32), 8017-8025 (2012). https://doi.org/10.1016/j. biomaterials.2012.07.040

292. S.K. Singh, M.K. Singh, M.K. Nayak, S. Kumari, S. Shrivastava, J.J.A. Grácio, D. Dash, Thrombus inducing property of atomically thin graphene oxide sheets. ACS Nano 5(6), 4987-4996 (2011). https://doi.org/10.1021/nn201092p

293. S.K. Singh, M.K. Singh, P.P. Kulkarni, V.K. Sonkar, J.J.A. Grácio, D. Dash, Amine-modified graphene: thrombo-protective safer alternative to graphene oxide for biomedical applications. ACS Nano 6(3), 2731-2740 (2012). https://doi.org/10.1021/ $\mathrm{nn} 300172 \mathrm{t}$

294. A. Chwalibog, S. Jaworski, E. Sawosz, M. Kutwin, M. Wierzbicki et al., In vitro and in vivo effects of graphene oxide and reduced graphene oxide on glioblastoma. Int. J. Nanomed. 10(1), 1585-1596 (2015). https://doi.org/10.2147/ijn.s77591

295. E. Sawosz, S. Jaworski, M. Kutwin, K. Vadalasetty, M. Grodzik et al., Graphene functionalized with arginine decreases the development of glioblastoma multiforme tumor in a gene-dependent manner. Int. J. Mol. Sci. 16(10), 25214-25233 (2015). https://doi.org/10.3390/ijms161025214

296. J.H. Shin, S.G. Han, J.K. Kim, B.W. Kim, J.H. Hwang et al., 5-day repeated inhalation and 28-day post-exposure study of graphene. Nanotoxicology 9(8), 1023-1031 (2015). https://doi. org/10.3109/17435390.2014.998306

297. Y.H. Kim, M.S. Jo, J.K. Kim, J.H. Shin, J.E. Baek et al., Shortterm inhalation study of graphene oxide nanoplates. Nanotoxicology 12(3), 224-238 (2018). https://doi.org/10.1080/ 17435390.2018 .1431318

298. J.K. Kim, J.H. Shin, J.S. Lee, J.H. Hwang, J.H. Lee et al., 28-day inhalation toxicity of graphene nanoplatelets in Sprague-Dawley rats. Nanotoxicology 10(7), 891-901 (2016). https://doi.org/ $10.3109 / 17435390.2015 .1133865$
299. B. Li, J. Yang, Q. Huang, Y. Zhang, C. Peng et al., Biodistribution and pulmonary toxicity of intratracheally instilled graphene oxide in mice. NPG Asia Mater. 5(4), e44 (2013). https:// doi.org/10.1038/am.2013.7

300. L. Mao, M. Hu, B. Pan, Y. Xie, E.J. Petersen, Biodistribution and toxicity of radio-labeled few layer graphene in mice after intratracheal instillation. Part. Fibre Toxicol. 13(1), 7 (2015). https://doi.org/10.1186/s12989-016-0120-1

301. A. Schinwald, F. Murphy, A. Askounis, V. Koutsos, K. Sefiane, K. Donaldson, C.J. Campbell, Minimal oxidation and inflammogenicity of pristine graphene with residence in the lung. Nanotoxicology 8(8), 824-832 (2013). https://doi.org/10.3109/ 17435390.2013 .831502

302. A. Schinwald, F.A. Murphy, A. Jones, W. MacNee, K. Donaldson, Graphene-based nanoplatelets: a new risk to the respiratory system as a consequence of their unusual aerodynamic properties. ACS Nano 6(1), 736-746 (2012). https://doi.org/10. $1021 / \mathrm{nn} 204229 \mathrm{f}$

303. S.G. Han, J.K. Kim, J.H. Shin, J.H. Hwang, J.S. Lee et al., Pulmonary responses of Sprague-Dawley rats in single inhalation exposure to graphene oxide nanomaterials. Biomed. Res. Int. 2015, 1-9 (2015). https://doi.org/10.1155/2015/376756

304. S. Liang, S. Xu, D. Zhang, J. He, M. Chu, Reproductive toxicity of nanoscale graphene oxide in male mice. Nanotoxicology $\mathbf{9}(1)$, 92-105 (2014). https://doi.org/10.3109/17435390.2014.893380

305. X. Zhang, J. Yin, C. Peng, W. Hu, Z. Zhu, W. Li, C. Fan, Q. Huang, Distribution and biocompatibility studies of graphene oxide in mice after intravenous administration. Carbon 49(3), 986-995 (2011). https://doi.org/10.1016/j.carbon.2010.11.005

306. B. Li, X. Zhang, J. Yang, Y. Zhang, W. Li, C. Fan, Q. Huang, Influence of polyethylene glycol coating on biodistribution and toxicity of nanoscale graphene oxide in mice after intravenous injection. Int. J. Nanomed. 9(1), 4697-4707 (2014). https://doi. org/10.2147/ijn.s66591

307. Y. Chong, Y. Ma, H. Shen, X. Tu, X. Zhou, J. Xu, J. Dai, S. Fan, $Z$. Zhang, The in vitro and in vivo toxicity of graphene quantum dots. Biomaterials 35(19), 5041-5048 (2014). https://doi.org/10. 1016/j.biomaterials.2014.03.021

308. S.A. Sydlik, S. Jhunjhunwala, M.J. Webber, D.G. Anderson, R. Langer, In vivo compatibility of graphene oxide with differing oxidation states. ACS Nano 9(4), 3866-3874 (2015). https://doi. org/10.1021/acsnano.5b01290

309. W.-Y. Pan, C.-C. Huang, T.-T. Lin, H.-Y. Hu, W.-C. Lin, M.-J. Li, H.-W. Sung, Synergistic antibacterial effects of localized heat and oxidative stress caused by hydroxyl radicals mediated by graphene/iron oxide-based nanocomposites. Nanomed. Nanotechnol. Biol. Med. 12(2), 431-438 (2016). https://doi.org/10. 1016/j.nano.2015.11.014 